\title{
Antibiotic resistance in humans and pigs : is there a relation?
}

Citation for published version (APA):

Kuske-Nijsten, G. H. M. (1995). Antibiotic resistance in humans and pigs : is there a relation ? [Doctoral Thesis, Maastricht University]. Rijksuniversiteit Limburg. https://doi.org/10.26481/dis.19951026gk

Document status and date:

Published: 01/01/1995

DOI:

10.26481/dis.19951026gk

Document Version:

Publisher's PDF, also known as Version of record

\section{Please check the document version of this publication:}

- A submitted manuscript is the version of the article upon submission and before peer-review. There can be important differences between the submitted version and the official published version of record.

People interested in the research are advised to contact the author for the final version of the publication, or visit the DOI to the publisher's website.

- The final author version and the galley proof are versions of the publication after peer review.

- The final published version features the final layout of the paper including the volume, issue and page numbers.

Link to publication

\footnotetext{
General rights rights.

- You may freely distribute the URL identifying the publication in the public portal. please follow below link for the End User Agreement:

www.umlib.nl/taverne-license

Take down policy

If you believe that this document breaches copyright please contact us at:

repository@maastrichtuniversity.nl

providing details and we will investigate your claim.
}

Copyright and moral rights for the publications made accessible in the public portal are retained by the authors and/or other copyright owners and it is a condition of accessing publications that users recognise and abide by the legal requirements associated with these

- Users may download and print one copy of any publication from the public portal for the purpose of private study or research.

- You may not further distribute the material or use it for any profit-making activity or commercial gain

If the publication is distributed under the terms of Article $25 \mathrm{fa}$ of the Dutch Copyright Act, indicated by the "Taverne" license above, 


\section{ANTIBIOTIC RESISTANCE In Humans AND PIGS \\ Is THERE A RELATION?}

Ruth Kuske-Nijsten 



\section{ANTIBIOTIC RESISTANCE IN HUMANS AND PIGS}

\section{IS THERE A RELATION ?}

\section{PROEFSCHRIFT}

ter verkrijging van de graad van doctor

an de Rijksuniversiteit Limburg te Maastricht, op gezag van de Rector Magnificus, Prof. Mr. M.J. Cohen, volgens het besluit van het College van Dekanen, in het openbaar te verdedigen op donderdag 26 oktober 1995 om 14.00 uur

door

Gertruda Hubertina Maria Kuske-Nijsten 


\section{Promotor}

Prof. dr. J.A. Knotmerus

\section{Co-promatores}

Drs. A.E.M.M wan den Bogarard

Dr. E. E. Strobberingh

\section{Beoordelingscommissite}

Prof. dr. P.G. Knipschild (voorzitter)

Prof. dr. F. Stumans (plaatsvervangend voorzitter)

Prof. dr. C.P.A. van Boven (Rijks Universiteit Leiden)

Prof. dr. A. Pijpers (Universiteit Utrecht)

Dr. G. Ramsay

Prof. dr. ir. M.J.M. Tielen (Universiteit Utrecht)

De studies gepresenteerd in dit proefschrift werden gefinancierd met behulp van grant 28.0275 van het Praeventiefionds. 
aan Andreas 
ISBN: $90-9008562-9$

Druk: Unigraphic 
Intraduction: General Background

Outline of the thesis

Chapter I: Review of the literature

Aims of the study

Chapter II: Monitoring antibiotic resistance of Enterobacterioceae isolated from the faecal flora of fattening pigs.

The Veterinary Quarterly 1993; 15:152-157.

Chapter III: Resistance in faecal Escherichia coli isolated from pig farmers and abattoir workers.

Epidemiology and Infection 1994; 113:45-52.

Chapter IV: Antibiotic resistance among Escherichia coli isolated from faecal samples of pig farmers and pigs.

The Journal of Antimicrobial Chemotherapy, accepted for publication.

Chapter V: In vitro transfer of antibiotic resistance between faecal Escherichia coli strains isolated from pig farmers and pigs.

The Journal of Antimicrobial Chemotherapy, accepted for publication..

Chapter VT: In vivo transfer of resistance plasmids in rat, human or pig derived intestinal flora using a rat model.

The Journal of Antimicrobial Chemotherapy, accepted for publication.

Chapter VII: Surveillance of antibiotic resistance among pigs using faecal floor droppings from trucks transporting fattening pigs.

Chapter VII: General discussion

Samenwarting

Dankwoord 

GENERAL BACKGROUND

OUTLINE OF THE THESIS 
. 


\section{INTRODUCTION}

\section{General Background}

Since the clinical introduction in 1935 of the sulphonamides, followed by penicillin in the early forties, antimicrobial agents have been used extensively in human and veterinary medicine. Shortly after the introduction of antimicrobial agents, however, treatment failures were observed caused by bacteria that had become resistant to the agents used and it was realized that the emergence of resistance was an inevitable consequence of the use of antimicrobial agents. The discovery that emergence and spread of resistance was not only caused by spontaneous mutations of bacterial chromosomal DNA followed by the dissemination of a single resistant cllone or strain, but that extrachromosomal bacterial genes coding for resistance could be transferred between bacteria greatly caused concern. The more so as this transfer not only readily occurs among bacteria of the same species, but also between different species. Especially the dense endogenous bowel flora of man and animals appears to be an ecological system that favours the inter- and intra-species transfer of resistance. The use of antibiotics in livestock inevitably selects for resistance in the endogenous flora of animals. This and the real possibility of transfer of either resistant bacterial strains or their genetic material to the human endogenous flora or human pathogens raised questions over whether and to what extent the use of antibiotics in food animals contributed to the occurrence of resistance in (potential) human pathogens. The increasing awareness of the importance of antimicrobial resistance and its potential public health hazard prompted the still ongoing discussion between the veterinary and medical profession about the risk of antibiotic use in animals and its possible threat to public health. In 1968 a joint committee was set up in the U.K. to examine the problem of the use of antibiotics in animal husbandry and veterinary medicine. The most important recommendation made in the Swann Report (8) was to prohibit the use of those antibiotics as growth promoters in animal feeds which are approved for therapeutic use in human and veterinary medicine. This recommendlation was put into effect in 1970 in the U.K., other member states of the European Union at that time soon followed. The effect of the Swann report on the use of antibiotics in animals was, however, low. Although clinically used antibiotics were no longer used as growth promotors and were replaced by other compounds, such as virginiamycin and avoparcin, total veterinary antibiotic usage actually increased due to an increased therapeutic usage. The most important contribution 
of the Swann repott that it made the veterinary profession aware of its responsibility to preserve the therapeutic usefulness of antimicrobial agents for the treatment of bacterial infections in arimals and in man.

In 1989 a Dutch expert working party set up by the Institute of Public Health and Environmental Hygiene (RIVM), recommended to prohibit the registration of the newer $\beta$-iactam antibiotics, the new aminoglycosidles and all fluoroquinollones for veterinary use (1). The at that time published Dutch Veterinary Drugs Act made this feasible by providing the possibility to refuse the registration of drugs for use in animals in the interest of public health; despite the fact that they might fulfil the required criteria for registration. The argument in the case of antibiotics was that the veterinary use of these agents might lead to resistance in micro-organisms (potentially) pathogenic for man. This report provoked, as could have been expected, strong reactions from the veterinary profession.

In 1990 a workshop was organised in The Netherlands to discuss the recommendations of the RIVM report of 1989 (6). Although the assumption that a decrease in the usage of antibiotics in veterinary practice should reduce the risks of transfer of resistant bacteria from animals to humans was generally accepted it remained unclear at the conference whether or to what extent veterinary use of antimicrobial agents contributed to the antibiotic resistance problems in human medicine. As a result of this conference, the Dutch Royal Society for Veterinary Medicine decided to develop a veterinary antibiotic policy with one national veterinary antibiotic formulary, this in order to safeguard the efficacy of veterinary antibiotic therapy for now and in the future and to take responsibility for public health (2). This policy was published in 1994 (3) and the first concept of a formulary is now circulating among the profession.

In December 1991 at the Fedesa Symposium in London, organised as a follow-up of the RIVM workshop, both medical and veterinary experts on antibiotic resistance discussed the relation between the usage of antimicrobials in veterinary medicine and the resistance encountered in human pathogens. The opinions differed widely. The veterinary microbiologist Espinasse was the only one who advocated that the usage of specific antimicrobial agents should be restricted to human medicine only (4). Considering the available evidence others, including the medical microbiologists, came to the conclusion that animals as a reservoir of antibiotic resistance were of negligible importance for man $(5,7,9)$.

The discussions mentioned illustrate the ongoing and increasing concern about the veterinary antibiotic usage as a potential human public health risk factor, i.e. that selection and transfer of resistant bacteria or resistance genes from animals to man may 
ultimately result in a loss of therapeutic efficacy of antibionics in human medicine.

In this thesis several aspects of the relationship between antimicrobial resistance in the intestinal flora of man and pugs, living in the same geographical area, were explored. Three groups of faecal samples of pigs were investigated. The firsi group, described in chapter II, consisted of samples collected at a single pig fattening farm, During a period of 11 months (from June 1991 to April 1992) faecal samples were collected from pigs housed in different compartments of the farm. The second group, described in chapters IV and VII, consisted of mixed faecal samples once-only collected at different farms (from July 1991 to December 1991) and the third group, described in chapter VII, consisted of floor dropping collected from trucks transporting fattening pigs (from May 1992 to July 1992).

Besides, three groups of humans with different intensity and frequency of contact with pigs or pig products were inwestigated, i.e. pig farmers, abattoir workers and (sub)urban residents.

The prevalence and degree of antibiotic resistance of Enterobacteriaceae (in particular Escherichia coli) isolated from the intestinal flora of pigs and humans were determined, as well as the antibiotic susceptibilities of $E$. coli isolates from the same faecal sanples. The results were related to risk factors such as recent use of antibioties and direct or indirect contact with pigs. In addition to these phenotypic markers, the resistance plasmid prolïles were analyzed and transfer experiments were performed in witro and in vivo to studly the capacity of $E$. coli strains isolated from pigs and humans to transfer their resistance plasmids. 


\section{REFERENCES}

1. Ad hoe Werkigroeg. Advies inzake inperking wan het arsenall wan antimicrobiele gemesmiddelen voor vereri-

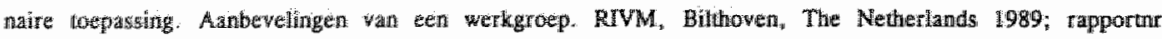
$358471003,1989$.

2. Bogaard vd AEM. A weterinary antibiotic policy: a personal wetw on the perspectives in the Netheriands. Vet Microbiol $1999 ; 35: 303-312$.

3. Bogaard vd AFM, Breewsma A, Julicher CHM, Mostert A, Niewwenhuijs JHM, Vaarkamp H et al Veter inair antibioticumbeleid: agnbewelingen van wen werkgroep. Tijdsch Diergeneeskd 1994; 119:160-183.

4. Esphthasse J. Responsible use of antimicrobials in veterinary medicine: perspertives in France. Wet Microbiol 1993: 35:289-301.

5. Kayser FH. Evolution of resistance in microorganisms of human origin. Vet Microbiol $1993 ; 35: 257-267$

6. Klingeren W, Nieuwenhuys BHM (ed). Proceedings Workshop: veterimair antibioticagebruik en volksgezondheid. RIVM, Bilthoven, The Netherlands, 1990.

7. Sinith $\mathbf{J T}$, Lewin CS. Mechamisns of antimicrobial resistance and implications for epidemiology. Vet Microbiol 1993: 35:233-242.

8. Swann M, Blaxter KL, Fleld HI, Howie JW, Lucas IAM, Millar ELM ef al. Joint Committee on the use of antibiotics in aminal husbandry and weterinary medicine. Report presented by the Secretary of State for Social Services, the Secretary of State for Scothand, the Minister of Agriculure, Fisheries and Food and the Secretary of State for Wales by Command of Her Majesty, 1969. London, Her Majesty's Stationary Office.

9. Whedemamn B. Monitoring of resistant organisms in man and identification of their origin. Vet Microbiol $1993 ; 35: 275 \cdot 284$. 


\section{Outiline of the thesis}

In chapter I the literature is reviewed conceming the prevalence of antibiotic resistance in the intestinal flora of food animals. The potential public healli risk of the possibility of transfer of resistance between animals and man is discussed. The problems caused by antibiotic resistance, the mechanisms involved, and the emergence, selection and dissemination of resistant bacteria and resistance genes are especially emphasized.

Chapter II, entitled "Monitoring antibiotic resistance of Enterobacteriaceae isolated from the faecal flora of fattening pigs", describes the results of a study into the prevalence and the degree of antibiotic resistance of faecall Enterobacteriaceae as well as the susceptibility of $E$. coli strains isolated, during an 11 month period, from three groups of fattening pigs at a single farm. The variation over time and the reproducibility of sampling were the subject of the study.

In chapter III, entitled "Resistance in faecal Escherichia coli isolated from pig farmers and abattoir workers", the prevalence and degree of antibiotic resistance of faecal $E$. coli isolated from pig farmers and abattoir workers are compared with a control group isolated from (sub)urban residents.

In Chapter IV, entitled "Antibiotic resistance among Escherichia coli isolated from faecal samples of pig farmers and pigs", the results obtained with faecal samples of pigs and of pig farmers (chapter III) at the same farm are presented. The prevalence and degree of resistance of faecal $E$. coli and the susceptibility(patterns) of $E$. coli isolates of both groups of isolates are compared.

Chapter $V$, entitled "In vitro transfer of antibiotic resistance between faecal Escherichia coli strains isolated from pig farmers and pigs", describes a study in which a sellection of the strains from the previous study (chapter IV) was used. Biotypes, plasmid pattens, transferability of antibiotic resistance and isolation and typing of plasmids were used as phenotypic and genotypic markers.

In chaprer $V_{*}$ entitled "In wivo transfer of resistance plasmids in rat- human- or pigo derived intestinal flora using a rat model", germ-free rats associated with different" specific Enterobactericceae-free intestinal floras were used to study the in vivo transfer of resistance plasmids. The animals were colonized with porcine and human donor strains. The influence of the different intestinal floras on resistance transfer was investigated.

Chapter VII, entitled "Surveillance of antibiotic resistance among pigs using faecal floor droppings from trucks transporting fattening pigs", was performed to investigate whether floor droppings collected from trucks transporting pigs to the slaughterhouse could be 
Wsed in a resistance survellance programme to replace the cumbersome and time consuming collection of rectal samples at different farms. The prevalence and degree of antibiotic resistance and susceptiblitites of faecal $E$. coli from the truck samples were compared with the resuls of the frecal samples collected at farms in the same geographical area (chapter IV).

In Chapter VIII the results of the studies presented are reviewed and discussed. Recommendation for future research are formulated. 
REVIEW OF THE LITERATURE

AIMS OF THE STUDY 



\section{Introduction}

Next to the application of the principles of hygiene and aseptic techniques, the introduction of antibiotics and the development of vaccines has been one of the most important advances in human and veterinary medicine.

The first antimicrobial agent, which is still in use todlay, was discovered by chemists in Germany, testing certain kinds of dye for antimicrobial activity in pursuit of Paul Ehrlich"s concept of chemotherapy $(36,63,78)$. Ironically, further inwestigation of an effective molecule, the red dye prontosil, showed that it was the part of its structure without dyeing properties that was responsible for the antimicrobial effect. This was the sulphonamide portion $(63,78)$. Once it was established that sulphonamides were effective antibacterial drugs, an enormous programme of chemical synthesis and modification was undertaken, resulting in many related compounds entering the medical armamentarium.

After this chemical approach, a microbiological one arose as a result from Sir Alexander Fleming's observation that a fungus contaminating an agar plate with staphylococei was able to inhibit the growth of these and other, mainly Gram-positive, bacteria $(36,63)$. The realisation of the fact that one micro-organism could produce a substance which was a potent killer of other bacteria had an enormous impact on the pharmaceutical industry. Huge programmes were set up to search for other soll fungi and bacteria producing antibacterial substances (36). Soon streptomycin, chloramphenicol and the tetracyclines were discovered (78). All these molecules appeared to be effective, even though they were not always as safe as penicillin. These compounds are the true antibiotics: natural substances produced by micro-organisms which in low concentrations kill or inhibit growth of other micro-organisms and do not harm the host (63).

A breakthrough in antibiotic development was a combination of the microbial approach and the chemical route. Naturally occurring antibiotics were chemically modified by substituting different side chains or incorporating atoms to improve their antibacterial activity or their pharmocokinetic properties. This has led to the development of large numbers of antibiotics, such as penicillins and cephalosporins $(36,38,116)$. This chemical synthesis has made the differentiation between natural substances and chemically derived drugs obsolete. Therefore, nowadays the word antibiotic is used in the broad sense including chemically produced antimicrobial agents, such as sulphonamides and quinolo- 
mes

Antibiotics have proved to be very effective and safe for treatment of bacterial infections in nitan and animals. Unfortunately, the use of antibiotics in both human and veterinary medicine exerts a strong selective pressure inducing resistance to the antibiotics used or to related antibiotics among bacteria. Consequenty medical and veterinary clinicians were forced to change their choice of antibiotics at relatively frequent intervals. This was until recently not considered a major problem as new compounds were avalable to replace the "Iost" antimicrobial agent. The contimuous stream of new antibiotics coming on the market during the last decades might have given the impression, that there would always be new antibiotics available to kill bacteria resistant to the older ones and the increasing resistance problem was ignored. However, after a half-century of virtually complete control over microbial diseases in the developed countries, the mid eighties have brought a worldwide resurgence of bacterial diseases (15).

An important factor in this phenomenon is the acquisition of antibiotic resistance genes by bacterial pathogens. Recently, bacterial strains resistant to most available antibiotics were identified among clinical isolates of enterococci $(29,82)$. This increase of resistance against several non-related antibiotics (multi resistance) among pathogenic bacteria in hospitals and in veterinary isolates, as well as the slowing-down in the introduction of totally novel antibiotics, has lead to a reappraisal of the significance of antibiotic resistance.

Nowadays antibiotic resistance is a problem in veterinary medicine and a major problem in hospitals, because infections caused by resistant bacteria result in prolonged morbidity and mortality from treatment failures and increased costs as newer, more expensive and often more toxic antibiotics are needed to treat common infections. As resistance spreads, involving more antibiotics and more pathogens, infections, which cannot be treated effectively with antibiotics, may become nore prevalent $(52,61,80$ ). Another reason for concern is that new antimicrobial agents will be used against multi resistant pathogens $(15,17,81)$. This practise will virtually ensure, that eventually resistance against the new antibiotics will appear in the currently multi resistant bacterial species.

Although the emergence of resistance may be an inevitable consequence of the use of antibiotics, there is clear evidence that it need not to occur to the degree that it does at this moment. The emergence of resistance and the selection and dissemination of resistant bacteria or their resirtance genes is greatly enhanced by the amount of antibictics used, as this provides resistant micro-organisms with a powerful neo-Darwinian adwantage. As the use of antibiotics and the transmission of micro-organisms are factors over which we have control, intervention is feasible $(15,18,49,56)$. 
The different aspects of the consequences of antibiotic usage and resistance in the microflora of animals and the possible public health risks involved will be reviewed:

\section{Antibiotic resistance}

Antibiotic resistance is the ability of micro-organisms to survive or even to grow in a concentration of an antibiotic that would inhibit or kill susceptible bacteria $(63,103)$. When an antibiotic is present in the bacterial environment, resistant bacteria will soon be the predominant organisms in that population. In considering the problem of antibiotic resistance of bacteria, it is the emergence of resistance in bacteria belonging to a susceptible species that is of concern and not unsusceptibility.

\section{Unsusceptibility}

Unsusceptibility, also called intrinsic or natural resistance, implies that all bacteria belonm ging to a certain species are not affected by a certain antibiotic. This can be caused because the target sites of that compound cannot be reached or are absent in that species $(9,101,103)$

\section{Resistance}

Resistance, sometimes called acquired resistance, has indeed to be acquired. This means that bacteria belonging to a species normally susceptible to a specific antibiotic are not inhibited or killed by that particular drug in the concentration usually effective $(9,103)$. In case of resistance the organism has obtained the means to survive exposure to that particular antibiotic. Several mechanisms can be involved. The bacteria may excrete enzymes that can destroy one or several related antibiotics $(30,116)$, Bacterial structures such as the cell wall or metabolic pathways might have been changed, resulting in the impossibility of the antibiotic to reach or bind to its target site $(102,115,117)$.

There are three ways for resistance to emerge in a bacterial species: selection, mutation and acquisition of new genes.

\section{Selection of resistance}

In case of selection a minority of the population requires a higher dose of a certain antibiotic to be inhibited or killed or was already resistant before the introduction of that particular agent $(21,36,46,63)$. During exposure to that agent the resistant or less suscep- 
thite bacterial strains have a selective advantage and as a result these strains become predominut in the bacterial population. The classical example of selection is the sudden emiergence of resistance in Staphylococcus aureus to penicillin shortly after its introduction $(12,63)$. Also the susceptibility of gonococci to penicillin has gradually decreased since this agent was used for treatment of this disease and consequently the required effective doses for treatment had to be increased (36). One of the causes was the selection of strains with a diminished permeability of the cell wall for penicillin (116). The increase of resistant dinical human Campylobacter spp. is allso most likely a result of selection caused by exposure to enrofloxacin, used to treat $E$. coli infections in poultry $(32,33)$. Campylobacter jejumi and Campylobacter coli are common intestinal inhabitants of poultry and people can be infected after consumption of insufficiently cooked or unlhygienic treated poultry meat $(33,39)$. However, treatment of human Campylobacter infections with quinolones has contributed to the problem of resistant strains $(2,87)$.

\section{Mutation}

Mutations are changes in the DNA sequence of the bacterial chromosome, that usually occur during replication $(27,101,103)$. If the mutation(s) cause the bacterium to become resistant, under antibiotic pressure these mutated bacteria can be selected and become the predominant population. This resistance is only passed on vertically to their offispring: clonal dissemination of resistance. Mutationally altered bacteria are often metabolically deranged (sick) and are at a selective growth disadvantage compared to the wild types under normal growth conditions. Hence, in the absence of a selective advantage, such as the usage of antibiotic(s), bacteria with chromosomal mutations mostly disappear spontaneously from the population (103). However, when the selective pressure is maintained (e.g. antibiotics are used) such mutants may establish themselves in the population and become a threat to human and animal health. So is the diminished susceptibility of gonococi also caused by a mutation reducing the affinity of the penicillin-binding proteins in the gonococcal cell membrane (108). Alarming is the recent observation that a single point mutation in $\beta$-lactamase gemes, like TEM-1, extends the activity spectrum of the produced $\beta$-lactamases from a few broadspectrum penicillins and first generation cephalosporins to nearly all the $\beta$-lactam antibiotics available at this moment for clinical use (8).

\section{Acquisition of new genes}

The most important way by which bacteria may develop antibiotic resistance is by acquisition of new genes by uptake of foreign genetic material $(3,101,103)$. It seems easier for 
ai micro-organism to pick up one or several existing resistance genes, than for a niw resistance gene to emerge, which requires many mutations. Gonococci became resistant to penicillin after acquiring the TEM B-lactamase gen from $E$. coll $(108)$. One might wonder where and why these genes conferring resistance to antbiotics originated from. One should bear in mind that antibiotics are naturally occurring substances produced by soil microbes (63), comparable to the production of benzylpenicillin by the fungus Penticilium notatum or chlloramphenicol by the bacterium Actinomyces venezuelae. These compounds are toxic, even to the micro-organisms that produce them, so in order to protect themselves antibiotic-producing bacteria also have resistance determinants. It has been spectlated that resistance genes in other bacteria have been derived from antibiotic producing soil microbes by horizontal gene transfer or by spontaneous mutation of bacterial genes, and that this mutation was maintained under selective pressure of exposure to antibiotics produced by soil bacteria $(4,63)$. Antibiotic resistance has been observed in bacterial pathogens from the pre-antibiotic era (36). Siddall (98) found resistance to cefoxitin and clindamycin in 140-year old Clostridium strains. Other studies have described the presence of resistance plasmids in Enterobacteriaceae isolated from human infections before medical use of antibiotics $(21,46)$.

\section{Plasmids}

Although most of the bacterial genes are found on the bacterial chromosome, some genes can be found on relatively small, circular, self-replicating DNA molecules, which are independent of the chromosame and are called plasmids $(83,103)$. A single bacterium can carry several types of plasmids and those that harbour the genes for antibiotic resistance are called resistance factors (R-factors) or resistance plasmids (R-plasmids). Plasmids tend to establish themselves stably in bacteria, even in the absence of a selective pressure, because genes essential for survival of the organism are also often located on plasmids. Plasmids can multiply independently of the bacterium that harbours them and, more important, they can be transferred to other bacteria, of the same and of other microorganisms, by several ways: transformation, transduction, or conjugation. This allows bacteria to adapt themselves quickly to changes in their environment, which means that if antibiotics are polluting their ecological niches bacteria become resistant. Usage of such an antibiotic on a large scale may than cause a rapid, maybe even worldwide, dissemination of resistance $(5,107)$. Plasmid mediated resistance has been observed for nearly all antibiotics: aminoglycosides, cephallosporins, chloramphenicol, penicillins, sulphonamides, tetracyclines and trimethoprim $(13,61)$. Exceptions to date are the fluoroquinolones, 
polymyxins, nitroimidazoles and nitrofurans $(13,78,86)$.

\section{Conjugation}

Conjugation is the bacterial version of a sexual encounter. Two bacteria come into close contact and exchange plasmids wia a bridge or mating pore from a donor to a recipient strain $(4,76,83)$. Conjugation seems to be the most important way of transfer of resistance. However, only genes on specialized conjugative plasmids can be exchanged by conjugation. Bacieria have solved this problem by another molecular tool: transposons.

\section{Transposons}

Transposons are small mobile DNA fragments that can jump between plasmids or even from chromosomes to plasmids and vice versa $(4,103)$. Unlike plasmids, transposons do not rely on a particular host cell or any specific host DNA in order to exist or multiply. This additional step allows virtually all resistance genes to be exchanged by conjugation, making for a very efficient way of transferring resistance and easy for R-plasmids to pick up new resistance genes passing through bacteria. Recently, transposons have been discovered which cannot only transfer themselves from one bacterium to another, but can also mobilize co-resident plasmids and make non-transferable plasmids transferable: conjugative transposons. Conjugative transposons are widespread among clinical isolates and the transfer of some is even regulated by tetracycline (93).

\section{Multi resistance}

If several resistance genes are located on a single plasmid then the bacterium becomes multi resistant: resistant to two or more unrelated antibiotics. The use of one antibiotic always favours the spread of plasmids containing resistance genes for that particular antibiotic, but in case of multi resistance the genes conferring resistance to several other antibiotics are simultaneously transferred. Consequently, all bacteria harbouring the new plasinid also show resistance to the antibiotics encoded by that plasmid. This leads not only to decreased usefulness of the selecting agent, but also to that of the other antibiotics (9). Thus, changing the use of one antibiotic does not stop the selective pressure unless all relevant drugs are withdrawn.

\section{Transaluction}

Transduction is a process in which a viral vector, a bacteriophage, is used to shuttle resistance genes from a resistant bacterium to a susceptible one (36). 


\section{Transformation}

In case of transformation, pieces of naked DNA contaming resistance genes are released from dead bacteria and taken up by other competent bacteria (36). As a number of antibiotic preparations have been shown to be contaminated with chromosomal DNA of the antibiotic-producing micro-organism, this might be a more important source of resistance than expected up to now (111).

\section{Dissemination of resistance}

Despite the fact that resistance always has been present in the bacterial population, betore the first penicillins came into clinical use, selection and spread of resistance has increased enormously since during the last 50 years a large number of antibiotics with distinct mechanisms of action have come available. The usage of enormous quantities of these drugs, not only for therapy and prevention of bacterial diseases in man and animals, but also as growth promoting agents in animal husbandry and for crop protection in agriculture, has challenged the entire prokaryotic world. As a result resistant bacteria can be found anywhere in the environment of man and animals: in water and soll, on pastures, in animal waste and on meat(products), fruits and vegetables $(68,75,88,106)$. Hence, transferable resistance is not confined to pathogenic micromorganisms. As a matter of fact the problems of resistance encountered in pathogenic bacteria could be considered as the top of the resistance iceberg $(24,40,62)$.

The acquisition of resistance by a bacterium and the spread of a resistant strain should be considered as two quite separate phenomenons. The most dramatic problem is a major outbreak "even epidemic, caused by a single strain which has acquired antibiotic resistance and probably additional factors or has encountered circumstances enabling the strain to spread widely in a particular population: hospital patients, the community at large and/or in animal populations. This clonal dissemination includes the events with Salnonella typhimurium type 29 and type 204 in which strains carrying plasmids conferring resistance to chloramphenicol, amongst other antibiotics, were spread among thousands of calves all over the U.K. and also affected several humans, whereas most other Salmonella spp. isolated at that time were sensitive to most antibiotics as at the present time $(7,22$, 104). Most outbreaks of human salmonellosis reported in the literature are single strain epidemics $(43,73,91)$. The interest in salmonella infections and resistance in salmonellae is high because they are easily detectable and traceable. The final goal, however, ought to 
be to make animals intended for food production free from zoonotic pathogens, such as Salmonellowe spp, and not to keep the causal bacteria susceptible to antibiotics.

Apart from sellective pressure by antibiotics, transfer of resistance genes between bacteria. is especially likely when the species live in close proximity. Such a situation is present in the intestinal tract of man and animals, which is inhabited by hundreds of bacterial species in high concentrations and among these there are often several (potential) pathogens. Most research on transfer of resistance among the endogenous flora of man and animals has therefore focused on the gut. Faecal samples represent the contents of the terminal colon and the rectum. This flora consists for more than $99.9 \%$ of obligatory anaerobic bacteria. Only a minority belong to facultatiwely anaerobic bacteriall species e.g. Enterobacteriacece, enterococei, lactobacilli and the so called transient flora, consisting of bacteria that are ingested and only shortly pass through the intestine $(10,16)$. The endogenous intestinal flora is also a major factor in the natural resistance to infections with bacterial pathogens. The establishment in, or colonization of, the intestinal tract by new pathogenic bacteria, resistant or not, is combatted by the stable endogenous flora, mainly the large numbers of anaerobes (41). This protection against colonization of the intestinal tract with exogenic bacteria constituted by the intestinal flora is called colonization resistance by van der Waaij (109). This form of resistance of the gastro-intestinal tract is a complete different phenomenon compared to bacterial resistance and should clearly be distinguished. Administration of antibiotics, however, can change the composition of the intestinal flora, disturbing the colonization resistance and so permitting overgrowth by resistant endogenous micro-organisms or colonization by exogenous strains. So the presence of antibiotics in the intestinal tract is not only a selective force for selection and spread of resistance among bacteria belonging to the intestinal fllora, but also favours acquisition of new bacteria from the environment, which may introduce new resistance genes.

Some people are exposed to higher risks of acquiring resistant bacteria or plasmids than others. Farmers might be exposed to antibiotics by the involuntary ingestion of medicated animal feed. It has been suggested that this, besides close contact with animals might have led to higher levels of resistant bacteria in their flora. Ojeniyi (85) and Levy et al. (59) showed that farm workers in close contact with poultry fed antibiotic supplemented feed acquired resistant $E$. coli strains from the birds. As the proportion of human populations who have contact with farm animals is small compared with those who do not, this route is expected to be of little importance for the general human health stams (65). Nevertheless, it can have local effects. The presence of drug residues in meat and meat products is also a minor risk, in this respect possibly a theoretical one. To prevent this 
risk, a specific time for whtholding antibiotics from animals prior to slaughter, a withdrawal period for each veterinary product used in food animals, has been legally laid down and highly sensitive analytical methods make it possible to detect very low drug levels. Regularly checking animals at slaughter and condemnation of positive carcasses or products should protect consumers from exposure to antibiotics in meat and meat products.

The majority of the commensals are found in high numbers in the lower part of the gastro-intestinal tract in both humans and animals and this is considened a major reservoir of resistant bacteria and a pool of resistance exchange. The resistant bacteria are excreted in the faeces. E. coli is the most common aerobically growing species found in the faecal flora of humans and animalls and it constitutes a reservoir of resistance plasmids $(58 ; 60$, 71,92). Several factors can influence these reservoirs and the spread of bacteria or plasmids. In vitro resistance can be transferred rapidly throughout a susceptible population $(47,77,112)$. In vivo transfer of resistance plasmids also occurs, but proceeds slower and at lower frequencies or only under certain conditions such as under antibiotic pressure $(59,75,85,113)$. Plasmids encoding for antibiotic resistance have been shown to be transferred from human or animal $E$. coli to the $E$. coll resident in the intestinal flora of humans. Even in the absence of selective pressure of antibiotics these resistance plasmids may persist in the intestinal flora (14). Many studies have shown that the therapeutic administration of most antibiotics to animals and humans is associated with an increased prevalence of resistant bacteria, not only of pathogenic species, but also of bacteria belonging to the commensal intestinal flora, such as the Enterobacteriacede $(17,35,42$, $48,90)$. In particular, the oral use of poorly absorbable antibiotics which reach the gut in high concentrations , such as tetracyclines, leads rapidly to the selection of resistant Enterobacteriaceae. Tetracycline resistance is relatively common in $E$. coll isollates from pigs $(1,54,55,100)$. As a result, during antimicrobial therapy the numbers of resistant bacteria increase, which enhances the chance of transfer of prevalent resistance genes to other pathogenic and non-pathogenic bacteria present.

In general, resistance is more common in individuals, that are using antibiotics or recently have done so. In a population the prevalence of resistance is related to the amount of antibiotics that the population is exposed to. 


\section{Humants}

A main cause for the presence of resistan bacteria in man is the use of antibiotics prescribed for therapy in general practice or in hospitals $(51,90,110,114)$. However, resistant bacteria can spread from person to person. Risk factors for human to human spread are: high prevalence of resistance, antibiotic use, close contacts, crowding, low sanitary levels and/or contaminated food.

Antibiotic usage in hospitals is high, because many patients are immune-compromised caused by the underlying disease or its treament, the increased frequency of invasive medical interventions and the prolonged survival of many patients with chronic debilitating disease. These patients represent large reservoir of resistant bacteria which can be spread to other patients; of which many have a disturbed colonization resistance, and to the general population by person to person contact and into the environment by waste products and sewage $(17,74,79)$. However, Linton et al. (70) calculated that, although the sewage from hospitals contained the highest percentage of resistant coliforms, the population outside hospitals represents the greatest reservoir of resistance factors, because of a larger sewage output. Newertheless, it has been shown that intestinal bacteria carrying resistance factors are widely spread in the environment $(19,69)$. Patients of general practioners showed high resistance percentages after antibiotic therapy and consequently they can spread resistance to the open population $(20,72,79)$.

Not only in hospitals, but also in other places where people are crowded together a high prevalence of resistant bacteria in their endogenous flora is found and the risk for resistance transfer is high. Studies showed that attending day-care centres by a large proportion of children in a neighbourhood had also an effect on antibiotic resistance in the open population in that neighbourhood. Reves et al. (89) observed that children attending day-care centres showed high trimethoprim resistance percentages compared to adults and to children not visiting day-care centres. Singh et al. (99) observed the presence of an unique gene in trimethoprim resistant strains isolated from children visiting the same day. care centre and it circulated between children visiting that centre. High resistance levels in the facal flora of a crowded population can be enhanced by envirommental conditions such as poor sanitation, food contamination and because of antibiotic usage $(6,53,58,94)$. Crowding and poor hygienic conditions facilltate person to person dissemination of resistance enhancing the levels of antibiotic resistance (6). 


\section{Animals}

Also in animals the prevalence of antibiotic resistance in their endogenous flora is inffuenced by the use of antibiotics. A distinction has to be made between antibiotic usage in domestic pets and in food animals. Although people have intimate contact with pets these animals represent a minor part of the animal population and are only treated with antibiotics on an individual basis. The total amount of antibiotics used for treatment of pets is very low compared to the amounts used for humans and food animals $(9)$. Hence, the risk of resistance selection and spread to humans has been supposed to be negligible. If nomal hygienic standards are maintained pet animals do not seem to be a greater risk than any other member of the family taking antibiotics. However, Davies et al (23) observed similar plasmid incompatibility groups in a small group faecal coliforms isolated from humans $(n=27)$ and domestic pets $(n=52)$ from which it was suggested that the plasmid populations were similar.

Food animals, like pigs, are given antibiotics not only for treatment and prevention of bacterial diseases, but antimicrobial agents are also added to the feed of these animals in low non-therapeutic doses to improve growth. This practise is considered highly effective in increasing productivity. In The Netherlands the usage of feed additives or growth promotors containing antibiotics, that are registered as therapentic drugs either for humans or animals or showing cross-resistance with therapeutically used antibiotics, is not allowed by law. Moteover, as growth promoting antibiotics have activity against Grampositive micro-organisms and not against most Gram-negative micro-organisms, such as Escherichica, its significance in terms of contributing to antibiotic resistance in either animal or human $E$. coli populations is not exactly kmown, but seems absent or negligible $(25,26)$. Breeding and raising of food animals is more and more concentrated in very large farms specializing in only one animal species instead of on small-scale family farms keeping different animals. In such settings strong management and animal husbandry techniques are emphasized as a way of minimising and controlling disease. To prevent introduction of new infectious agents and outbreaks of infectious diseases, good hygiene, vaccinations and several other policies are strictly adhered to in intensive animall farming. By employing the closed herd principle it is possible to rear and fatten animals at the same farm. If new animals have to be added to the population these animals are kept in quarantine for a period of time before they are allowed to join the herd. Another method is the "all-in, all-out" policy meaning that all animals leave the farm at the same time. Only after a period of cleaning and disinfection of the stables new animals are introduced on to the premises. All these measures are meant to prevent introduction of new 
pathogentic bacteria from outside the compound, but not to prevent spread of microorganisms within a stable or fam. Condinions are such, that when introduced, infectious diseases can spread rapidly through a large number of animals in a herd or flock, sometimes with dire consequences. Because of crowding and intensive (faecal-oral) contact between animals bacteria can easily spread from one animal to another. In case of bacterial diseases antibiotics are not only used in individual animals, but at the first sign of illness among some animals the whole group is often treated rather than waiting for the disease to be manifest in the entire group. Usage of antibiotics, however, is generally minimized to keep costs down and because prolonged usage tend not to work well in such sertings. Despite this, reliance on antibiotics has become structural in intensive livestock farming $(9,31)$. Indiwidual animals are treated either parenterally or by oral dosing, but whole groups of animals by mixing the antibiotic through the feed or drinking water of the animals, which is called mass-medication (31). In The Netherlands the amount of antibiotics used for mass medication of food animals is approximately three times the amount used for treatment of individual animals (9). Mass-medication with antibiotics has been shown to select for the presence of large numbers of resistant $E$. coli in the intestinal flora of animals $(44,66,67)$. In chickens, receiving tetracycline-supplemented feed, the intestinal flora changed within one week from low percentages of tetracycline resistant micro-organisms to more than $60 \%$ resistant bacteria. In contrast, chickens not fed tetracycline-supplemented leed kept low numbers of resistant bacteria in their intestinal tract (60). Also Bourque et al. (11) observed a significant increase in resistance to neomycin, chloramphenicol and ampicillin in pigs under the influence of antibiotic supplemented feed. Smith (100) and Ojeniyi (85) have shown that food animals represent an enormous reservoir of plasmid-bearing $E$. coli. A first risk of selecting resistant bacteria in these animals is by direct antibiotic use. This is not only due to the amount of antibiotics used, but enhanced also by the strong selection forces of mass-medication and, maybe even more, by the total lack of hygienic barriers between animals to controll the dissemination of resistant bacteria.

\section{Transfer of resistance from food animals to man}

Because humans are often in close contact with animals or consume animal products, spread of bacterial resistance between both populations has been strongly suspected, despite the fact that resistance emerges independently in animals and in humans (28, 69,105 ). Zoonotic bacteria causing infections in man can be transferred from animals to 
man e.g. Salmonella spp. and Campylobacter spp.

As food animais represent an enormous reservoir of plasmid-bearing $E$. colt, these strains might reach the human intestinal flora by the same way as animall pathogens are transmitted to humans e.g. by direct contact with animals and by handling or eating contam nated food products of animal origin. These strains can either colonize the humans or transfer resistance to the human intestinal flora during their passage through the intestinal tract. It still is much debated to what extent these resistant bacteria do colonize the human intestinall tract or transfer resistance. Hence, the question to what extent in wivo transfer of resistance factors from animals to man occurs and its importance has not been answered yet.

\section{Animal contact}

Healthy humans who come in close contact with farm animals show higher resistance levels in their faecal flora than persons without animal contacts. Three to five months after chickens had been fed tetracycline an increase in resistant intestinal bacteria was observed in the farm personnel, but not in their neighbours (60). Levy et al. (59) demonstrated that poultry $E$. coli strains from chickens receiving tetracycline-medicated feed, could colonize the human intestinal tract, but this occurred only in two out of 11 persons. Some investigators have found similar antibiotic resistance patterns between animals and man in close contact. A strong association between the resistance patterns of the $E$. call isolates of farm families and their liwestock was also observed by Fein et al. (34). Saida et al. (92) found that resistance plasmids of pig $E$. coli strains could be observed in $E$. coli isolated from humans in contact with these pigs and that those people in closest contact with the pigs harboured the highest frequency of resistance plasmids. This finding suggested the presence of a common pool of resistance genes among Enterobacteriaceae in animals and man. In contrast, others did not find a consistent relationship between plasmid profile and resistance pattern of animal strains and strains isolated from humans in contact with these animals $(84,95)$.

\section{Meat and meat products}

During slaughtering, carcasses are inevitably contaminated with gut flora, especially when slaughtered under poor hygienic conditions $(64,66)$. Howe et al. (45) showed that direct carcass contamination did accur from the rectal comtents and from cross contamination from other animals. Shooter et al. (96) isolated $E$. coli from floors, instruments and carcasses in an abattoir, showing that bacterial contamination was commonly present. 
Shooter al. (96) also investigated meat on arrival in wospital kitchen and showed $E$. Goli contamination. Consequently hands and kitchen surfaces become contaminated with bacteria when the meat is handled. As a result humans may become colonised with resistant $E$. coli after handling uncooked or not properly handled cooked meat $(64,66)$. Handling and ingestion of contaminated raw meat has been suggested as the most importaint toute by which animal $E$ coli strains might reach man (64). In contrast, Guinee et al. (37) showed higher percentages of resistant $E$. coll in vegetarians than in meateating individuals. This might be due to contamination of vegetables with resistant bacterial strains from the ervironment $(57,88,97)$.

\section{In conclusion}

From the literature it is clear that the use of antibiotics by humans themselves is considered to be a major contributing factor to the problem of antibiotic resistance in man $(50,51,90,110,114)$, However, a contribution to this problem by the extensive usage of antibiotics in veterinary medicine cannot be excluded $(28,69)$. Animals carry large numbers of resistant bacteria and each time that animals are treated with antibiotics this could be considered as a contribution to this problem. Moreover, current animal husbandry practices ensure the rapid dissemination of resistant bacteria and resistance genes in a herd.

The potential public health risks associated with veterinary antibiotic use are:

1. selection of resistant micro-organisms under the pressure of antimicrobial therapy in animals, especially the intensively reared animals intended for food production

2. contact with or ingestion af animal products contaminated with enteric bacteria of animal origin harbouring resistance factors which may colonize the human intestinal flora or transfer of resistance plasmids to this flora

To find out if and to what extent resistance genes in the intestinal tract of pigs contribute to the resistance problems encountered in human medicine the present study was designed. 
As described before, the literature is not clear about the possible public health risk of antibiotic use in veterinary medicine. Animals might be a sounce of resistance genes tor the human intestinal flora, but it is unclear to what extent. The present study was designed to detect if and to what extent, antibiotic resistance found in the human intestinal flora was derived from resistant bacteria from animals. Therefore, three groups of people with different intensity and frequency of contact with pigs or pug products were compared:

A. pig farmers, who have daily intensive contact with pigs and pig faeces, and are regularly exposed to antibiotics used for pig medication

B. abattoir workers, who have daily contact with pigs, pig carcasses or pig meat

C. as a control group (sub)urban residents, who are not in contact with previous mentioned risk factors

Furthermore, pigs living at the same farm as the pig farmers were investigated. The influence of direct contact with animals or animal products as well as recent antibiotic use in human and pig medicine was investigated.

* The prevalence and high degree of antibiotic resistance in the faeces of pigs housed in different compartments at the same farm was monitored during 11 months to study the variation in prevalence of resistance over time in a population of different groups of pigs.

* The prevalence and high degree of resistance to antibiotics commonly used in pig and human medicine as well as resistance patterns of faecal $E$ coli isolated from pigs and humans with different contact with pigs and antibiotics, i.e. pig farmers, abattoir workers and the open population, were determined.

* In vitro and in vivo transfer experiments with plasmids of porcine and human $E$. coli strains isolated at the same farm were performed.

* Finally, a feasible and reliable method for monitoring antibiotic resistance in pig populations was devefoped. Faecal samples of pigs living at farms and floor droppings collected from trucks transporting fattening pigs were compared for the prevalence of resistance as well as for antibiotic susceptibility and resistance patterns. 


\section{REFERENCES}

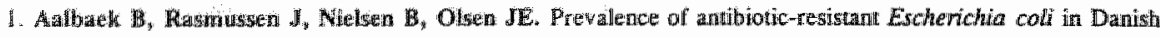
pigs and cattit. APMS 1991:99:103-1110.

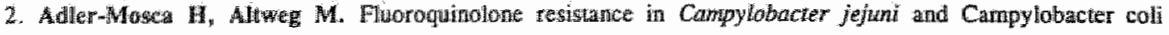

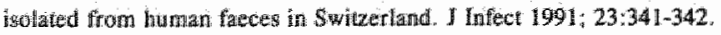

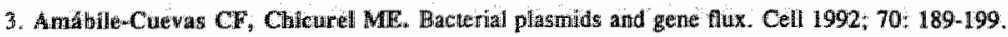

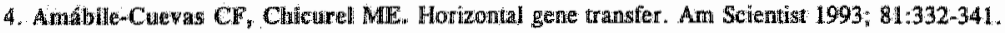

5. Amyes SGH. The suctess of plasmid encoded resistance genes in clinical bacteria. I Med Microbiol 1989; $28: 73 \cdot 83$.

6. Amyes SGB, Tait S, Thomson Cr, Paytre DJ, Nandivada LS, Jegudason MV et all. The incidence of antibiotie resistance in aerobic faecal flora in Soun India. J Antimicrob Chemother 1992; 29:415-425.

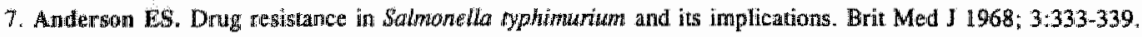

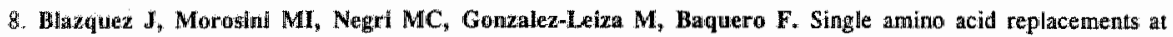
positions allered in naturally occuring extended spectrum TEM H-lactarnases. Antimicrob Agents Chemother 1995: $39: 145-1,49$.

9. Bogaard vd ARM, Breewsmia AJ, Julicher CHM, Mostert A, Nieuwenhuijs JHM, Vaarkamp H et all: Veterinair antibioticumbeleid: aanbevelingen wan een werkgroep. Tijdschr Diergeneeskd 1994 119:160-183.

10. Bouissou $\mathrm{J}$. Basis of the evaluation of the microbiological risks due to veterinary ding residues in food. Vet Mícrobiol 1993; $35: 187-192$.

11. Bourque $\mathbf{R}$, Lallier $\mathbf{R}$ Lariviere $\mathbf{S}$. Influence of oral artibiotics on resistance and enterotoxigenicity of Escherichia coll. Can J Comp Med $1980 ; 44: 101-108$.

12. Broda P. Plasmids in lhuman and veterinary medicine, In: Plasmids, pp 101-124. Freman WH and company (ed). Oxford and San Francisco, 1979.

13. Bryan LE. Mechanisms of plasmid mediated drug resistance. In: Plasmids and transposons, pp 57-81. Stuttard C, Rozee KR (ed). Academic Press, New York, 1980.

14. Chaslus-Dancla E, Gerbaud G, Lagorce M, LaFont JP, Courvallin P. Persistence of an antibiotic resistance plasmid in intestinat Escherichio coli of chickens in the abserhce of selective pressure. Antimicrob Agents Chemother $1987 ; 3: 7,784-788$.

15. Cohem MLL. Epidemiology of drug resustance: implications for a post-antimicrobial era. Science 1992; $257: 1050.1055$

16. Corpet DE An evaluation of methods to assess the effect of antimicrobial residues on the thuman gut flora. Var Microbiol 1993; 35:199:213.

17. Courcoll RJ, Pinkas M, Martin G. A seven year survey of antibiotic susceptibility and its realuonship with usage. Antimierob Chemother 1989; 23:441-451.

18. Daschner He. Cost-effectiveness in hospital infection control-lessons for the 1990s. I Hosp Infect 1989; $13.325-336$

19. Datta N. Drugg resistance and $R$ factors in the bowel bacteria of London potients before and after admissicn to hospital. Br Med J 1969; 2:407-411.

20. Datta N, Faters MC, Reeves DS, Brumfitt W, Orskow F, Orskow 1. R-factors in Escherichia coli in faces after oral chemotherapy in general practice. Lancet $1971 ; 1-1: 312-315$.

21. Datta. N, Unghes VM. Plasmids of the same Inc groups in Enterobocteria before and after the medical use of antibiotics. Nature 1983; 306:616-617. 
22. Davies J. Mechanisms of antibiotic resistance. Currenc Concepis, The Upjohn Company, 1980,

23. Davies M, Stewart PR. Transferable drug resistance in man ard animals: genetic relationship berwen plasnids in enteric bacteria from man and domestic pets. Aust Vet 11978 ; $54507-512$.

24. Degener JE, Swit ACW, Michel MF, Valkenburg HA, Moller L Faecal carriage of aerobilo grams negarive bacilli and drug resistance of Escherichia coll in different age groups in Dutch urban conmanuties. Med Microbiol 1983; 16:139-145.

25. Devriese LA. Nueritional antibiotics and antibionic resistance in luman and veterinary medicine. Med Pac Landbow Rijlesiniv Gent 1989; $54: 1535-1541$.

26. Djek v PJ. Further bacterial evaluation of virginiamycin. Chenother 1969; 14:322-332.

27. Doss SA. Chromosomally-mediated antibiotic resistance and wirulence. J Med Microbiol 1994; 40:305-306.

28. Dupont HL, Steele JH. Use of antimicrobial ageats in animal feeds: implications for human huesth. Rev Infect Dis 1987; 9:447-460.

29. Edmond MB, Ober JF, Weinbaum DL, Phaller MA, Hwang T, Sanford MD et al. Vancomycin-tesistant Enterococcus faecium bacteremia: risk factors for infection. Clin Infeet Dis 1995: 20:1126-1133.

30. Edson RS, Terrell CL. The aminoglycosides. Mayo Clin Proc 1991; 66:1158-1164.

31. Elbers ARW, Cromwijk WAJ, Hunneman WA, Tielen MJM. Logboekregistratie op wleesvarkenasbedrijwen in thet Integrale Keten Beheersing (IKB) project. Tijdschr Diergeneesto $1990 ; 115: 249.261$.

32. Endix HP, Mouton RP, Reyden vd T, Ruijs GJ, Biever M, Klingeren v B. Fluoroquinolone resistance in Campylobacter spp. isolated from human stools and poultry products. Lancet 1990; 335:787.

33. Endtz HP, Ruijs GJ, Klingeren $\mathbf{v}$ B, Jansen WH, Reyden vd T, Mouton RP. Quinolone resistance in Campylobacter isolated from man and poultry following the introduction of fluoroquinolones in vererinary medicine. Antimicrob Agents Chemother 1991: 27:199-208.

34. Fein D, Burton G, Tsutakawa R, Blenden D. Maching of antibiotic resistance patterns of Escherichia coll of farm families and their animals. J Infect Dis 1974; 130. 274-279.

35. Gellin G, Langlois BE, Dawson KA, Aaron DK. Antibiotic resistance of Gram-negative renteric batcteria from pigs in three herds with different histories of antibiotic exposure. Appl Environm Microbiol 1989; $55: 2287$. 2292.

36. Greenwond D. Antmicrobial chemotherapy. Greenwood D (ed). Oxford University Press, New York, 1989.

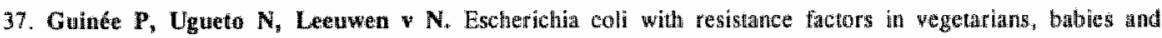
nonveyentains. Appl Microbiol 1970; 20:531-535.

38. Gustaferro CA, Steckelberg JM. Cephalosporin antimicrobial agents and related compounds. Mayo CHun. Proc $1991 ; 66: 1064-1073$.

39. Harris NV, Thompson D, Martin DC, Nolan CM. A survey of Campylobacter and other bactierial contaminants of pre-market chicken and retail poultry and nueats, King County, Washington. Ann J Public: Healut $1986 ; 76: 401-406$.

40. Hawkey PM. Resistant bacteria in the normal human flora. I Antimicrob Chemother 1986; 18, 5uppl. C. $133 \cdot 139$.

41. Hentgens DJ. Role of the intestinal microftora in lost defence against unfection. In: Human unbestinat micronoria in health and disease. pp 311-331. Hentgers DJ (ed). Ac Press lne. 1983.

42. Hinton M, Kaukas A, Lim SK., Linton AH. Preliminary observations on the influence of antibiotics on the ecology of Escherichia coli and the enterococei in the faecal florit of healthy young chickents. I Antumicrob 


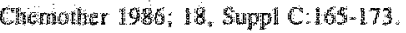

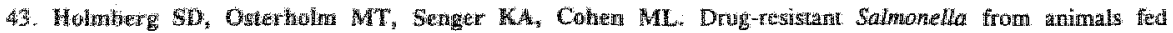

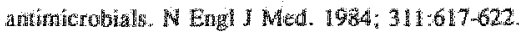

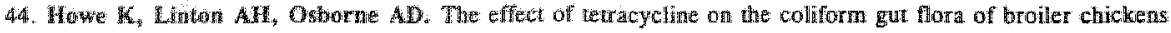

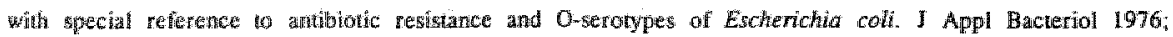
40.43 .464$.

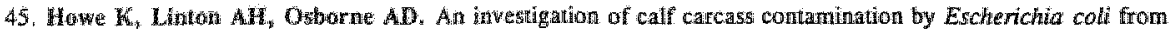
the guh contents at slatghte. I Appl Bacteriol 1976; $1.37-45$.

46. Hughes WM, Data N. Congugative plasmids in bacteria of the "pre-antibiotic "era. Nature 1983; $302: 725$. 726.

47. Hunter JË, Benned M, Hart CA, Sluelley JC, Walton JR. Apramycin-resistant Eschenchia coll isolated from pigs andi al stockman. Epideniol Intect 1994; 112:473-480.

48. Jones TT, Langlous BR, Cromwell GL, Ways VW. Eftect of chloretracycline on the spread of R-100 plasmid containing Escherichia coll BEL $15 R$ from experimentally infected pigs to uninfected pigs and chickens. J Animall Sci $1984 ; 58.519 .526$.

49. Jones $\mathrm{RN}$. The curent and future inapact of antimicrobial resistance among nosocomial bacterial pathogens. Diagn Microbial Infect Dä 1992;15:35.10S.

50. Jukes WH. Antibiotics in animal feed. N Engl J Med 1970; 282:49-50.

51. Kayser FH. Evolution of resistance in microorganisms of human origin. Vet Microb 1993: 35:257-267.

52. Kuse H, Sorum H. Transfer of nultiple drug resistance plasmids between bacteria of diverse arigins in natural microenvitonments. Appl Enwironm Microbial 1994; 60:4015-4021.

53. Kunin CM, Lipton HL, Tupasi $T$, Sacks $T$, Seheckler WE, Jivami $A$ et all, Social, behavorial and practical factors affecting antibiotic use worldwide: Report of task force 4. Rev Infect Dis 1987; 9, Suppl 3: $\$ 270-\$ 285$

54. Langlois BE, Dawson KA, Leak I, Aaron DK. Antimicrobial resistance of fecal coliforms from pigs in a herd not exposed to antimicrobial agents for 126 months. Vet Microbiol 1988; 18:147-153.

55. Langlois Ble, Dawson KA, Leak I, Aaron DK. Effect of age and housing location on antibiotic resistance of fecal coliforms from pigs in a non-antibiotic-exposed herd. Appl Environm Microbiol 1988; 54:1341-1344.

56. Lee KR, Leggiadro RJ, Burch KJ. Drug use evaluation of antibiotics in a pediatric teaching hospital. Infect Control Hosp Epidemiol 1994: 15:710 712.

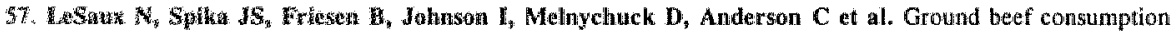

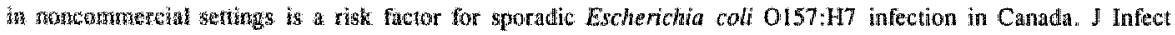

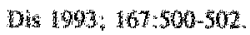

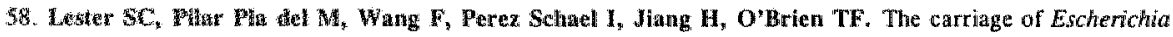

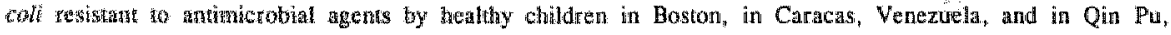

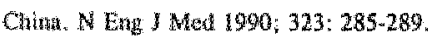

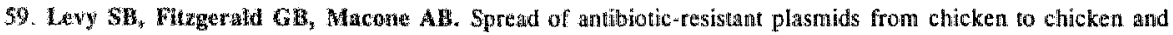
Trom chicken to man. Wature 1975, 260:40-42.

60. Levy S3, Fitgerald GB, Macone AB. Changes in untestinal flora of farm personnel after introduction of a tetracychine-supplemented fed on a fam. N Engl I Med 1976; 295.583-588.

61. Levy SB. Microbial resistane to antibiotics. An evolving and persistent problem. Lancet 1982 ; $i: 83-88^{\prime}$

62. Levy SM, Marshall B, Schinederberg $\mathrm{S}$, Rowse D, Davies J. High frequency of antimicrobial resistance in human fecat flora. Antimierob Agents and Chemother 1988; 32:1801-1806. 
63. Lewy SB. Antbiotics, animats and the resistance gene pool. In: The antbiotic paradox: how miracle drugs are destroyung the miracle, pp 137-156. Levy SB (ed). Plenum Press, New York, 1992.

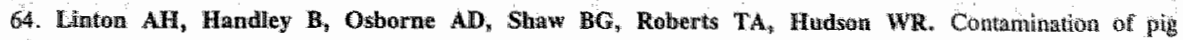

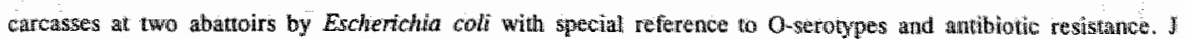
Appl Eacterioll 1976; 41:89-110.

65. Linton AH. Antibiotic resistance: The present sinution reviewed. Ver Recond 1977; 100:354-360.

66. Linton AH, Howe K, Bennet PM, Rjchmond MAt. The colonisation of the humangut by antibiotic lresistant Escherichia coll from thickens. J Appl Bacteriol $1977 ; 43: 465-469$.

67. Linton AH, Handley D, Osborne AD. Fluctuations in Escherichia coli O-seroypes din pigs throughour life in the presence and absence of antibiotic treatment. I Appl Bacteriol $1978 ; 44: 285-298$.

68. Linton AH. Flow of resistance genes in the enwironment and fron animals to man. A Antmicrob Chemother $1986: 18$, Suppl C:189-197.

69. Limton KB, Lee PA, Richmond MH, Gillespie WS. Antibiotic resistance and transmissible R-factors in the: intestinal coliform flora of healthy adults and childen in an urban and a rural community. Hyg. Camb 1972 , $70: 99-104$.

70. Limton KB, Richmond MH, Bevan R, Gillespie: WA. Antibiotic resistance and $\mathrm{R}$ factors in coliform bacilli isolated from hospital and donestic sewage J Med Microbiol 1974; 7:91-103.

71. London N, Nijstem R, Bogaard vd A, Stobberingh E. Antibiotic resistance of faecal Ervterobacteriaceae isolated from healthy wolunters, a 15-week follow-up study. J Antimicrob Chemother 1993; 32:33-91.

72. London N, Nijsten R, Mertens P, Bogaard wd A, Stobberingh E. Effect of antibiotic therapy on the antibiotic resistance of faecal Escherichia coll in patients attending general practioners. J Antimicroly Chemother $1994 ; 34: 239: 246$.

73. Lyons RW, Samples CL, DeSilva HN, Ross KA, Julian EM, Checko PJ. An epideriuc of resistant salmonella in a mursery. JAMA $1980 ; 243: 546-547$.

74. Ma MY, Goldstein EJC, Friedman MH, Anderson MS, Mulligan MEx Resistance of Gram-negative bacilli as rehated to hospital use of antimicrobial agents. Antimicrob Agents Chemother 1983; 24:347-352.

75. Marshall B., Petrowski D, Levy SB. Inter- and intraspecies spread of Escherichica coli in a farm environment in the absence of antibiolic usage. Proc Natl Acad Sci USA 1990; 87:6609-6613.

76. Mazodier $\mathbb{P}_{4}$ Davǐes $J_{m}$ Gene transfer between distantly related backeria, Annu Rev Gienet $1991 ; 25: 147-171$,

77. Mee BJ, Nikoletti SM. Plasmids encoding trimechoprim resistance in bacterial isolateg from man and pigs 1 Appl Bacteriol 1983; 54:225-235.

78. Mitsuhasthi S. Drug resistance in bacteria: history, genetics and biochenistry. I Intermat Med Resiearch. $1993 ; 21: 1-14$.

79. Moller JK, Leth-Mak $A$, Bitlow $\mathbf{P}$, Christiansen $C$, Christiansen $\mathbf{G}$, Stenderup A, Trangferable and nontransferable drug resistance in enveric bacterila from hospital and fitom general practice. Seand 1 lnfect 1976 ; $8+112 * 116$.

80. Murray $\mathbb{B E}$. New aspects of antimicrobial resistance and the resulting therapeutic dilemnas, Infect Dis 1991: 163:1185-1194.

81. Murray BE. Problems and detemmas of antimicrobial resistance. Pharmacother 1992; 12;865-935.

82. Norris AH, Reilly JP, Edelstein PH, Brenan PJ., Schuster MG. Chloramphenicol for the treatment of vancorrycin ressistant enterococcal infections. Clin Infect Dis 1995; 20:1137-1144.

83. Nowick RP, Clowes RC, Cohen SN, Curtiss $\mathbf{R}_{*}$ Datta $\mathrm{N}_{n}$ Stanley $\mathbf{F}$. Uniforn nomenclature for bacterial 


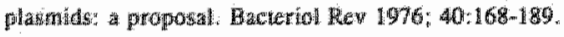

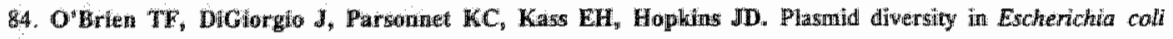
isclated from grocessed poultiy processors. Vat Mitrobiol 1993; 35:243-255.

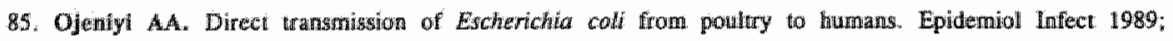
$103.513-522$

86. Prescott Jf, Desmond Baggot JD. Animicrobial Therapy in veterinary medicine. Prescott JF, Desmond Baggor Jy (ed). Blackwell scientific pubticationes, 1928 ;

87. Reina $y_{3}$ Alomat P. Fuoroquinolone-resilstance hin thermophilic Campylobacrer spp. isolated from stools of Spanish pratients. Lancet $1990,336: 186$.

88. Aemington JS, Sehimpif SC. Please don't eat the salads. N Engll Med 1981; 304:433-435.

89. Reves RR, Fong M, Plckering LK, Bartlet A, Alvarez M, Mlurray BE. Risk factors for fecal colonization with trimethoprim sesistant and mulitesistan Escherichia coli among children in day-care centers in Houlston, Texas: Antimictob Agenss Chemother 1990:34:1429.1434.

90. Richmond MH, Linton KD. The use of tetracycline in the community and its possible reliation to the textretion of tetracycline-resistant bacteria. I Antimicrob Chemother $1980 ; 633-41$.

91. Riley LW, Cohen ML, Senls JE, Blaser MW, Birkness KA, Hargrett NT et al. Importance of host factors in human salmonellosis caused by multiresistant strains of Salmonella. I Infect Dis 1984; $149: 878-883$.

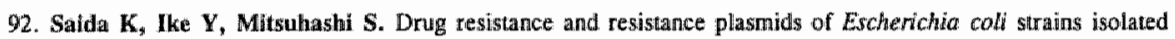
from pigs, slaughteres, and breeders of pigs in Japan. Antimicrob Agents Chemother 198.1; 19:1032-1036.

93. Salyers A.A, Shoemaker NB. Broad host range gene transfer; plamids and conjugative transposons. FEMS Microbial 1acology 1994; 15;15-22.

94. Shanalian PMA, Wylie BA, Adrian PV, Koormhof HJ, Thomson CJ, Amyes SGB. The prevalence of antimicrobial resistance in buman faecal flora in Soutli Africa. Epidemiol Infect 1993: 111:221-228.

95. Shears P, Suliman G, Hart CA. Occurrance of mutiple antibiotic resistance and $R$ plasmids in Enterobacteriaceae isolated from chillaren in the Sudan. Epidem Infect 1988; 100:73-81.

96. Shwoter RA, Rousseau SA, Cooke EM, Breaden AL. Animal sources of common serotypes of Escherichia colf in the food of hospical patients. Lancet 1970; 2-1:226-228.

97. Shooter RA, Faiers MC, Cooke EM, Breaden AL, O'Farrell SM. Isolation of Escherichia coli, Psetdomonas aeruginosa and Klebsiella from food in hospitals canteens and schools. Lancet 1971; 2. $1: 390929$

98. Siddall $\mathbf{R}$. Ancient bacteria resistant to some antibiotics. New Scientist 1989; 34 .

99. Singh KV, Reves RR, Plekering LK, Murray BE. Identification by DNA sequernce analysis of a new plasmid enoodsd trimethopim resistance gene in fecal Escherichio coli isolates firom children in day-care centers. Antinicrob Agents CHemother 1992; $36: 1720-1726$.

100. Smith HW. Antibiotic-resistant Eschertchita colf in market pigs in 1956-1979: the energence of organisfis with plasmidt borne trimethoprim resistance. J Hyg. Camb 1980; 84:467-477.

101. Smith JT, Lewin CS. Mechanisms of antimicrobial resistance and implications for epidemiology. Vet Mircrobiol 199:; 35:233-242.

102. Speer BS, Shoemaker NB, Salyers AA. Bacterial resistance to tetracyeline: mechanísms, transter and clinical significans. Clin Microbiol Rev 1992; 9:387-399.

103. Stratton CW. New insights on the genetic basis for resistance. Infect Control Hosp Epidemiol 1989; $10: 371-375$

104. Threlfall EJ, Ward LR, Ashley AS, Rowe R. Plasmid-encoded trimethoprim resistance in multiresistant. 


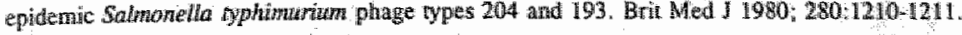

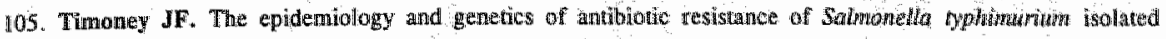
from diseased animals in New York. I Infect Dis 1978; $137,67-73$.

106. Timoney JF, Linton AH. Experimental evological sudies on H2 phsinids in the intestine and hewes of the call. I Apl Bacterio $1982 ; 52: 417-424$.

107. Trieu-Cuot $\mathbf{P}$, Derlot E, Conrvalin P. Enhanced conjugative transfer of plasnid DNA from Exchericha colit to Staphylocaccus aurew and Listenia monocytogenes. FEMS Mtorobiol letters 1993: 109:12-24.

108. Verhoef $\mathrm{J}$. Worldwide resistance against amtibioncs. Int J Antimicrob Agents 1994: 4:141-142.

109. Waraj vd D, Berghuis-Vries d JM, Lekkerkerk-Wees vd JEC. Colonzation resistance of the digustive ract in convertional and antibiotic-treated mice. J Hyg, Camb 1971; 69:405-411.

110. Waiton JR. Antibiotic resistance: An overview. Vet Record $1988 ; 122: 249-251$.

111. Webb V, Davies J. Antibiotic preparations contain DNA: a scurce of drug mesistance genes? Antimicrab Agents Chemowher 1993; 37:2379-2384.

112. Wells DM. James $O B$. Transmission of infectious drug resistance from animals to man. J Hyg. Camb 1973; 71:209-215.

113. Wiedemann B. Resistance transfer in vivo and its inhibition. In. Bacterial plastnids and antibiotie resistance, pp 75-90. Kremery V, Rosival L, Watamabe T (ed). Springer-Verlag, Heidelberg, 1972.

114. Whederramn B. Monitoring of resistant organisms in man and identification of their origin. Vet Microbiol $1993 ; 35: 275 \times 284$.

115. Wolfson JS, Hooper DC. Filuoroguinotone antimicrobial agents. Clin. Microbiol Rev 1989; 2:378-424.

116. Wright $\mathrm{AJ}_{4}$ Wikowske CJ. The Penicillins, Mayo Clin Proc 1991; 66:1047-1063.

117. Zinner SH, Mayer KH. Sulfonamides and trimethoprim. In: Peinciples and practice of infectious diseasts, pp 325 334. Mandell GL, Douglas RG, Bennet JE, (eds). Clutrchil Livingstone Inc, New York, 1990. 
MONITORING ANTIBIOTIC RESISTANCE OF ENTEROBACTERIACEAE ISOLATED FROM THE FAECAL FLORA OF FATTENING PIGS

Published as:

Antibiotic resistance of Enterobacteriaceae isolated from the faecal flora of fattening pigs Nijsten R., London N., Bogaard v.d. A., Stobberingh E.

The Veterinary Quarterly 1993; 15:152-157 


\section{SUMMARY}

From June 1991 to April 1992407 faecal samples were collected from three groups of pigs (I $n=248$, II $n=87$, III $n=72)$ at a pig fattening farm to determine the prevalence and the degree of antibiotic resistance of Enterobacteriaceae as well as the antibiotic susceptibility of the strains isolated. Despite the absence of mass-medication daring the abservation pertod, the prevalence of resistance to the most commony used antimicrobial agents in veterinary medicine was high (range amoxycillin 70\%-97\%, oxyternacycline $89 \%-100 \%$, sulphamethoxazole $88 \%-100 \%$, trimethoprim $78 \%-100 \%$. The high degree of resistance to oxytetracycline and sulphanethoxazole ranged from $8 \%-67 \%$ and $4 \%-46 \%$, respectively. The percentage of the isolated Escherichia coli strains resistant to oxytetracycline, streptomycin and suphamethoxazole ranged from $49 \%$ to $68 \%$; the other agents tested showed lower percentages $(0-13 \%)$. Resistance to three or more antibiotics was observed in $43 \%$ of the isolates. Of the 52 resistance patterns that could be distinguished, $51 \%$ was accounted by only four patterns: oxytetracycline +streptomycint sulphamethoxazole 20\%, sulphamethoxazole $12 \%$, streptomycin - sulphamethoxazole $11 \%$ and streptomycin +oxytetracycline $8 \%$. 


\section{WTRODUCTION}

The use of antibiotics in medical and weterinary practice has led to an increase in bacterial resistance in both populations, which might interfere with the effective treatment of bucterial infections $(11,14,26)$. However, the use of antibiotics is not the only reason for the increase in resistance. It is known that resistant bacteria can be transferred in different ways $(27)$. One of them is from animal to humans, but vice versa is also possible $(23,28)$. However, the frequency of transfer of resistant bacteria in vivo is difficult to determine (14). It is still debated to what extent the use of antibiotics in veterinary medicine is an important cause of the resistance problem encountered in humans, but it has been shown that antibiotic use in humans is of major importance $(6,31)$. Hospitals are especially breeding places for resistance, and newly admitted patients are a common source of resistant hospital strains. More specially they, or better their bacterial flora, are the barometers of antibiotic use in the community and therefore reflect the frequency of resistance there (22). The same is most likely the case in animal populations. Moreover, as such resistant bacteria represent a constant pool of resistance genes potentially transferable to pathogenic bacteria and indirectly transferable by animal products contaminated by enteric flora to the human intestinal tract, it seems appropriate to monitor this resistance $(29,34)$.

Some studies described the prevalence of resistance in human and in animal enteric flora, but the results are difficult to compare due to differences in geographic locations, time and because of the various methods used to determine antibiotic resistance $(3,4,8,12,29)$. In addition, almost no data are available about the stability of the prevalence of resistance over a certain period of time.

The present study was undertaken to investigate the prevalence of antibiotic resistant Enterabacteriaceae in faecal samples of pigs and changes in resistance over time (11 months) on a pig, fattening farm. In addition, the degree of resistance and the reproducibility of sampling were determined as well as the antibiotic resistance patterns of the isolated Escherichio coli.

\section{MATERIALS AND METHODS}

\section{Housing conditions of the pigs}

The finishing house ( \pm 600 pigs) consisted of five compartments, each containing eight pens with \pm 15 pigs per pen. Pigs were obtained from five breeders and each compart- 
ment housed pigs from wo different breeders. An "all in, all out" system was used for each cormpartment. After removal of the pigs for slaughter, the compartmerits were thoroughly cleaned and disinfected with chloramide".

\section{Faccal sampling}

Three different groups of pigs were sampled, between June 1991 and April 1992; 407 faecal samples were collected in total. The farm was visited by the same person twelve times to collect the faecal samples, the first four times once a week and then monthly. Each time faecal samples came from the same three (out of five) compartments. On the first seven occasions (period 1-7), six rectal samples (6 out of 15 pügs) from one pen and one floor sample from the other pens were collected from each of the three compartments. More than six rectal faecal samples were collected during the periods 3 and 4 (12 and 2 more, respectively). During the remaining periods (8-12) only floor samples, one from each pen, were taken.

group I $(\mathrm{n}=248)$ : from June to August 1991 (period 1-6),

group II $(n=87)$ : from October to December 1991 (period 7-9),

group III $(n=72)$ : from February to April 1992 (period 10-12).

\section{Antibiotic use}

\section{Growth promotion}

During the sampling period two types of feed-mix were supplied. From arrival until 16 weeks of age the pigs were given pellets containing $40 \mathrm{mg} / \mathrm{kg}$ of the growth promoter virginiamycin, an antibiotic which is not active against Enterobacteriaceae. Subsequently pellets containing $20 \mathrm{mg} / \mathrm{kg}$ of virginiamycin were given until the pigs reached the age of 6 months.

\section{Therapentic use}

During the sampling period 15 pigs received parenteral antimicrobial treatment. One pig (pertiod 2: second week) was treated with penicillin ${ }^{2}$ for 6 days. In period 8 two pigs received oxytetracycline ${ }^{* 3}$ for 6 days and in the periods 10 and 11 oxytetracycline ${ }^{* 3}$ was used for eight and four pigs respectively. No information about previous antibiotic use could be obtained from the suppliers.

\footnotetext{
"Haldrater", Veip bu, Wijk bif Dwarstede, The Netherlands.

"Duplocillin", Mycofarm, De Bilt, The Netherlands.

"B Geomycine" Dopharmo, Raamstonkweer, The Netherlonds.
} 


\section{Microbial analysis of the faecal samplles}

Faecal samples were transported immediately to the nacrobiological laboratory where one gram of each sample was diluted in $9 \mathrm{ml}$ of $0.9 \%$ sodium chloride solution tin 20 \% glycerol) and stored at $-20^{\circ} \mathrm{C}$ until assayed. Samples $(37 \mu)$ of $10^{2}$ and $10^{3}$ dilutions in $0.9 \%$ sodium chloride solution were then inoculated on Levine-agar (BBL $11221^{*}$ ) plates with and without antibiotics, using a spiral plater ${ }^{* 5}$. Antibiotics were used in the agat plates in the following concentrations: amoxycillin (Amx $25 \mathrm{mg} / \mathrm{l}$ ), ciprofloxacin (Cip 4 $\mathrm{mg} / 1$ ), flumequin (Flu $4 \mathrm{mg} / \mathrm{l}$ ), neomycin (Ne $8 \mathrm{mg} / 1$ ), nitrofurantoin (Ft $50 \mathrm{mg} / 1$ ), oxytetracycline (Ot $25 \mathrm{mg} / \mathrm{l}$ ), sulphamethoxazole (Smx $100 \mathrm{mg} / \mathrm{l}$ ), trimethoprim (Tmp $8 \mathrm{mg} / 1$ ). Apramycin (Ap $32 \mathrm{mg} / \mathrm{l}$ ) was tested in the periods 8-12. For trimethoprim testing $5 \%$ lysed horse blood was added to the agar. These antibiotics were selected because they are regularly used therapeutically in pigs in The Netherlands, except for apramycin, which has not been used on large scale. Amoxycillin is not used commonly in pig medicine, but the in vitro activity is the same as that of ampicillin, which is used more extensively. Ciprofloxacin and mitrofurantoin have cross-resistance with enrofloxacin and furazolidon, respectively. Enrofloxacin has not been nsed on large scale yet on pig farms in The Netherlands, but furazolidon has been used extensively for several decades. Because of the poor solubility of furazolidon nitrofurantoin was tested.

Escherichia coli appears on Levine-agar plates as purple colonies with a black centre and a metallic green shine. Only these colonies were counted. The minimum detectable level of bacterial growth, by using the spiral plater, was $10^{3}$ Enterobacteriaceae/g faeces. Other Enterobacteriaceae, however, may grow on the plates as well. From each plate with and without antibiotics one colony, which answered the description of $E$. coli, was picked up and tested for growth at $42^{\circ} \mathrm{C}$ overnight in tryptone water (Oxoid $142^{* 6}$ ) and with the indole reaction. If both tests were positive the micro-organism was considered to be an E. coli and stored in a peptone glycerol (87\%) solution (Oxoid CM9/ Merck 4094*) at $-20^{\circ} \mathrm{C}$. Ninety-four per cent of all colonies tested were indole positive and showed growth at $42^{\circ} \mathrm{C}$ and were thus considered to be $E$. coli.

\footnotetext{
* Becton Dickinson BV, Etten-Leur. The Netherlands,

"Model C. Sprival Systems linc. Satm en Kip. Ureckn, The Metherlands.

"PCH Diagnostica. Marartem, The Netheriands.

"Merck Nederland. Amsterdam, The Netherlands.
} 
The prevalence of resistance (\%) in the population is given by the number of samples that grew on antibiotic-containing plates divided by the total number of samples tested $x 100 \%$.

\section{Degree of antibiotic resistance}

The degree of antibiotic resistance of each faecal sample to each of the agents tested was assessed as described before $(5,21)$. It was calculated as the number of colony forming units (CFU) of resistant Enterobacteriaceae divided by the total number of Enterobacteriacede. Two degrees of antibiotic resistance to a particular agent could be distinguished: a low degree, i.e. less than $50 \%$ of the faecal Enterobacteriaceae flora was resistant to that agent, and a high degree, i.e. $50 \%$ or more (thus the majority) of the faecal Enterobacteriaceae flora was resistant to that agent.

\section{Antibiotic susceptibility testing}

The antibiotic susceptibility of the $E_{\text {. coli }}$ strains isolated from the Levine-agar plates without antibiotics was determined using a microbroth dilution method in Iso-sensitest ${ }^{\mathrm{R}}$ broth (Oxoid CM473) with an inocullum of $5 \times 10^{5} \mathrm{CFU} /$ well.

The antimicrobial agents tested and the breakpoint concentrations for susceptibility according to the guidelines of the Dutch Working Party (16) were as follows: amoxycillin (Amx $16 \mathrm{mg} / \mathrm{l}$ ), amoxycillin +clavulanic acid (Amc $16 \mathrm{mg} / \mathrm{l}$ ), chloramphenicol (C 8 mg/D), gentamicin (Gm $4 \mathrm{mg} / \mathrm{ll}$ ), nalidixic acid $(\mathrm{Na} 8 \mathrm{mg} / \mathrm{l})$, meomycin $(\mathrm{Ne} 16 \mathrm{mg} / \mathrm{l})$, nitrofurantoin (Ft $32 \mathrm{mg} / \mathrm{l}$ ), oxytetracycline (Ot $16 \mathrm{mg} / \mathrm{l}$ ), streptomycin (S $16 \mathrm{mg} / \mathrm{l}$ ), sulphamethoxazole (Smx $128 \mathrm{mg} / \mathrm{l}$ ) and trimethoprim (Tmp $2 \mathrm{mg} / \mathrm{l}$ ). For apramycin (Ap) the breakpoint concentration was $16 \mathrm{mg} / \mathrm{l}$ (15). For trimethoprim testing thymidine phosphorylase was added to the Iso-sensitest ${ }^{\mathbb{R}}$ broth. After incubation for $18-24 \mathrm{hrs}$ at $37^{\circ} \mathrm{C}$, the minimal inhibiting concentration (MIC) was determined as the lowest concentration that inhibited visible growth. Escherichia coli strains ATCC 25922 and ATCC 35218 were used as controls for the susceptibility tests.

\section{Statistical analysis}

The means of the antibiotic prevalence of the different periods within one group were compared by using Student's t-test (significance $\mathrm{P} \leq 0.05$ ). To compare the three different groups of pigs with each other, Student's t-test for the difference of two population means with pooled variance was used (significance $P \leq 0.05$ ). This last test was also used to compare the means of the rectal and floor faecal samples from the pigs of group I with each other.

The error in the method introduced by making tenfold dilutions and by using the spiral 
plater was calculated from the standard error of the mean and was $0.5{ }^{10} \log$.

\section{RESULTS}

After seven periods of faecal sampling it was found that there were no significant differences between the prevalence of antibiotic resistant Enterobacteriaceae in the individual rectal and floor samples (Table 1). Therefore, only floor samples were collected during the periods 8-12. Of the total number of purple colonies with a black centre and a metallic green shine, $94 \%$ were indole positive and showed growth at $42^{\circ} \mathrm{C}$ and were identified as $E$. coli. No resistance to any of the antimicrobial agents tested was observed in 4 of the 407 faecal samples $(1 \%)$.

\section{Prevalence of antibiotic resistance}

The prevalence of resistant Enterobacteriaceae was compared per antibiotic as a function of time. The prevalence of resistance (\%) to oxytetracycline over time in the different groups is shown in Figure 1. The prevalence of resistance $(\%+S D)$ to the other compounds is given in Table 2 .

A high prevalence percentage of resistance to oxytetracycline, sulphamethoxazole, amoxycillin and trimethoprim was found. Resistance to ciprofloxacin was not observed.

Table l: Prevalence of resistance (\%) of rectal and floor faecal samples from the pigs of group I $(04=248)$.

\begin{tabular}{|c|c|c|c|c|c|c|}
\hline \multirow[t]{2}{*}{$\begin{array}{l}\text { antmicrobial } \\
\text { rgent }\end{array}$} & \multicolumn{3}{|c|}{$\begin{array}{l}\text { rectal samples } \\
n=122\end{array}$} & \multicolumn{3}{|c|}{$\begin{array}{l}\text { Foor samples } \\
\|=126\end{array}$} \\
\hline & $X$ & $\mathrm{SD}$ & range & $x$ & SD & range \\
\hline Amx & 69 & 15 & $(50.87)$ & $\pi 1$ & 17 & $(38-81)$ \\
\hline $\mathrm{Cip}$ & 0 & 0 & & 0 & 0 & \\
\hline Flas & 1 & 2 & $(0-6)$ & 0 & 0 & \\
\hline $\mathrm{Ft}$ & 7 & 16 & $(0-40)$ & 10 & 12 & $(0.29)$ \\
\hline $\mathrm{Ne}$ & 36 & 24 & $(20-83)$ & 36 & 16 & $(14-62)$ \\
\hline Oth & 86 & 16 & $(67-100)$ & 91 & 13 & $(67-100)$ \\
\hline $\operatorname{Sm} x$ & 86 & 13 & $(72-100)$ & 89 & 18 & $(52-100)$ \\
\hline Tinp & 90 & 20 & $(50-100)$ & 86 & 25 & $(38-100)$ \\
\hline
\end{tabular}

$X=$ mean, $S D=$ shandand deviation: Amx $=$ amoxycillin, Cip wiprofloxacin. Flu = flumequin, Ne= neomycin,

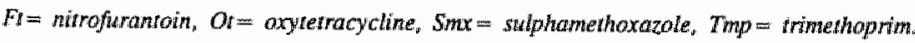




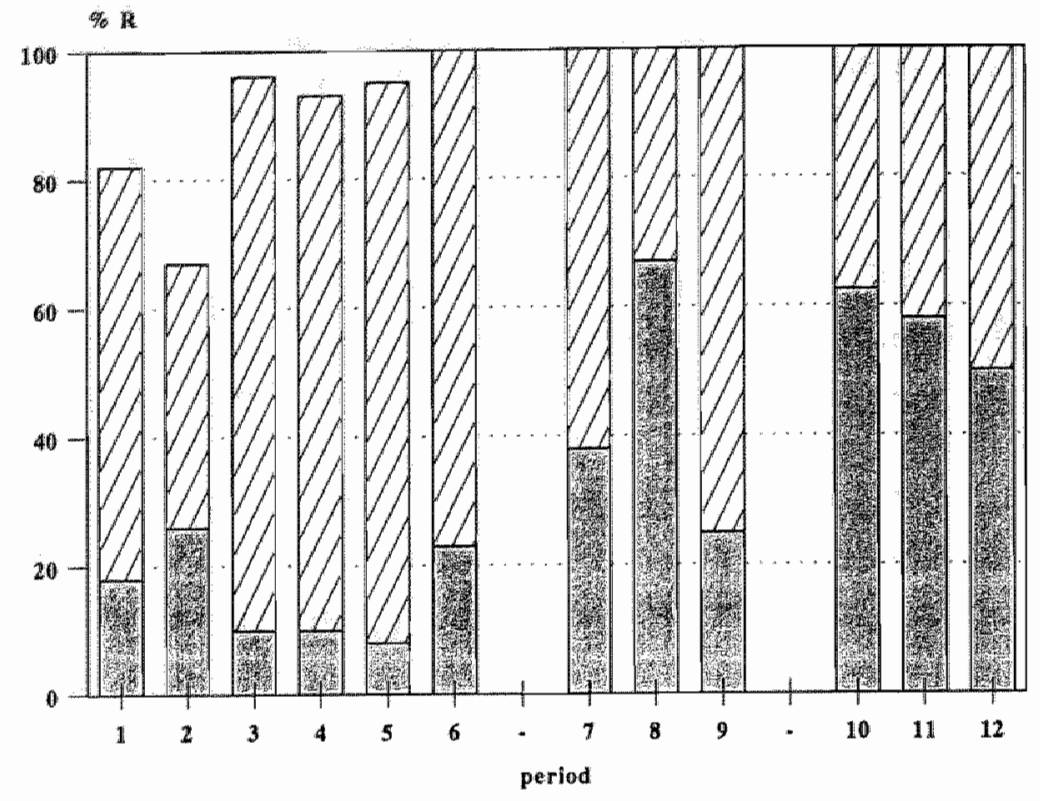

high degree of $\mathrm{R}$ Dlow degree of $\mathbb{R}$

Fig.l: Prevalence of resistance (\%) to oxyterracyctine of Enterobacteriaceae isolated from three groups of pigs as a function of time. Also shown are the frequencies (\%) of low degree (<50\%) and high degree ( $\geq 50$ \% resistance. Growp I: periods $1-6,1 \mathrm{~L}: 7-9, \mathrm{III}: 10-12 ; \% R=$ resistance percentage.

One sample showed resistance to flumequin and another to apramycin. The prevalence of resistance to nitrofurantoin was low (3-14\%).

Within the three groups no significant differences were observed between the samples taken at different times, except for group I in the periods 2 and 4 . During period 2 the prewalence of resistance to neomycin was higher (i.e. $72 \%, \mathrm{X}=$ mean $36 \%$ ) and for the other antibiotics significantly lower than during the other periods (Amx $44 \%, X=70 \% ; \mathrm{Ft}$ $3 \%, X=9 \% ;$ Ot $67 \%, X=89 \% ; \operatorname{Smx} 62 \%, X=88 \% ;$ Tmp $44 \%, X=88 \%$ ). During period 4 only a significant difference was observed for nitrofurantoin $(34 \%, X=9 \%)$. Between the groups there were only significant differences between group I and III for amoxycillin and between group II and II, II and III for neornycin (Table 2).

\section{Degree of antibiotic resistance}

The degree of resistance (\%) to oxytetracycline over time in the different groups is shown in Figure 1. A high degree of resistance to oxytetracycline and sulphamethoxazole was present in all periods tested (Table 3 ). The percentage ranged from $8 \%$ to $67 \%$ for oxytetracycline in periods 5 and 8 , respectively. For sulphamethoxazole the percentage 


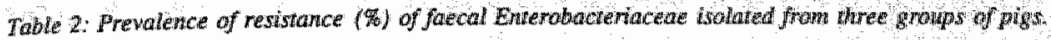

\begin{tabular}{|c|c|c|c|c|c|c|c|c|c|}
\hline \multirow[t]{2}{*}{ group: } & \multirow[b]{2}{*}{$x$} & \multicolumn{2}{|c|}{$\begin{array}{l}1 \\
\mathrm{n}=248\end{array}$} & \multirow[b]{2}{*}{$x$} & \multicolumn{2}{|c|}{$\begin{array}{l}n \\
\mathbb{n}=87\end{array}$} & \multirow[b]{2}{*}{$x$} & $m$ & \multirow{2}{*}{ range } \\
\hline & & $\mathrm{SD}$ & range & & $\mathrm{SD}$ & range & & SD & \\
\hline Amx & 70 & $15^{a}$ & $(44-84)$ & 88 & 15 & $(71-97)$ & 97 & $2^{a}$ & $(96-1000)$ \\
\hline Cip & $a$ & 0 & & 0 & 0 & & 0 & 0 & \\
\hline Flu & 0.4 & 1 & $(0-3)$ & 0 & 0 & & 0 & 0 & \\
\hline $\mathrm{Ft}$ & 9 & 13 & $(0-3,4)$ & 3. & 5 & $(0 n 8)$ & 14 & 21 & $(0-38)$ \\
\hline $\mathrm{Ne}$ & 36 & $19^{b}$ & $(21-72)$ & 83 & $11^{1 x}$ & $(71-93)$ & 50 & $18^{a}$ & $(38-71)$ \\
\hline Ot & 89 & 12 & $(67-100)$ & 100 & 0 & & 100 & 0 & \\
\hline $\operatorname{Sm} x$ & 88 & 14 & $(62-100)$ & 100 & 0 & & 100 & 0 & \\
\hline $\operatorname{Tmp}$ & 88 & 22 & $(44-100)$ & 100 & 0 & & 78 & 16 & $(67-96)$ \\
\hline Ap & -- & $\cdots$ & & 0 & 0 & & $\mathbb{1}$ & 2 & $(0-4)$ \\
\hline
\end{tabular}

Legend see Table $I_{;}-\mathrm{z}=$ not tested, $A p=$ apramycin; $"$ " $"=$ significant different $(P \leq 0.05)$.

Table 3: High degree of resistance (\%) of foecal Enterobacteriaceoe isolated from three groups of pigs over the study period.

\begin{tabular}{|c|c|c|c|c|c|c|c|c|c|}
\hline \multirow[t]{2}{*}{ group: } & \multirow[b]{2}{*}{$\mathrm{X}$} & \multicolumn{2}{|c|}{$\begin{array}{l}I \\
n=248\end{array}$} & \multicolumn{3}{|c|}{$\begin{array}{l}\text { II } \\
n=87\end{array}$} & \multicolumn{3}{|c|}{$\begin{array}{l}\text { III } \\
n=72\end{array}$} \\
\hline & & SD & range & $x$ & $\mathrm{SD}$ & range & $x$ & SD & range \\
\hline $\operatorname{Am} x$ & 18 & 13 & $(0-36)$ & 0 & 0 & & 6 & $s$ & $(0-8)$ \\
\hline Cip & 0 & 0 & & 0 & 0 & & 0 & 0 & \\
\hline Flu & 0 & 0 & & 0 & 0 & & 0 & 0 & \\
\hline $\mathrm{Ft}$ & 0 & 0 & & 0 & 0 & & 0 & 0 & \\
\hline Ne & 3 & 6 & $(0-15)$ & 0 & 0 & & 0 & 0 & \\
\hline Ot & 16 & $8^{* 50}$ & $(8-26)$ & 43 & $2 \beth^{*}$ & $(25 \times 67)$ & 51 & $11^{\mathrm{fi}}$ & $(42-63)$ \\
\hline $\operatorname{Sm} x$ & 12 & 6 & $(6-23)$ & 19 & 15 & $(4-33)$ & 26 & 19 & $(8-46)$ \\
\hline Tmp & 5 & 4 & $(0-10)$ & 1 & 2 & $(0-3)$ & 0 & 0 & \\
\hline $\mathrm{AP}$ & 0 & 0 & & 0 & 0 & & 0 & 0 & \\
\hline
\end{tabular}

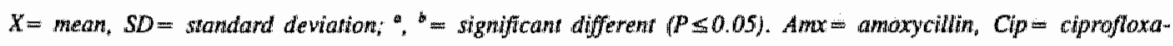
cin, Flu $=$ flumequin, $F t=$ nitrofurantoin, $N e=$ neomycin, $O t=$ oxytetracycline, $\operatorname{Simx}=$ sulphamethoxazole, Timp $=$ trimethoprim, $A p=$ apranycin. 
ranged from $4 \%$ (period 9) to 46\% (period 11). The range for amoxycillin was between $0 \%$ and $36 \%$ (period 1 ) and for trimethoprim betwen $0 \%$ and $10 \%$ (period 2). A high degres of restistance was not found for nitrofuramioin, apramycin or flumequin. Only in period 2 was a high degree of resistance observed in $15 \%$ of the samples resistant to reomycin.

Significant differences between the faecal samples of one group of pigs taken at different thmes were found for group $I$, in period 1 for amoxycilin $(28 \%, X=$ mean $18 \%)$, sulphamethoxazole $(23 \%, X=12 \%)$ and in period 6 for trimethoprim $(0 \%, X=5 \%)$. In period 2 there were sigmifficant differences for amoxycillin $(0 \%, \mathrm{X}=18 \%$ ), neomycin $(15 \%, X=3 \%)$, oxytetracycline $(26 \%, X=16 \%)$ and trimethoprim $(10 \%, X=5 \%)$. A significant difference between the three groups of pigs was noticed for oxytetracycline between group I and II and between I and III (Table 3 ).

\section{Antibiotic susceptibility}

The antibiotic susceptibility was determined for 387 out of 407 faecal samples. Eleven Enterobacteriaceae showed no growth at $42^{\circ} \mathrm{C}$ and were indole negative, and nine $E$. coll

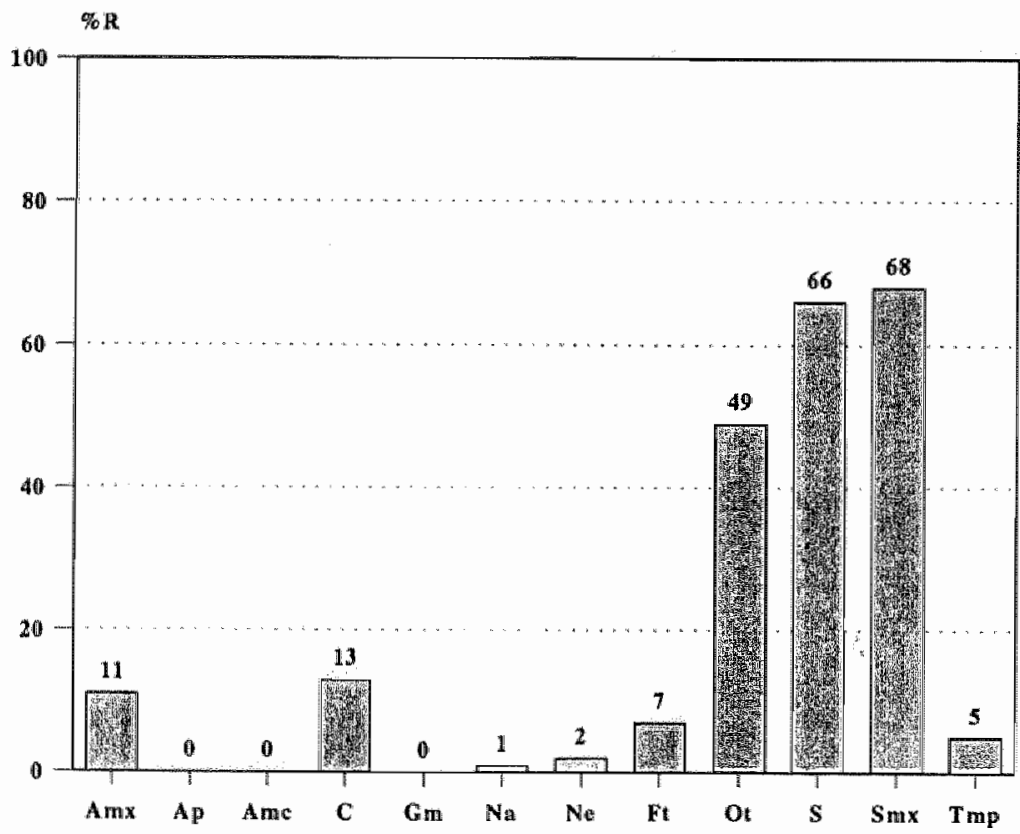

Fig. 2: Antibionic resistance (\%) of $E$. coll isclated from pigs $(n=387)$. Abux $=$ amoxycillin, Ap= apramycin,

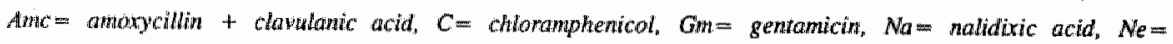

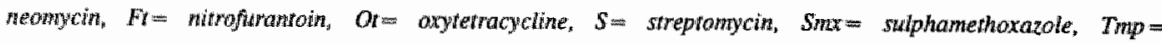
mimethoprim: on = resistance percentage. 
isolates were overgrown by Bacillus spp. Forty $(10 \%)$ of the 387 isolates were susceptible to all the antibiotics tested. Resistance to oxytetracycline, streptomycin and sulphamethoxazole was found in $188(49 \%), 257(66 \%)$ and $263(68 \%)$ strains respectively (Figure 2$)$. Distinctly lower percentages of resistance observed for the other agents tested, i.e. amoxycillin $11 \%$, chloramphenicol $13 \%$, neomycin $2 \%$, nalidixic acid $1 \%$, nitrofurantoin $7 \%$ and trimethoprim $5 \%$. No resistance to apramycin amoxycillin +clavulanic acid or gentamicin was found (Figure 2).

Eighty-five faecal isolates $(22 \%)$ were resistant to only one antibiotic and $94(24 \%)$ to two, $112(29 \%)$ to three, $37(10 \%)$ to four, $13(3 \%)$ to five, and 5 (1\%) to six antibiotics. Only one isolate was resistant to 7 of the 12 antibiotics tested. Overall, 52 different resistance patterns were observed. The combination of oxytetracycline + streptomycin + sulphamethoxazole $(n=76,20 \%)$ was most frequently observed, followed by sulphamethoxazole alone $(n=46,12 \%)$ and in combination with streptomycin $(n=42$, $11 \%$ ). Resistance to the combination streptomycin and oxytetracycline was found in 32 strains $(8 \%)$, resistance to amoxycillin in combination with oxytetracycline, streptomycin and sulphamethoxazole was observed in 11 strains $(3 \%)$.

\section{DISCUSSION}

The results of this study showed a high prevalence of resistance to oxytetracycline and sulphamethoxazole in the absence of recent antibiotic therapy during the stay at this farm. This is in accordance with the results of other studies $(13,23,35)$. It is very likelly that the resistant strains found in this study were already present in the faecal flora of the pigs when they arrived at the farm, probably due to transfer from the faecal flora of the sow to the piglets and perhaps also because of antimicrobial therapy before weaning.

In this study a high degree of antibiotic resistance was observed for the most commonly used antibiotics in veterinary medicine (amoxycillin, oxytetracycline, sulphamethoxazole, trimethoprim) and also for neomycin. Except for oxytetracycline the high degree of resistance was constant over time. A high degree of resistance means that the majority of faecal Enterabacteriaceae are resistant to the antibiotic tested and can be considered to be a major reservoir of resistance genes (21). In humans, a high degree of resistance of Enterobacteriaceae in the faecal flora of individuals was also found to be constant over time (24).

In this study minor differences were observed between different groups of pigs, pigs from 
differen breders and between pigs from different compartments. The data confirm the hypothesis that resistance in a population against a particular antibiotic is relatively constant and more related to the amounts of antibiotics used previously than currently $(20,23)$. However, this does not mean that these antibiotics are no longer viseful. In pigs oxytetracycline is mainly used for the treatmente of respiratory tract infections and still seems very effective. Trimethoprim, used for respiratory and gastrointestinal infections, is still an effective agent, especially in combination with sulphonamidles.

Largiglois et al.(18) showed that the use of antibiotics is not the only factor that influences the prevalence of resistant bacteria. The age of the animals studied and the housing conditions should also be taken into account. The highest resistance percentages for ampicillin, streptomycin, sulphamethoxazole and tetracycline were observed in pigs aged 6 months or younger. High resistance to carbenicillin, which has never been used on a large scale in pigs, was also observed (18). The age of the pigs and the housing conditions in intensive pig husbandry, which enforces high faecal contact, are probably important factors in the present study as well.

Veterinary and human use of quinolones for the treatment of bacterial infections has given rise to resistant bacterial strains $(2,9,25)$. In recent years new fluoroquinolones (ciprofloxacin, morfloxacin, enrofloxacin) have become available for clinical use. Enrofloxacin is only registered for use in veterinary medicine and is not available for human therapy. It is, however, closely related to and shows complete cross-resistance with ciprofloxacin (19). Both new agents have proved their usefulness in treating infections caused by bacteria resistant to the older quinolones $(9,26)$. However, after a few years of clinical use an increase in resistance was observed in poultry as well as in human isolates; the increase was more marked for Campylobacter spp. than for the Enterobacteriaceae $(10,30)$. It has been suggested that especially the veterinary use of quinolones could lead to an increase in the bacterial resistance of human pathogens (1). However in this study ciprofloxacin-resistant $E$.coli strains were not isolated and only one faecal sample (1/407) showed resistance to flumequin.

Neomycin is mainly used in young pigs for the treatment of diarrhoea. The differences found for neomycin resistance are most likely related to the use of this drug by the breeders. As mentioned earlier this could not be confirmed because information about antibiotic use could not be obtained from the pig breeding farms.

Apramycin is an aminocyclitol antibiotic registered for use in animals only. Apramycin is rarely used in veterinary practice in The Netherlands. Because of the cross-resistance between apramycin and gentamicin, it has been suggested that the use of apramycin in animals may lead to gentamicin-resistant isolates in hospitall patients (7). Several studies 
described the transfer of resistance to apramycin between bacteria from animals to human gut flora $(15,33,36)$. In this study apranycin-resistant faecal strains were isolated in only 1 out of the 120 samples tested. It is not likely that this low resistance to apramycin will be a risk factor for gentamicin resistance in humans.

The percentage susceptibility described in the present study was similar to that obtained for a group of healthy pigs described by Wray (35). Similar percentages (except for $\mathrm{S}$ and Smx) were observed by Langlois et al. (17), who investigated a herd of pigs which had not received antibiotics in 13 months prior to the study (Table 4). The fact that different microbiological methods were used in these studles cannot explain the differences found in resistance to some antibiotics.

The results of this sudy showed high resistance to drugs commonly used in veterinary medicine, i.e. oxytetracycline and sulphamethoxazole. The high percentage of streptomycin resistance can be explained by the possible carriage of drug resistance on the same plasmid as that for oxytetracycline and sulphamethoxazole. Other investigators have also found this antibiotic resistance profile $(29,32)$.

Although in recent years the use of chloramphenicol in pigs has been forbidden in The Netherlands, $13 \%$ of the $E$. coli strains were resistant to this drug. This is most likely due to a common plasmid which encodes for $S m x+S$ or for $S m x+S+O t$, in addition to chloramphenicol. In this study only 2 out of 50 chloramphenicol-resistant faecal isolates showed single resistance to chloramphenicol. The majority (48 out of 50) of the chloramphenicol resistant isolates also showed resistance to one or more other antibiotics, especially sulphamethoxazole, oxytetracycline and streptomycin. Saida er al. (32) also described resistance to combinations of chloramphenicol with $\operatorname{Smx}+S$ or $\operatorname{Smx}+S+O t$ in

Table 4: Antibionic resistance (90) in different studies.

\begin{tabular}{|c|c|c|c|c|c|c|}
\hline antibiotic agent & Amx & $\mathrm{C}$ & $\mathrm{Ne}$ & $O$ & $S$ & $\sin x$ \\
\hline present study & $\| 1$ & 13 & 2 & 49 & 66 & 68 \\
\hline \multicolumn{7}{|l|}{$1991-1992$} \\
\hline Langlois (17) & 9.2 & 0.8 & 0.8 & 59.1 & 34.5 & 15.6 \\
\hline \multicolumn{7}{|l|}{1988} \\
\hline Wray (35) & 10 & 0 & 2 & 34 & 70 & 86 \\
\hline 1983 & & & & & & \\
\hline
\end{tabular}

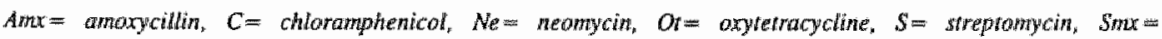
sulphamethoxazole. 
$1 \%$ and $22.2 \%$ of the pigs, terispectively.

Remarkably, the resistance to furazolidon, which has been used extensively for many yeare, was relatively low $(7 \%)$.

\section{CONCLUSION}

The results of this study suggest that for resistance survellance a single collection of floor faecal samples in severall compartments of pig fattening farms gives a reliablle indication of the prevalence and the degree of antibiotic resistance of Enterobacteriaceae in these pig fattening units. In addition the prevalence and the degree of resistance are relatively stable over an extended period of time (in this study 11 months) in the absence of massmedication. Thus, regular monitoring once a year seems sufficient to detect major changes in the prevalence and degree of antibiotic resistance of Enterobacteriaceae of the intestinal flora of fattening pigs.

\section{ACKNOWLEDGEMENTS}

We would like to thank M. Norder, J.Kellens, J. Philips and N. Kieser for skilled technical assistance, P. Terporten for his help with statistical problems, J. Hunter for kindly providing apramycin and Mr. Mares tor allowing as carry out the investigations on his farm. This work was supported by a grame project number 28.0275 , of the Prewention Fund of The Netherlands.

\section{REFERENCES}

1. Ad hoc Werkgroep. Adves ibzake inperking wan het arsenaal van antimicrobiele geneesmiddelen voor weterinaire toepassing. Rappottri, 358471003, RIVM, Nederlatad 1989.

2. Adler-Mosca H, Altwege M. Fluoroquinolone resistance in Campylobacter jejum and Compylobacter coli isolated from human facees in Switzerland. I Irfect 1991; 23:341-342.

3. Ahart JG, Burton GC, Blenden DC. The influence of antimicrobial agents on the percentage of tetracycline resistant bacteria in faces of humans and animals. I Appl Bacteriol 1978; 44:183-190.

4. Bonten M, Stobberingh $\mathbb{E}_{*}$, Phillps $J_{1}$ Howben $H_{2}$ High prevalence of antibiatic resistant Escherichia coli in fuccal samples of students in the soutth-east of the Netherlands. I Antimicrob Chemother 1990; 26;585-592.

5. Bonten M, Stobberingh L, Phllps J, Houben H. Antibiotic resistance of Escherichia coli in faecal samples of hoalthy people in two different areas in an industrialized country. Infect 1992; 5:258-262.

15. Burst SI, Woods DR. Evolution of transferable antibiotic resistance in colliform bacteria from remote wironmens. Antimicrob Agents; Chenother 1976; 10-567-568. 


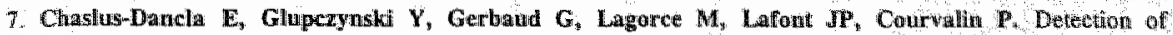
apranycin resistan Enterobacheriaceae in hospital isolates. FENS Microbiol Leters $1989.61261-266$

8. Degener JE, Hoof v MMS, Sithhout WAH, Luchmun R. Veranderde gevoeligheid wan Erchembha, hol woor antbiotica in de bewolking. Ned Tijdschr Geneeskund 1990; 134:2296-2299.

9. Dupont HL. Use of quinolones in the treatment of gastro-intestinal infeotions. Eut I Clin Mlotobiol Infect Dins $1991: 10,325-329$.

10. Endtz H, Mouton RP, Reyden vd T, Rujs GJ, Biever M, Klingeren v B. Fluproquinalone vesistance in Campylobocter spp. isolated from human stools and poultry products. Lance 1990: 787.

11. Greenwood D. Control of the spread of resistance. In: Antimicrob Chemother, Oxford University Press $1989 ; 153-159$.

12. Guimee P, Ugueto N, Leeuwen $\vee$ N. Escherichia coli with resistance factors in vegetarians, babivis and Ihonvegettarians. Appl Microbiol 1970; 20*531-535.

13. Iflinton M, Kaukas A, Lim SK, Linton AH. Preliminary observations on the influence of ankibiotics on the ecology of Escherichia coli and the enterococci in the faccal flora of healthy young chickens. J Antimicrob Chemother 1986; 18 Suppl C:165-173.

14. Holmberg SD, Osterholm MT, Senger KA, Cohen ML. Drug resistant Salmonelia from animals fed antimicrobials. The $\mathbb{N}$ Engl I Med 1984; 311:617-622.

15. Hunter JEB. Apramycin-resistant Escherichio coli in farm animals and man. Thesis University of L. verpool, 1992.

16. Klingeren $\vee$ B, Mouton RP. Standaardisatie van gevoeligheidsbepalingen. Verslag wan de werkgroep richtijnen gewoeligheidsbepalingen, 1990. Rijksinstituut voor Volksgezondheid en Milieuhygiene "Blthoven. The Netherlands. ISBN $90-6960-004-8$.

17. Langlois BE, Dawson KA, Leak $I_{y}$, AAron DK. Antimicrobial resistance of fecal coliforms from pigs in a herd not exposed to anthimicrobiall agents for 126 months. Vet Microbiol $1988 ; 18: 147-153$.

18. Langlois BE, Dawson KA, Leak I, Aaron DK. Effect of age and housing location on antibiotic resistance of fecal coliforms from pigs in a non-matibiotic-exposed herd. Appl Environm Microbiol 1988; 54:1341-1344.

19. Leathes M. Dutch worküng party recommends curbs on vet antibiotic use.. Animal Pharin 1988 157:27-2.8.

20. Levy SB. Playing antibiotic pool: time to tally the seore. N Engl J Med 1984; 311:663-665.

21. Lery SB, Marshall B; Sichluederberg S, Rowse D, Davis J. High frequency of antimicrobial resistance in human fecal for Antimicrob Agents Chemother 1988: 32:1801-1806.

22. Levy SB. The antibiotic paradox: how miracle drugs are destroying the miracle. 1st edition New York: Plenumi Press, 1992.

23. Linton AH. Flow of resistance genes in the environment and from animals to man. J Arthmicrob Chemother 1986; 18 Suppl $189-197$

24. London N, Nijstem $\mathbf{R}$, Bogaard vel A, Stobberingh $\mathbf{E}$. Antibiotic tresistance of faecal Ernterobacteriaceae isolated from healthy woltinteers, a 15wwek follow-up study. I Antimicrob Chemother 1993; 31;83-91.

25. Mevius DJ, Brenthink HJ, Miert ASJPAM. In vitro activity of flumequine in comparison witl several other antimicrobial agents against five pathogens isolated in calves in the Netherlands. Vet Quart 1990; $12.212-219$.

26. Midtredt $\mathbb{T}$. The influence of quinolones on the faecal flora, Scand J Infect Dis 1990; Suppl 68:14-18.

27. Murray BE New aspects of antimicrobial resistance and the resulting therapeutic dilemmas. I Infect Dis $199 ; 163: 1185-1194$. 


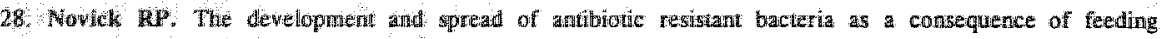

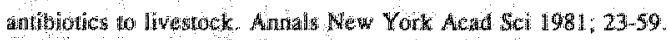

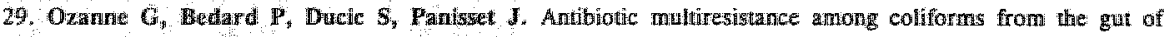

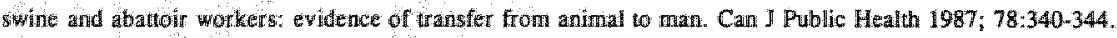

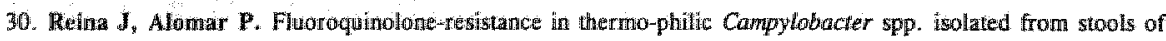
Spanish patientis. Lancel 19:00*336:186.

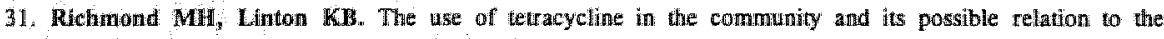
excreton of bacterias I Anthicrob Chenother 1980; $6: 33-41$.

32. Saida $\mathrm{K}, \mathrm{Ike}$, Mitsuhwoth $\mathrm{S}$. Drug resistance and R plasmids of Escherichio coll strains isolated from phgs: slatughterers and breeders of pigs in Japan. Antimicrob Agents Chemother 1981, 19:1032-1036.

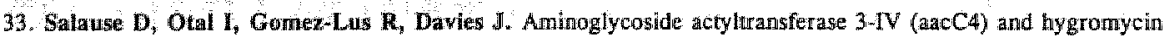
B 41 phosphotransferase (bphB) in bactera Isolated from human and artimal sources. Amtimicrob Agents Chemother $1990 ; 34: 1915-1920$.

34, Shooter RA, Roussera SA, Cooke EM, Breaden AL. Animal sources of common serolypes of Escherichia con in the food of hospital patients. Lancet 1970; $226-228$.

35. Wray C. Some aspects of the occurence of resistant bacteria in the normal animal flora. I Antimicrob Chemother 1986; 18 Suppl C:141-147.

36. Wray C, Medges $\mathbf{R W}$, Shannon KP, Bradleys DE. Apramycin and gentamicin resistance in Escherichio colli and Solmonellos isolated firom farm animals. I Hyg Camb 1986:97;445-456. 
RESISTANCE IN FAECAL ESCHERICHIA COLI ISOLATED FROM PIG FARMERS AND ABATTOIR WORKERS

Nijsten R., London N., Bogaard v.d. A., Stobberingh E.

Epidemiology and Infection 1994; 113:45-52 
om three populations of healthy adult volunteers (290 pig ers, 160 (sub)urban residents) living in the South of The for the prevalence and degree of antibiotic resistance of

revalence of resistance to amoxycillin, neomycin, oxytetraund trimethoprim were observed. The pig farmers showed the ance and the (sub)urban residents the lowest. In contrast no I degrees of resistance were observed, except for neomycin. td abattoir workers have regular contact with pigs differences were observed. However, because abattoir workers with ig (carcass) contact did not show significant differences, this rtant source of resistant $E$. coli in pig farmers.

pig farmers (5\%) and abattoir workers ( $8 \%$ ) than by (sub)ursult in significantly different resistance percentages. 


\section{NTRODUCTION}

Since the introduction of antimicrobial agents these have been successfully used to prevent and treat bacterial diseases in man and other species. The availability of antibiotics means that many previously severe infections can now be treated. In addition, antibiotics are used for growth promotion in animal husbandry and in agriculture for crop protection. As antibiotics are not only very effective, but also remarkably safe drugs this safety may have provoked liberal even lavish use in man and other animals. The use of antibiotics, however, leads inevitably to emergence of resistance in the endogenous bacterial flora of treated persons and animals alike, against the antibiotics used or to other drugs $(4,18)$. These enteric micro-organisms may colonize other persons or animals and transfier resistance plasmids to their faecal flora. Consequently, the environmental bacterial population may be contaminated after faeces excretion. Lester et al. (9) showed that persons with a few resistant bacteria in their intestinal flora will have more chance of developing an infection with resistant bacteria after antibiotic therapy than persons with no resistant strains at all.

Many studies have examined the resistance of enteric bacteria in humans after antibiotic therapy $(1,6,8,17,25)$, but there is much less information available on the prevalence of antibiotic resistance in the faecal flora of healthy adults who have not used antibiotics recently $(2,3,5,13,16)$. However, such subjects are potential recipients of antimicrobial agents. Farm workers can directly become colonïzed by resistant bacteria due to close contact with animals and their faeces $(10,11,21)$, but are also directly exposed to antibiotics used for treatment or prewention of diseases in amimals (12). Abattoir workers have daily contact with contaminated carcasses and gut contents $(7,14,15,26)$. A common risk factor for colonization with resigtant microorganisms in all three groups is personal use of antibiotics.

To elucidate the importance of spread of resistance from food animals to man we studicd in the same region the antibiotic resistance in three populations with different risks of exposure to faecal bacteria from pigs, i.e. pig farmers, abattoir workers and as a control group, (sub)urban residents. As the faecal flora is considered the most important reservoir of resistant micro-organisms and the antibiotic resistance of this flora is an indicator for the resistance of potentially pathogenic bacteria in a population $(8,9,13,28)$, faecal samples of these three populations were analyzed for the prevalence and degree of antibiotic resistance of $E$. colli. 


\section{Collection of the faecal samples}

Faecal samples ${ }_{*}$ one from each person, were received from adult pig farmers (290), pig abattoir workers (316, of which 73 were meat-inspectors) and (sub)urban residents (160) all living in the same area. After receipt; the samples mere diluted $\left(10^{-1}\right)$ in physiological saline, containing $20 \%$ (v/v) glycerol and stored at $-20^{\circ} \mathrm{C}$ until examined. All participants were asked to answer a questionnaire concerning antibiotic use in the previous three months. Additional information about recent hospital stay and previous antibiotic use by family members was obtained from the pig farmers and abattoir workers. The abattoir workers were also asked to give some information about keeping domestic animals or pigs and their daily duties at the slaughterhouse.

\section{Bacteriological analysis of the faecall samples}

The methods used to determine the prevalence and degree of resistance were as described before (19). In brief, after thawing the samples $\left(10^{1}\right)$, tenfold dilutions $\left(10^{-2}-10^{-5}\right)$ in physiological saline were made. Thirty-seven $\mu$ l of these dilutions were inoculated with a spiral plater on Levine-agar plates (BBL 11221, 27), a selective medium for $E$. coli, with and without antibiotics. The antibiotic concentrations (Table 1) were based on NCCLS guidelines and modified where appropriate so that the data was comparable with that of previous studies $(2,3)$. Only colonies with the appearance of $E$. coli (i.e. purple with a black centre and a metallic green shine) were counted. The total number and the number of resistant $E$, coli were determined. The minimum detection level of bacterial growth was $10^{3}$ colony forming units (CFU)/g faeces. From each agar plate without antibiotics one colony with the appearance of $E$. coli was picked and tested for growth at $42^{\circ} \mathrm{C}$ overnight in tryptone water (Oxoid $L A 2$ ) and for the indole reaction. If these tests were positive the micro-organism was considered to be $E$. coli. For the first 50 isolates this identification was confirmed with Api-20E test (BioMerieux, Den Bosch, The Netherlands).

\section{Prevalence of antibiotic resistance}

The prewalence of antibiotic resistance was defined as the percentage of faecal samples showing any growth of $E$. coli on antibiotic-containing plates.

\section{Degree of antibiotic resistance}

The degree of resistance of each sample was calculated as the percentage of the total number of collonies that was resistant. Two degrees of antibiotic resistance to a particular antimicrobial agent were distinguished $(3,13)$, namely the proportion of faecal samples 
with a ratio $<50 \%$ was defined as low degree of resistance, and the proportion of faecal samples with a ratio $\geq 50 \%$ was defined as high degree of resistance (thus the majority of the strains showing resistance to that agent).

The antimicrobial agents used in this study were selected because these or closely related compounds are regularly used for the treatment of bumans and pigs in The Netherlands, except apramycin which is only registered for use in animals but is not extensively used in The Netherlands.

\section{Statistical analysis}

In the analysis of the differences in prevalence and degree of antibiotic resistance of the faecal samples of the three populations a Chi Square test with continuity correction was performed. A Fisher Exact test was used if the expected frequency in at least one cell was 5 or less. A two-sided significance level of $\leq 0.05$ was used.

Multiple logistic regression was used to analyze the contribution of the origin of the three study populations (independent variable) to the prevalence of resistance (dependent variable) to a particular antibiotic. The antibiotics other than the dependent variable were considered to be independent variables simultaneously, a two-sided significance level of $\leq 0.05$ was used.

The error of the method by using the spiral plater and by making tenfold dilutions, calculated from the standard error of the mean, was $0.5^{10} \log$.

\section{RESULTS}

Nimety-five per cent of the pig farmer colonies, $94 \%$ of the abattoir workers colonies and $92 \%$ of the (sub)urban residents colonies that grew on Levine-agar plates showing the morphology typical of $E$. colit were identified as $E$. coli. The other colonies tested were also Enterobacteriaceae: Klebsiella spp., Citrobacter spp., Enterobacter spp. and Proteus spp. Finally 278 samples of pig farmers, 289 of abattoir workers and 150 of (sub)urban residents were included in the analysis. The other samples failed to grow on the agar plates without antibiotics.

Antibiotic use was recorded by 15 pig farmers and 17 family members. Two farmers had been hospitalized recently. Twenty-five abattoir workers and 25 family members recorded antibiotic use, 5 abattoir workers had been hospitalized recently. By the (sub)urban residents no antibiotic use in the three previous months was recorded. Intensive contact 


\begin{tabular}{|c|c|c|c|c|c|c|c|}
\hline & & \multicolumn{3}{|c|}{ Prevalence } & \multicolumn{3}{|c|}{ High degriee } \\
\hline \multirow{2}{*}{\multicolumn{2}{|c|}{$\begin{array}{l}\text { Antibioties } \\
\text { mg/l }\end{array}$}} & $P F$ & AW & UR & $\mathrm{PF}$ & A & UR \\
\hline & & $n=278$ & $\mathrm{n}=289$ & $n=150$ & $n=278$ & $\mathrm{n}=2.89$ & $\mathrm{n}=150$ \\
\hline Amx & (25) & 62 & $42^{2}$ & $47^{16 d}$ & 7 & 9 & 13 \\
\hline$A p$ & $(32)^{* * *}$ & 3 & 1 & $\mathfrak{m}$ & 0 & 0 & 畩 \\
\hline $\mathrm{Cip}_{\mathrm{p}}$ & (4) & 1 & 0 & a & 0 & 0 & 0 \\
\hline Nai & (32) & 5 & 3 & 1 & 1 & 0 & $a$ \\
\hline Ne & (8) & 66 & $36^{i}$ & $25^{5+4}$ & 7 & $2^{2}$ & $2^{\text {bej }}$ \\
\hline$F_{t}$ & $(50)$ & 8 & 4 & 3 & 0 & 0 & 0 \\
\hline ot & (25) & 79 & $47^{*}$ & $36^{\text {sat }}$ & 10 & 15 & 8 \\
\hline $\sin x$ & $(100)$ & 84 & $45^{2}$ & $40^{15 x}$ & 17 & 13 & 10 \\
\hline Tmp & (8) & 53 & $23^{i}$ & $15^{\text {bid }}$ & 4 & 4 & 3 \\
\hline
\end{tabular}

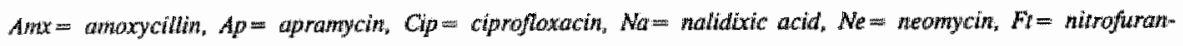
toin, $O t=$ oxyterracycline, $S m x=$ sutphamethoxazole, Tmp $=$ rimethoprim. ** Aprantycin was only tested for the slaughterhouse workers and the lasit 116 famers faecal samples. $P F=$ pig farmers, $A W=$ abotroir workers, $U R=(s w b)$ urban residents; $n t=$ nor tested. Significantly different $(P \leq 0.05): P F$ and $A W:$, PF and UR: "AW and UR: "PF and $A W$ and UR

with pigs or pig carcasses was recorded by 182 abattoir workers, whereas 1.04 workers had other duties as well or no direct contact. No information about contact with pigs or pig carcasses was obtained from the remaining abattoir workers $(n=30)$. Fiffy-two per cent of the abattoir workers did keep at least one domestic animal, whereas only three persons kept pigs.

\section{Prevalence of antibiotic resistance}

The prevalence and high degree of resistance are shown in Table $\mathbb{1}$ and Figure 1. The most significant differences were noticed between pig farmers and (sub)urban residents. The highest prevalence percentages were found for the pig farmers and the lowest for the (sub)urban residents. The highest percentages (i.e. $47 \%$ ) in the abattoir workers and in the (sub)urban residents group were recorded for oxytetracycline and amoxycillin, respectively, and in the pig farmer group for sulphamethoxazole (84\%). Further analysis as to the patterns of prevalence of resistance to amoxycillin, neomycin, oxytetracycline and trimethoprim of $E$. coll isolated from the three populations studied clearly showed that the highest percentage of fully susceptible strains (34\%) as well as the lowest percentage of completely resistant isolates (4\%) were found in the (sub)urban residents. The converse was observed for the pig farmers. 


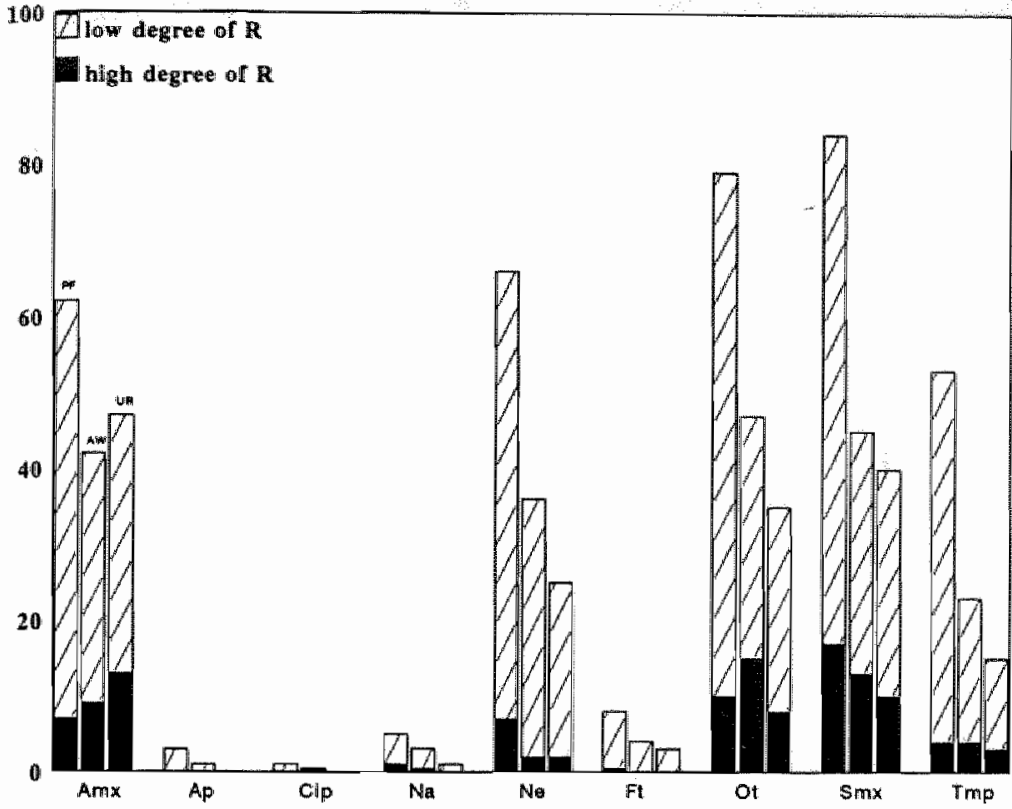

Figure 1: Prevalence of antibionic resistance (\%) of Escherichia coli isolated from pig famers (PF, first bar per antibiotic), abattoir workers (AW, second bar) and (sub)urban rexidents (UR, thind bar). Also shown are the proportions (\%) of low degree (<50\%) and high degree $(\geq 50 \%)$ of resistance. Amx $=$ amoxycillin, $A p=$

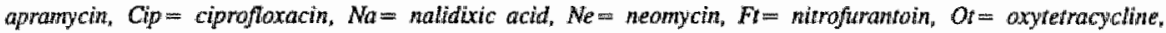
$S m x=$ sulphamethoxazole, Timp $=$ trimethoprim. ${ }^{\circ} R=$ resistance percentage.

Logistic regression analysis was performed to estimate the relative risk of prognostic and risk factors (i.e. antibiotics used and population groups) with regard to the (sub)urban residents. The odds ratio (OR), with the 95 \% confidence interval (CI), for resistance to a particular antibiotic under consistent circumstances was calculated. Both pig farmers (OR $0.4, \mathrm{Cr} 0.2-0.6)$ and abattoir workers (OR $0.5, \mathrm{CI} 0.3-0.9)$ showed a low odds ratio for amoxycillin resistance. The pig farmers showed a high odds ratio for neomycin (OR 3.6 , CI 2.5-5.4), sulphamethoxazole (OR 6.5, CI 4.0-10.6) and trimethoprim (OR 2.1, CI 1.42.9). Resistance to oxytetracycline appeared to be independent of the population tested. For the other antibiotics tested no significant prognostic and risk factors were found.

\section{Degree of antibiotic resistance}

As presented in Figure 1 all three populations showed, except for neomycin, similar percentages for high degree of resistance, but distinct variations in low degree of resistance. The prevalence and degree of resistance of the meat-inspector samples were not 
Bgnificanly different from those of the abatoir workers. In addition, no differences in prevalence and degres of resistance were observed between abattoir workers with and without domestic animals. Because only three abattoir workers kept pigs no conclusions about the influence of regular contact with pigs could be drawn.

No significant differences could be observed between abatioir workers with intensive and those without or with less intenisive contact with pig faecal contents or pig carcasses.

No significantly different prevallence or degree of resistance rates were observed for those people who had recently used antibiotics compared with those who had not used antibiotucs recently (pig farmers $5 \%$, abattoir workers $8 \%$. Nor were differences observed for those recording recent hospital stay (pig farmers $1 \%$, abattoir workers $2 \%$ ) or antibiotic use by family members (pig farmers $6 \%$, abattoir workers $8 \%$ ) when compared with those who did not record these factors.

\section{DISCUSSION}

The present study showed significant differences in prevalence of resistance between pig farmers and (sub)urban residents for antibiotics extensively used in human and veterinary medicine in The Netherlands (20). In contrast, the prevalence of the high degree of resistance was, except for neomycin, not significantly different. Several investigators have also observed differences in resistance of the faecal flora of pig farmers / abattoir workers and urban residents $(16,22,24)$ suggesting that contact with livestock was one route by which antibiotic resistance entered the human gut flora. In contrast, Levy et al. (13) found no significant difference between rural and urban residents. The general trend in their study was for lower numbers of resistant bacteria to be found in rurall samples.

Remarkably, in the present study $15(5 \%)$ pig farmers and $25(8 \%)$ abattoir workers used antibiotics during the three months previous to faecal sampling, whereas none of the (sub)urban residents mentioned recent antibiotic use. This might be an indication that people in contact with pigs or pig careasses have a greater risk of bacterial infections. A recent study about occupational risk factors for pig farmers showed that pig farmers often suffer from chronic a-specific respiratory tract afflictions, because of regular exposure in pig stables to dust containing fungi, endotoxins, disinfectants etc. (23). This exposure resullts in a higher probability of respiratory tract infections, which could explain the relaw tively high percentage of antibiotic usage among the pig farmers. Unfortunately, no information about the reasons of antibiotic therapy was obtained. Moreover, in one of the slaughterhouses studied, each month $4 \%$ of the workers were treated with antibiotics for 
wounds or eczema (personal communication). Because the control group of (sub)urban residents did not mention recent use of antibiotics, this therapeutic use among pig farmers and abattoir workers night explain the higher prevalence of resistance in these groups than in the (sub)urban residents. The relatively low numbers of pig farmers $(n=15)$ and abattoir workers $(\mathrm{n}=25)$ who mentioned antibiotic use could not explain the observed differences between the three populations. Also recent use of antibiotics by family members appeared to be of no influence on antibiotic resistance in this study.

Contact with pigs, pig carcasses or pig faeces might be a possible reason for the differences in prevalence of resistance observed between on one hand pig farmers and abattoir workers and on the other hand the (sub)urban residents. Although no information about the professions of the last group was obtained, it is to be expected that they do not have regular direct contact with pigs. However, no significant differences were observed between the abattoir workers with intensive and those with less intensive pig contact. Therefore, other factors such as more intensive faecal contact, less personal hygiene and protection taken by farmers as compared to abattoir workers might have contributed to these differences. Moreover, it is very likely that direct contact with antibiotics used for treatment of pigs is an additional risk factor for emergence of resistance and selection of resistant strains in the intestinal flora of pig farmers. The results of the logistic regression analysis underscore these suggestions.

Remarkably, significantly different prevalences and high degrees of resistance to neomycin were observed for the pig farmers. Because neomycin is seldom used orally and never parenterally in human medicine but frequently in pigs, the suggestion seems likely that it is not human but mainly veterinary use of neomycin that is responsible for a higher prevalence and high degree of resistance in pig farmers.

This study showed significant differences in the prevalence of antibiotic resistance in the faecal flora of the three populations tested. Direct contact with pigs and pig carcasses may contribute to antibiotic resistance in pig farmers and abattoir workers, in addition to common risk factors such as personal use of antibiotics. Moreover, it is likely that direct contact with antibiotics in medicated pig feed, i.e. mass-medication, influences the prevalence of antibiotic resistance in pig farmers. In the present study only prevalence and degree of resistance were determined. Comparison of plasmids and transfer experiments between pig and human isolates may elucidate the mechanisms inwolved. 


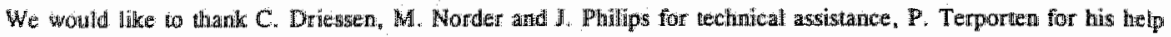

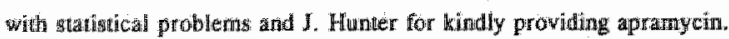

Aso we would like to thank the Animal Health Laboratory South Metherland (Prof. Dr. Ir. M.J.M. Tielen), the

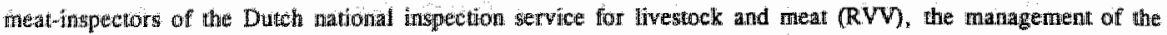
slaugherhouges Coweco and Encebe for their co-operation. We are rery gratefal to Prof. Dr. A. Knothenus and Prof. Dr. D. Mclaren for critical refing of dhe maluseript. This work was suported by a granit, project rumber 28.0275 , of the Prewention fund of The Netherlands.

\section{REFERENCES}

1. Ahart $\mathrm{JG}_{3}$ Burton GC, Blenden DC. The infuence of artimicrobial agents on the percentage of tetracycline: resistant bacteria in faeces of humans and animals. J Appl Bacteriol 1978; 44.,183-190.

2. Honten M, Stobberingh E, Philips J, Houben A. High prevalence of antibiotic resistant Escherichia coli in faecal samples of students in the south-east of The Netherlands. Antimicrob Chemother $1990 ; 26: 585-592$.

3. Bonten M, Stobberingh E, Phillips J, Houben A. Antibiotic resistance of Escherichia coli in fecial samples of healthy people in two different areas in an industrialized country. Infection 1992; 20:258-262.

4. Datta $N$. Drug resistance and $\mathrm{R}$ factors in the bowel bacteria of London patients before and after admission to hospital. Brit Med I 1969, 2:407-411.

5. Degener JE, Hoolt $\vee$ IMS, Stiphouk $\vee$ WAHJ, Luchmun $\mathbf{R}_{*}$ Veranderde gevoeligheid wan Escherichia coli voor antibutotica in de bevolking. Ned Tijdschr Genesk 1990; 47:2296-2299.

6. DuPomt HL. Use of quinolones in the treatment of gastrointestinal infections. Eur I Clin Microbiol lnfect Dis: $1991 ; 10: 325-329$.

7. Howe K, Linton AH, Osborne AD. An investigation of calf carcass contamination by Escherichia coli from the gut contents at slaughter. I Appl Bacteriol $1976 ; 41: 37 \cdot 45$.

8. Kling P, Ostensson R, Granstrom S, Burman L. A 7-year survey of drug resistance in aerobic and anacrobic fecal bacteria of surgical inpatients: clinical relevance and relation to local antibiotic consumption. Scand J thatect Dis 1989; 21:589.596.

9. Lester SC, Pilar del M, Wing F, Perez Schael I, Jiang H, O'Brien TF. The cartiage of Excherichia coli resistant to antmicrobial agents by healthy children in Boston, in Caracas, Venezuela, and in Qin Pu, Chind. $N$ Erigl J Med 1990:323:285-289

10. Levy SB, Fitzerald GB, Macone AB. Spread of antibüotic-reststant plasmids from chicken to chicken and from chicken to mati: Nature 1976; $260: 40-42$.

11. Levy SB, Fitzgerald GD, Macone AB. Changes in intestinal flora of farm persontel after introduction of a ketracycline-supplemented feed on a farm. $N$ Engl Med 1976; 295:583.588.

12. Levy SB. Emergence of antibiotic resistant bacteria in the intestinal flora of farm inhabitants. Infect Dis $1978: 137,688-690$.

13. Levy SB, Marshall B, Schluederberg S, Rowse D, Dawies J. High frequency of antimicrobial resistance in human fecal flora. Antimicrob Agents Chemother 1988; 32:1801-1806.

14. Linton AH, Handley B, Osborne AD, Shaw BG, Roberts TA, Fudson WR. Contamination of pig carcas- 


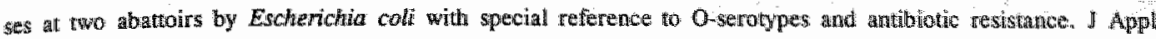
Bacterial 1976; $41: 89-110$.

15. Linton AH, Howe $\mathrm{K}$, Bewnet PM, Richmond MH. "The colonisation of the human gent by antibionic resistan Escherichia coli from chickens. J Appl Bamteriol 1977; 43.465-469.

16. Linten $\mathrm{KB}_{\text {; }}$ Lee PA, Richmond MH, Gillespie WA, Rowland AJ, Baker Viv. Antibiotic resistanew and transmissible R-factors in the intestimal coliform fora of healthy adulis and children in an urban and rural communiny. J Hyg. Camb 1972; 70:99-104.

17. Midwedt T. The infuence of quinolones on the faecal fora. Scand J Infect Dix 1990; \$uppl $63: 14+18$.

18. New HC. The emergence of bacterial resistance and its influence on emperic therapy. Rev Intect Dis 1983 ; S:Suppl $\$ 9-\$ 20$.

19. Nijsten R, London N, Bogaard vd A, Stobberingh $\mathbf{E}$. Antibiotic resistance of Enterobacteriaceae iswated from the faecal hora of fatening pigs. Vet Quart 1993; 15:152-157.

20. Nota Beleidsgraep "Veterinaire Apotheek" "Veterinair antibioticum beleid. Koninklijke Nederlaridse Maatschappij voor Diergeneeskunde 1992.

21. Ojeniyi AA. Direct transmission of Escherichia coll from poultry to humans. Epidemiol Infect 1989: $103: 513-522$.

22. Ozanne $\mathbf{G}$, Bedard $\mathbf{P}$, Duchc $\mathbf{S}$, Panisset JC. Antibiotic multiresistamce anong coliforms isolated from the gut of swine and abbatoir workersin evidence of transfer from animal to man. Can J Public Health 1987; $78: 340$ 344 .

23. Preller L, Vogellang P. Gezondheid varkenshouder an risico's blootgesteld. Stichting Gezondheidsdienst voor Dieren in Zuid-Nederland, Bioxtel/Heythuysen; 1993. Rapporinr 93.001.

24. Saldm $\mathbf{K}$, Ike: $\mathbf{Y}$, Mitsuhasili $\mathbf{S}$. Drug resistance and R plasmids of Escherichia coli strains isolated from pigs, slaughterers and breeders of pigs in Japan. Amtimicrob Agents Chemother 1981; 19:1032-1036.

25. Seydel JK, Wempe E. Bacterial growth kinetics of $E$. coli in the presence of various trinethoprim derivates wone and in combination with sulfomamides. Chemother $1980 ; 26 \% 361-371$.

26. Shooter RA, Rousseau SA, Cooke EM, Breaden AL. Animal sources of common serotypes of Escherichia coli in the food of hospital patients. Lancet 1970 226-228

27. Society of American Bacteriologists. Manual of Microbiological Methods, McGrawHill, New York 1957.

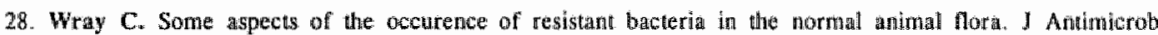
Chemolher 1986: Suppl C 18:141-147. 
60 
ANTIBIOTIC RESISTANCE AMONG ESCHERICHLA COLI ISOLATED FROM FAECAL SAMPLES OF PIG FARMERS AND PIGS

Nijsten R., London N., Bogaard v.d. A., Stobberingh E.

The Journal of Antimicrobial Chemotherapy, accepted for publication 


\section{SUMMARY}

The prevalence and degree of antibiotic resistance of 290 faecal samples of pig farmers and 291 faecal samples of pigs were determined. Significantly higher prevalence and high degree of resistance percentages of Escherichia coll were observed in the pig samples. Moreover, the porcine $E$. coll isolates showed significantly higher resistance percentages for chloramphenicol, nitrofurantoin, oxytetracycline, streptomycin and sulphamethoxazole than the farmer strains. The pig isolates were mainly resistant to oxytetracyclinestreptomycin and oxytetracycline-streptomycin-sulphamethoxazole and the farmer isolates to amoxycillin, sulphamethoxazole and streptomycin-sulphamethoxazole. Comparing the resistance patterns of the farmer $E$. coli isolates with those of the pigs from the same farm $(n=259)$ only $4 \%$ of both isolates showed resistance to the same antibiotics.

The results of the present study strongly suggested that the resistance in the faecal flora of the pig farmers and their pigs is distinctly different. 


\section{INTRODUCTION}

Antilbiotics are extensively used for bacterial infections in human and veterinary medicine. This use selects for resistant micro-organisms which may transfer resistance factors to other bacteria and may contribute to the enhancement and spread of these microorganisms (18). Transfer of resistant bacteria has been described between different animal species from human to human, from animals to humans and vice versa $(10,16,20,21,22$, $28,30,31,32)$.

In contrast to humans and pets, pigs are often treated as a group (mass-medication). Pigs, like other animals, medicated with antibiotics may select resistant Escherichia coli in their faecal flora which may transfer their resistance plasmids to other (pathogenic) bacteria (e.g. Salmonella spp.) $(17,32,34)$. Moreover pigs have intensive faecal contact and show coprophagy, so by this route they are also continuously exposed to contamination with faecal bacteria and antibiotic resistance genes. People in close contact with animals or using animall products may become colonized with these resistant bacteria from animal intestimal flora. Alternatively, their endogenous flora might become resistant by transfer of plasmids from bacteria of animal origin that pass through their intestinal tract $(10,11$, $21,33)$.

In a previous study it was observed that pig farmers, compared to abattoir workers and (sub)urban residents, showed the highest prevalence of resistance (27). Several other factors than direct contact with pigs and pig faeces, like exposure to antibiotics used for treatment of pigs and persomal use of antibiotics were suggested to be of influence on the prevalence of resistance in pig farmers. If contamination with intestinal pig fora is important the same resistance levels and comparable resistance patterns could be expected in faeces samples of pig farmers compared to samples from their pigs. However until now no data are available to confirm or reject this hypothesis. Therefore, the present study was undertaken to compare the prevalence and the degree of antibiotic resistance of $E$. coli in the faecal tlora of nearly 300 pig farmers (27) and of the pig population living at their farms. In addition, the antibiotic resistance patterns of $E$. coll strains isolated from both groups were compared. 


\section{Collection of the faecal samples}

Pig famers in the South of The Netherlands were asked to collect, in small plastic containers, one fresh faecal sample from themselves and one mixed faecal sample from three randomly chosen pigs. Faeces were preferably to be collected from mature gilts and/or heavy porkers. In addition, the farmers were asked to fill in a questionnaire about recent hospital stay, recent use of antimicrobial agents for mass-medication in pigs and antibiotic use by the farmer or his family during the three months preceding the sample collection. The faecal samples and the questionnaire were, immediately after collection, sent to the bacteriological laboratory where at the same day they were diluted $\left(10^{-1}\right)$ in $0.9 \%$ saline, containing $20 \%(\mathrm{v} / \mathrm{v})$ gllycerol and stored frozen at $-20^{\circ} \mathrm{C}$ until examined. Samples obtained 72 hours or more after collection were excluded.

\section{Bacteriological analysis of the faecal samples}

The methods used to determine the prevalence, the degree of resistance and the susceptibility were as described before $(26,27)$. The prevalence of antibiotic resistance $(\%)$ in the population was defined as the number of faecal samples that showed growth of $E$. coli on the antibiotic containing agar plates divided by the total number of samples tested multiplied by $100 \%$. The prevalence of resistance to a particular antimicrobial agent is the sum of the low and the high degree of antibiotic resistance $(3,19)$. The low degree of antibiotic resistance is the prevalence (\%) of faecal samples for which $<50 \%$ of the $E$. coli showed resistance to a particular antibiotic. The high degree of antibiotic resistance is the prevalence (\%) of faecal samples for which $\geq 50 \%$ of the $E$. coll showed resistance to a particular antibiotic (thus the majority of the strains showing resistance to that agent).

The antibiotic susceptibility of the $E$. coll strains, isolated from the faeces samples on Levine-agar plates (BBL 11221) without antibiotics, was determined using a microbroth dilution method in Iso-Sensitest ${ }^{\mathrm{R}}$ broth (Oxoid CM473), with an inoculum of approximately $5 \times 10^{5} \mathrm{CFU} /$ well obtained by dilution of an avernight culture. The breakpoint concentrations used for determining susceptibility are shown in Table 2. $E$. coll isolates showing resistance to nalidixic acid were further tested for resistance to flumequin $(4 \mathrm{mg} / \mathrm{l})(24)$ and ciprofloxacin ( $2 \mathrm{mg} / \mathrm{l}$ ). The $E$. coli strains ATCC 25922 and ATCC 35218 were used as controls each time susceptibility testing was performed.

The antimicrobial agents tested in this study were selected because these or closely related antibiotics are regularly used in human and/or pig medicine in The Netherlands, except for apramycin which is only used in animals but not on a large scale. 


\section{Statistical analysis}

In the analysis of the differences in prevalence of resistance, high degree of resistance. the resistance percentages and the resistance pattems of the faecal samples of the pigs and the pig farmers a Chi Square test with continuity correction was performed. A Fisher Exact test was used if the expected frequency in at least one cell was 5 or less. A twosided significance level of $\leq 0.05$ was used. A Mann-Whitney test was performed to test if significant differences were present between pigs and farmer living at farms with different husbandry methods. A two-sided significance level of $\leq 0.05$ was used.

The error of the method by wsing the spiral plater and by making tenfold dilutions, calculated from the standard error of the mean, was $0.5^{10} \mathrm{log}$.

\section{RESULTS}

The data observed for the pig farmers have been presented in a previous study (27). To facilitate comparison with the pig data they are repeated in present study. Ninety-five per cent of the pig farmer colonies and $96 \%$ of the pig colonies that grew on Levine-agar, showing the morphology typical of $E$. coll, were identified as $E$. coll . The other colonies tested were also Enterobacteriaceae: Klebsiella spp., Citrobacter spp., Enterobacter spp. and Proteus spp. In total 291 faecal samples of pigs and 290 samples of humans were received. All of the 291 pig samples showed growth on the agar plates without antibiotics, whereas 12 out of 290 farmer samples failed to grow. So, for the final analysis 291 pig and 278 farmer samples were included. From six pig and 12 farmer samples $E$. coli could not be isolated, because of overgrowth by Bacillus spp. or the isolate was indole negative and these were thus excluded from further testing. Finally the antibiotic susceptibility was determined of 285 faecal pig $E$. coli strains and 266 farmer strains, one strain per sample.

\section{Prevalence of antibiotic resistance}

The prevalences of resistance to neomycin and commonly used drugs in human and pig medicine (i.e. amoxycillin, oxytetracycline, sulphamethoxazole and trimethoprim) ranged from 92-100\% in pig faecal samples and from $53 \%-84 \%$ in the farmer samples (Table 1). Significant differences in prevalence of resistance were observed for these antibiotics and for nitrofurantoin. The prevalence of resistance to the other antibiotics tested was distinctly lower in both groups. 


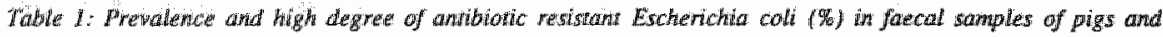
pig formers.

\begin{tabular}{|c|c|c|c|c|c|}
\hline & & Prevale & & Highi de & \\
\hline Antibichiti & & Plgg & Pig Farmers & Pigs & Pig Farmers \\
\hline & $m g / \|^{*}$ & $n=291$ & $n=278$ & $n=291$ & $\mathrm{n}=278$ \\
\hline Amx & 25 & 98 & $62^{\circ}$ & 11 & 7 \\
\hline$A p^{\text {*idit }}$ & 32 & 8 & 3 & 0 & 0 \\
\hline $\mathrm{Cip}$ & 4 & 2 & 1 & 0 & 0 \\
\hline Plo**** & 4 & 2 & - & 0 & - \\
\hline $\mathrm{F}_{t}$ & 50 & 17 & $8 *$ & 0 & 0 \\
\hline $\mathrm{Na}^{* * * * 1}$ & 32 & - & 5 & $-\infty$ & $\mathbb{1}$ \\
\hline Ne & 8 & 92 & $66 \%$ & 2 & $7 *$ \\
\hline or & 25 & 100 & $79 *$ & 25 & $10^{*}$ \\
\hline Sm. & 100 & 100 & $84^{*}$ & 24 & 17 \\
\hline Trip & 8 & 99 & $53^{*}$ & 7 & 4 \\
\hline
\end{tabular}

$m g / N^{*}=$ andibiotic concentrations in the agar plates: ${ }^{*}=$ siguificantly different $(P \leq 0.05)$ for a particular antibiotic berween pig fanthers and pigs; ** apranycin was ontly tested for the last 144 pigs and 116 farmers faecal samples: *** = flumequin was only tested for the pig and nalidixic acid only for the human samples; $-=$ not

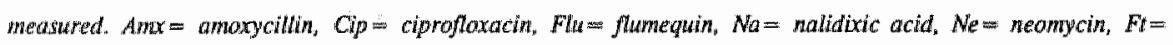
nitrofurantoin, Ot= oxytetracycline, Smx $=$ sutphamethoxazole, Thyss trimethoprim, Ap $=$ apramycin.

\section{Degree of antibiotic resistance}

For all frequently used antibiotics a high degree of resistance was observed (Table 1).

Significant differences were only observed for neomycin and oxytetracycline.

\section{Antibiatic susceptibility of the $E$. coli isolates}

Most $(74 \%)$ of the strains isolated from pigs showed resistance to two or more antibiotics, whereas almost half of the farmer isolates (43\%) were multi resistant (Figure 1). The percentage of strains showing no resistance to any antibiotic rested was twice as high in the farmers $(34 \%)$ as in the pigs $(15 \%)$. Significantly higher resistance percentages to chloramphenicol " mitrofurantoin, oxytetracycline, streptomycin and sulphamethoxazole were observed for the pig isolates. The $E$. coli strains isolated from both the pig farmers and their pigs, that appeared to be nalidixic acid resistant $(n=5$ and $n=1$, respectively) were also resistant to flumequin, but susceptible to ciprofloxacin. Moreover, higher $\mathrm{MIC}_{90}$ values for trimethoprim and $\mathrm{MIC}_{50}$ values for oxytetracycline and streptomycin were observed for the pig isolates (Table 2).

The $E$. coli isolates showed 70 different resistance patterns for the pigs and 52 for the 


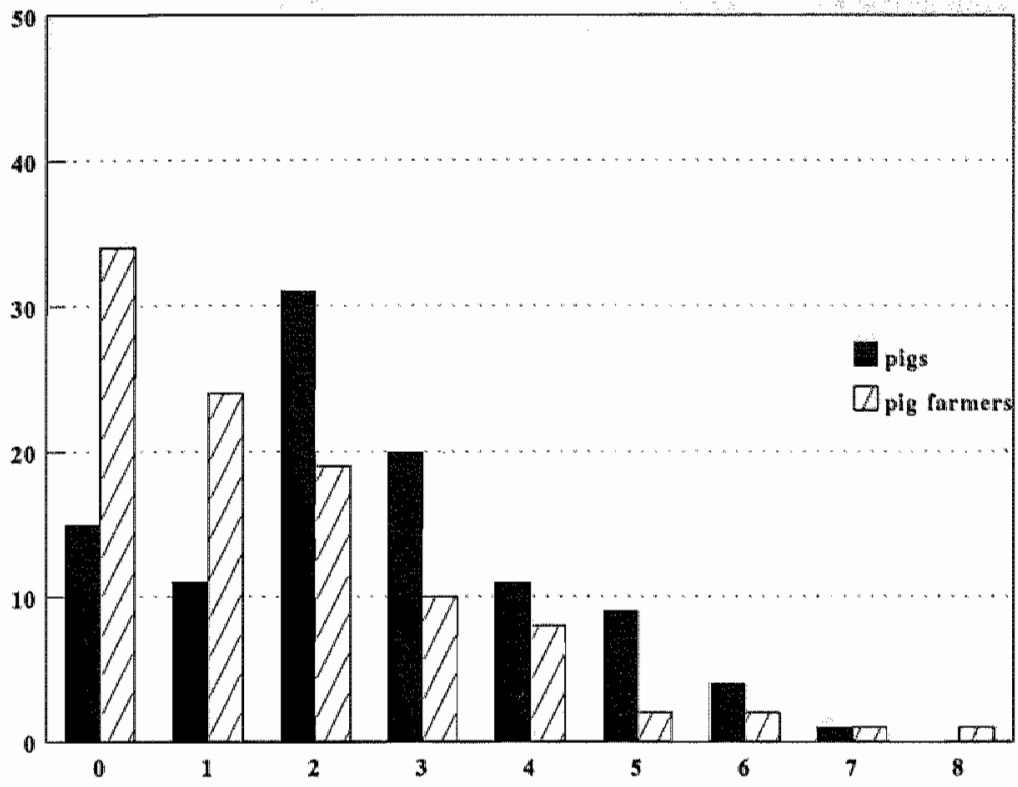

Figure 1: Antibiotic resistance (\%) of $E$. coli to multiple antinicrobial agents, isolated from faecal pig samples $(n=285)$ and pig farmer samples $(n=266)$, On to $8=$ number of antibiotics, ${ }^{\circ} R=$ percentage of resistant $E$ coll isolates.

farmers. Forty-six and 36 resistance patterns of the pigs and the pig farmers respectively were observed only once or twice. The percentages of the most frequently isolated resistance patterns in pigs and pig farmers differed significantly for: oxytetracyclinestreptomycin, oxytetracycline-streptomycin-sulphamethoxazole, amoxycillin and sulphamethoxazole (Table 3 ). When paired $E$. coli isolates $(n=259)$ of farmers and pigs living at the same farm were compared $10(4 \%)$ of these isolates were resistant to the same antimicrobial agents. The patterns of the remaining 249 combinations showed differences in one, two or more antibiotics $(22 \%, 32 \%$ and $38 \%$ respectively). These differences were mainly due to differences in resistance to oxytetracycline, streptomycin or sulphamethoxazole.

Recent antibiotic use in pigs (mass-medication) was recorded by 25 out of 291 farms $(9 \%)$ and 15 farmers out of $290(5 \%)$ and 17 family members $(6 \%)$ had used antibiotics themselves. Two out of 284 farmers recorded recent hospital stay. From 253 farms we were informed about the type of pig farming. Eighty-seven farms housed only fattening pigs, whereas the other farms $(n=166)$ housed both breeding and fattening pigs. 


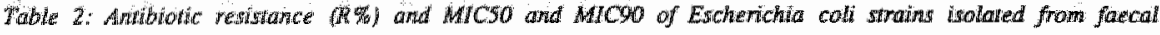
samiphes of pigs and pig formuers.

\begin{tabular}{|c|c|c|c|c|c|c|c|}
\hline \multicolumn{2}{|c|}{ Antibiotic } & \multicolumn{3}{|c|}{ Pigs $(n=285)$} & \multicolumn{3}{|c|}{ Pig Farmers (n=266) } \\
\hline & $\operatorname{mg} / /^{*}$ & Micso & MIC90 & $\mathbf{R}$ & MIC50 & MIC90 & $\mathrm{R} \%$ \\
\hline Antin & 16 & 8 & $\geq 64$ & 25 & 16 & $\geq 64$ & 28 \\
\hline Ap & 16 & 4 & 8 & 0 & 4 & 8 & 0 \\
\hline Anc & 16 & 4 & 16 & 0 & 4 & 8 & 0 \\
\hline $\mathrm{c}$ & 8 & 8 & 16 & 13 & 8 & 8 & $7 *$ \\
\hline $\mathrm{Fi}$ & 32 & 16 & 32 & 8 & 16 & 32 & $3 *$ \\
\hline Na & 8 & 4 & 8 & 0 & 4 & 8 & 2 \\
\hline Ne & 16 & 2 & 4 & 7 & $\leq 1$ & 2 & 3 \\
\hline Ot & 16 & $\geq 256$ & $\geq 256$ & 57 & 8 & $\geq 256$ & $32^{*}$ \\
\hline$\$$ & 16 & 32 & $\geq 128$ & 71 & 4 & $\geq 128$ & $34^{*}$ \\
\hline $\sin x$ & 128 & 64 & $\geq 1024$ & 45 & 32 & $\geq 1024$ & $35^{*}$ \\
\hline Trop & 2 & 0.5 & 512 & 16 & 0.5 & 2 & 10 \\
\hline
\end{tabular}

mg/l$/^{\wedge}=$ Breakpoint concentration, according to the guidelines of the Dutch Working Party on Susceptibility Testing of Antibiotics (14), except for apramycin which accorded to Hunter (12); * significantly different resistance percentage $R \%(P \leq 0,05)$ for a particular antibiotic benween pig farmers and pigs. MCSO/90 = Mimimal Inhibitory Concentration $(m g / 6)$ at which 50\%/90\% of the strains are intibited, $R$ \% $=$ resustance percentage. Amc = amoxycillin +ctavatanic acid, $C=$ chloramphenicol, $S=$ streptomycin, see also legend Table 1 .

Table 3: Most frequently isolated patteris of drug resistance in Escherichia coll strains of pigs and/or pig farmers

\begin{tabular}{|c|c|c|c|}
\hline Pattern & $\begin{array}{l}\text { Pigs }(n=285) \\
n(n)\end{array}$ & $\begin{array}{l}\text { Pig Farmers ( } \mathrm{n}=266) \\
\mathrm{n}(\%)\end{array}$ & \\
\hline Ot s & $42(1.5)$ & $10(4)^{*}$ & \\
\hline Ot $\mathrm{s} \operatorname{sinx}$ & $27(10)$ & $10(4)^{*}$ & \\
\hline$S \operatorname{Sin} x$ & $21(7)$ & $14(5)$ & \\
\hline$\$$ & $15(5)$ & $4(2)$ & 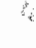 \\
\hline $\operatorname{Amx}$ & $2(1)$ & $24(9)^{*}$ & \\
\hline $\operatorname{smx}$ & 1. $(0)$ & $19(7)^{*}$ & \\
\hline Ot & $6(2)$ & $11(4)$ & \\
\hline
\end{tabular}

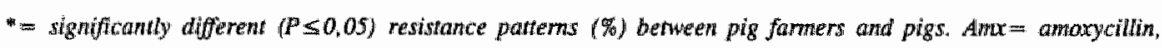
$O t=$ axyteracycline, $S=$ streptomycin, Smx $=$ sulphamethoxazole, Thp $=$ trimethoprim. 
No significantly different prevalence of resistance could be observed between farmers

living at fattening or at mixed farms, except for sulphamethoxizole which showed a higher mean rank for people living at mixed farms. In contrast, pigs living at fattening farms showed significantly higher mean ranks for amoxycillin, neomycin, oxytetracycline and trimethoprim (data not shown).

\section{DISCUSSION}

In the present study faecal pig samples showed significantly higher prevalences and high degrees of resistance to commonly used antibiotics and neomycin than those of the pig farmers. On a yearly basis the total amount of antimicrobials used in The Netherlands in pig medicine is higher (125 mg/kg pig) than in human medicine (75 $\mathrm{mg} / \mathrm{kg}$ human) (2).

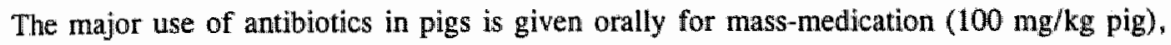
mainly oxytetracycline. As by this medication a total group of pigs is treated with an antibiotic the chance of development and spread of resistance in a herd is higher than after therapy of individual animals. The high use of antibiotics in pig medicine in general and the intensive faecal-oral contact between pigs might explain the high resistance percentages observed in the pigs in this study.

Also differences in antibiotic susceptibility and resistance patterns were observed for pig farmers and pig strains. In faecal samples collected at the same farm only in $4 \%$ the same resistance pattern was found. No significant differences could be observed between pigs or people recently treated with antibiotics compared with those not having been treated recently. Therefore, recent antibiotic therapy could not explain the observed differences between pigs and pig farmers. Differences in type of farming were reflected in the group of pigs, suggesting that the farmers form a more uniform group than the pigs. This finding strengthened the idea that the pigs in this study are not the most important source of antibiotic resistant bacteria in the faecal flora of the pig farmers. If transfer of resistant bacteria from pigs to famers and colonization of the faecal flora of farmers had occurred also differences between the two groups of farmers, working at different farms, might have been expected.

As observed in a previous study (27) pig farmers showed significantly higher resistance percentages than the control group ( $=$ (sub)urban residents). A possible explanation could be direct contact with antibiotics e.g. in medicated pig feed. As allergy to veterinary antibiotics such as tylosin (5) is not uncommon in pig farmers, this route cannot be excluded. 
Medicated pig feed may contain $0.4-1 \mathrm{~g}$ (oxy)tetracycline per $\mathrm{kg}$. A pig farmer might ingest this feed involuntary via hands or inhaled dust. Several studies thave shown that small children playing outdoors do not ingest more than $300 \mathrm{mg}$ soil daily $(4,6,7)$. Moreover, during daily activities pig farmers spend approximately five hrs a day in the pig stables. The air in these contains about $6 \mathrm{mg}$ dust $/ \mathrm{m}^{3}(29)$. The daily inhalarion of dust, for an important part consisting of pig feed, can be estimated at $36 \mathrm{~g}$. Therefore, in the worst case the involuntary inhalation and ingestion of pig feed by pig farmers is about $36 \mathrm{~g}$ a day and thus in the extreme case an uptake of $36 \mathrm{mg}$ of (oxy)tetracycline. Moreover, pigs are fed oxytetracycline medicated pig feed less than once a year (2). The defined daily dosage of tetracycline for adult humans is $1000 \mathrm{mg}$ (15). Therefore, any important influence of ingestion of medicated pig feed on the resistance in the faecal flora of pig farmers seems to be very unlikely.

There was no clear explanation for the higher percentage of high degree of resistance to neomycin in the farmer samples. In humans neomycin is used mainly locally and only seldomly orally, whereas in pig medicine the drug is used extensively, especially for the treatment of diarrhoea in young pigs.

Several studies suggested that the use of nalidixic acid selects for resistance to nalidixic acid and nalidixic acid derivatives i.e. the quinolones $(9,36)$. Moreover, it was speculated that especially the veterinary use of fluoroquinolones might lead to an increase in bacterial resistance in human pathogens against this group of antibiotics (13). Howewer, both farmer and pig isolates in this study showed only a low percentage of resistance to nalidixic acid (Table 2). These strains were also resistant to flumequin, but susceptible to ciprofloxacin. This data suggest that nalidixic acid might select for flumequin resistance, but not for ciprofloxacin resistance but, because of the low number of nalidixic acid resistant strains no definite conclusions can be made.

Resistance to chloramphenicol in the pig flora was $13 \%$ despite the fact that this drug has not been used for many years in food animals in The Netherlands. It has been officially forbidden in pig medicine since 1990. This thas also been observed in Denmark where chloramphenicol in pig medicine has been withdrawn for more than 10years (1). In the present study only 3 out of 38 chloramphenicol resistant pig isolates showed resistance to chloramphenicol alone. Thirty-five strains were also resistant to oxytetracycline, streptomycin or sulphamethoxazole suggesting a plasmid or chromosomal (mar-A) related resistance $(8,23)$ selected by the use of these antibiotics. The supplementation of pig feed with copper and zinc salts may be an additional sellection force, as heavy metal resistance genes are often located on resistance plasmids (35). Also other reasons for the presence of chloramphenicol resistance in the absence of selection pressure by this antibiotic might be 
passible. Piglets might become colonized with resistant bacteria derived from other pigs (sows) and the stable environment. Also newly introduced pigs can spread strains to onsite pigs. Therefore, resistant bacteria or resistance plasmids might circulate for a long time on farms. Other sources of resistant bacteria might be survival of bacteria after cleaning the stables or introduction of resistance genes by rodents or contaminated pig feed.

The prevalence and high degree of resistance in the faecal flora and the susceptibillity and resistance patterns of the isolates clearly showed differences between both groups. Apart from direct contact with pigs and pig faeces pig farmers are exposed to several factors that might influence antibiotic resistance: antibiotics used for pigs in treatment of pigs and involuntary consumption of pig feed (hand contamination or dust) and personal treatment with antibiotics. As observed in a previous study recent antibiotic use by pig farmers was higher than in (sub)urban residents, but seemed to be of no significant influence on antibiotic resistance in pig farmers (27). It can however, not be excluded that in the long term this personal antibiotic consumption might be responsible for higher numbers of resistant bacteria in the faecal flora of farmers. Direct contact with pigs and pig faeces can also not be excluded as a risk factor, but did not seem to be a major factor in this study. No influence of recent antibiotic treatment of pigs could be observed in this study. However, the influence of mass medication cannot be excluded as a risk factor on antibiotic resistance in pig farmers.

Further studies (including plasmid analysis and transfer experiments) are necessary to investigate similarities between bacterial populations and/or plasmids isolated from the pig farmers and their pigs.

\section{ACKNOWLEDGEMENTS}

We thank C. Driessen, M. Norder, N. Kieser and J. Philips for skilled technical assistance "P. Terporten for lints help with statistical problems and $\mathrm{I}$. Humter for kindly providing apramycita. Also we thank the Aminat Heahth Service in the Southern Netherlands (Prof. Dr. Ir. M.J.M. Tielen) for their wo-operanion by the collecting of the faecal samples. We are very grateful to Dr. Molller for his program for the analysts of drug resistant bacteria (25) and to Prof. Dr. A. Knotunerus for criticall reading of the manuseripe. This work was supported by a guant, projeck number 28.0275, of the Prewention Fund of The Netherlands. 


\section{REFERENCES}

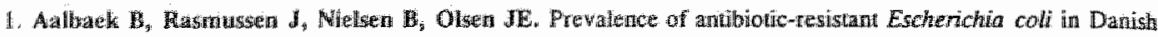

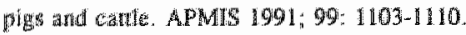

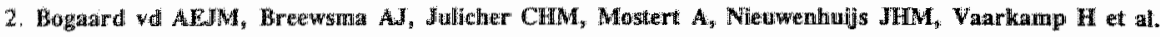

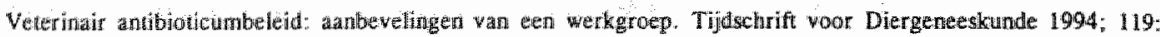
160.183 .

3. Borten M, Stobberingh $\mathbb{E}$, Plvilips $J$, Fowben A. Antbiotic resistance of Escherichia coll in fecal samples of healthy people th wo different areas in an industrallized country. Infecton 1992; 20:258-262.

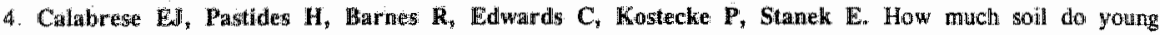
children ingest: an epideniological strdy. IRegt Tox Pharm 1989; 10:123-127.

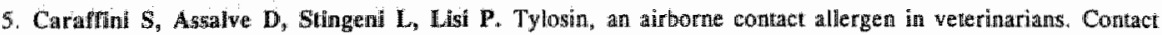
Detroatits $1994 ; 31,327-328$

6. Clausting P, Brunekreef B; Wijnen $v$ JHt. A method for estimating soil ingestion by children. Int Arch Oceup Environ Healih $1987 ; 59.73 .82$.

7. Dawis 5 , Waller $P_{v}$ Buschbom $\mathbb{R}$, Ballou $J$, White $P$. Quantitutive estimates of soil ingestion in normal children betwen the ages of 2 and 7 years: population based estimates using aluminium, silicon and itaniwm as snil traces elements. Arch Enwiron Health 1990; 45:112-122.

8. Hächler H, Colıen $\mathrm{S}$, Levy SB. Mar A, a regulated locus which controlls expression of chromosomal multiple antibiotic resistance in Escherichia coli. I Bactertol 1991; $1735532-5538$.

9. Hiral K, Aoyama $\mathbb{M}$, Suzue $S$, Irikura $T$, Mobe $S$, Mitsuhashi $S$. Isolation and characterization of norfloxacin resistant mutants of Escherichia coli K-12. Antimicrob Agents Chemother 1986; 30:248-253.

10. Holmberg SD, Owterthotm MT, Senger KA Cohen ML. Drageresistant Solnonella from animals fed antimicrobials. N Engl J Med 1984; 311:617-622.

11. Holmberg SD, Wells JG, Cohen ML. Animal-to-man transmission of antimucrobial-resistant Salmonella: investiganions of U.S. ontbreaks, $1971-1983$. Sictence 1984: 225:833-835.

12. Hunter" IEB. Apramycin-resistan Escherichia coll in tarn animals and man (Thesis). University of Liverpool 1992.

13. Klingeren $\vee \mathbf{B}_{\text {, Hartman }} \mathbf{E G}$, Meer vd IWM, Mouton RP, Overgoor GHA, Verheijden JHM. Advies

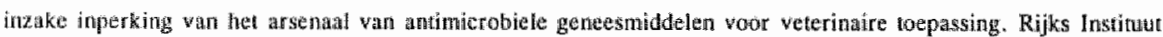
voor Volksgezondleid en Milhendiyguene, Bilthowem. The Netherlands, rapportne, 358471003, 1989.

14. Klingeren $\vee$, Mouton RP. Standaudisatic wan gevoeligheidstbepalingen. Verslag vam de werkgroep

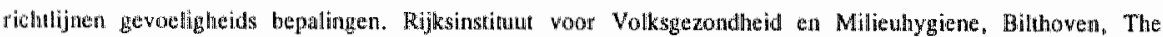
Netherlands ISEN 90-6960-004-8, 1990.

15. Kuy vd A. Formentherapeutisch Kompas 1993-1994, Ziekenfondsrida, Amstelweten.

16. Levy SB, Fitzgerald GB, Macone AB. Sppead of antibliotic resistant placmids from chicken to chicken and from chicken to man. Nature 1976; 260:40k-42

17. Leyy SB. Emergence of antibitic resisunt bacterin in the intestinal flora of farm inhabiants. Infeet Dis 1978: $137: 688-690$

18. Lewy SR. Playing antibiotic pool: kime to tally the score. N Engl J Med 1984; 311:663665.

19. Lewy SB, Marshall B, Schluederberg S, Rowse D, Davies J. High frequency of antimierobial resistance in human feral fora. Antmicrob Agents Chemother 1988; 32:1801-1806.

20. Linton AH, Howe $K_{3}$ Bennet $\mathbf{P M}_{n}$ Riclumond MH. The colonisation of the lhuman gut by antibiotic resis- 
Latit Escherichia coli from abickens. I Appl Bescteriol 1977; $43,465469$.

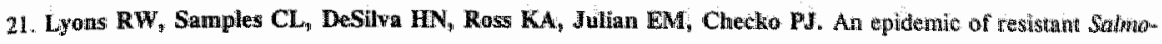
niella in nursery. JAMA $1980 ; 243: 546-547$.

22. Marshall $\mathbf{B}$, Petrowski $\mathbf{D}$, Levg $\mathbf{S B}$. linter- and intraspecies pgread of Escolterichia coll in a farm environment in the absence of antibiotic usage. Proc Nall Acau Sci USA 1990; 87:6609-6613.

23. Mee B. Nikoletti SM. Plasmids encoding trimethoprian resistance in bacterial isolates from man snd pigs. $J$ Appl Bacteriol 1983; $54: 225-235$.

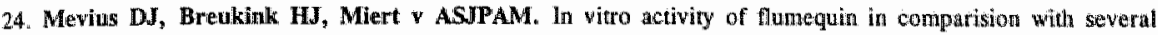
other antimicrobial agents against five pathogens isolated in calwes in the Netherlands. Wet Quar: 1990; $12 \% 212$. 220 .

25. Moller JK. A microcomputer-assisted analysis of drug resistance in hacteria. Comp Meth Proger Bioned $1986 ; 23: 217-223$

26. Nijsten R, London N, Bogaard vd A, Stobberingh E. Antibiotic resistance of Enterobacteriacede isolated from the faecal flora of fattening pigs. Vet Quart $1993 ; 15: 152-157$.

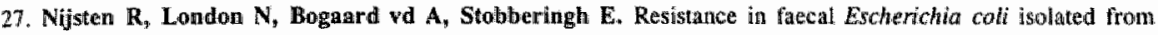
pig farmers and abantoir workers. Epidemiol Infect 1994; 113:45-52.

28. O"Brien TF, Hopkins JD, Gllece ES, Medeiros AA, Kent RL, Blickburn BO et al. Molecular epidemiology of antibiotic resistance in Salmonella from animals and human beings in the United States. N Engl J Med 1.982; 307:1-6.

29. Preller L, Vogelzang P. Gezondheid varkenshouders aan risico's blootgesteld. Stichting Gezondheidsdienst voor dieren in Zuid-Neder land, Boxtel/Heythuysen, 1993. Rapportmr. 93001

30. Rolland RM, Hausfater $G$, Marshall $B_{3}$ Stuart L. Antibiotic resistant bacteria in wild primates: increased prevalence in baboons feeding on human refuse. Appl Environm Mictobiol 1985; 49:791-794.

31. Shooter RA, Roussean SA, Cooke EM, Breaden AL. Animal sources of common serotypes of Escherichia coli in the food of hospital patients. Lancet 1970; 226-228.

32. Snvth HW. The transfer of ancibiotic resistance befween strains of Enterobacteria in chicken, calfes and pigs. J Med Microbiol 1970; 3,:165-180.

33. Spika JS, Waterman SH, Soo Hoo GW, Louis MES, Pacer RE, James SM et al. Chloramphenicol resis tant Sofronellic newpont traced through hamburger to dairy farms. N Engl I Med 1987; $316: 565 \% 570$

34. Stallones RA. Epidemiology and public policy: prom and anti-biotic. An J Epidemiol 1982; 15:485-491.

35. Wnorowski AU. Resistance to antibiotics of heavy metal-tolerant and heavy metall-iseristive bacterial strains: 1 Envirion Soi Health 1993; A28(1):203-215.

36. Yoshicta H, Bogaki M, Nakanara M, Nakamura S. Quinolone resistance devermining region in tha: DNA gyrase gyr A gene of Escherichia coll. Antimicrob Agents Che rother 1990; 34:1271-1272. 

IN VITRO TRANSFER OF ANTIBIOTIC RESISTANCE BETWEEN FAECAL ESCHERICHIA COLI STRAINS ISOLATED FROM PIG FARMERS AND PIGS

Nijsten R., London N., Bogaard v.d. A., Stobberingh E.

The Journal of Antimicrobial Chemotherapy, accepted for publication 


\section{SUMMARY}

Faecal Escherichia coli isolated from pig farmers and pigs were analyzed to biotypes, plasmid patterns and transferability of antibiotic resistance. Two groups of isolates, consisting of pairs of pig famer and pig strains from the same farm with the same (group A) and with different resistance patterns (group B), were investigated.

Only one pair of strains of group $A$ and one of group $B$ showed the same biotype for the pig and pig farmer isolate.

The whole plasmid patterns and plasmid profiles after restriction analysis of the paired strains of group A showed only minimal similarities.

A striking phenomenon was that in group $B 10 / 11$ pig isolates transferred resistance and in group A about $50 \%$ of the strains. Transfer experiments showed similar transfer fre quencies for pig farmer and pig strains of group $A$ and $B$.

The present study does nor provide conclusive evidence for the presence of a common pool of resistance plasmids anong pig farmers and their pigs. 


\section{INTRODUCTION}

Antibiotics are considered to be one of the most important discoveries in the history of medicine. However, the extended use and maybe misuse of these compounds has resulted in an increase of resistance in bacteria, which are not sensitive any mote to the killing on inhibiting effects of antibiotics. This phenomenon is widely observed in human as well as in veterinary medicine $(1,10,22)$. Not only selection and spread of resistant micro organisms, but especially intra- and inter-species transfer of antibiotic resistance genes via plasmids has caused this problem of antibiotic resistance $(8,20,30)$. By plasmid analysis i.e. whole plasmid and digesting plasmids with restriction endonucleases it is possible to track antibiotic resistance plasmids in the bacterial population $(19,24,29)$.

A common pool of resistant and susceptible micro-organisms shared by animals and humans is suggested in several studies. From this pool humans can pick up resistant bacteria and resistant genes from animals directly or indirectly. Directly via contact with animals $(7,25,26)$ or indirectly by ingesting foods contaminated with faecal flora of food animals $(11,15,18)$. Exidence for the existence of a common pool of micro-organisms or even resistance genes and the transfer of resistance plasmids from animals to humans has been provided by Levy $(12,13)$ and others $(14,15,20,21,29)$. However, O'Brien et al. (24) strongly suggested different plasmid populations in poultry and poultry workers. Moreover, Jansson et al. (8) demonstrated in only one out of 400 trimethoprim resistant Enterabacteriaceae isolated from Swedish individuals the presence of dihydrofollate reductase type IX, a gene which is common in pig isolates in Sweden.

The aim of the present study was to analyze the genetic basis of resistance of Escherichia coli strains isolated from the faecal flora of pig farmers and their pigs by plasmid analysis and transferability of antibiotic resistance. The analysis of the antibiotic resistant donor strains and transconjugants included the comparison of biotypes and phenotypes as well as genotypes of the resistance patterns. Besides transfer to a laboratory strain, $E$. coli $\mathrm{K} 12$, also matings with two susceptible wild $E$. coli strains were tested, to analyze the influence of the recipient strains used.

\section{MATERIALS AND METHODS}

\section{Bacterial strains and study population}

Donor strains were selected from our collection of $E$. coli isolated from faecal sampies of 
pig farmers and of pigs on their farms (23). If a common pool of resistance genes should exist, from which transfer of these genes could take place, it was expected that pig farmer and pig isolates collected at the same farm and showing the same resistance pattern could easily tranter their plasmids. In addition it was expected that the plasmid sizes of pig-pig farmer combinations with the sime resistance pattern were similar. In contrast, however, pig famer and pig isolates collected at the same fam, but showing different resistance patterns were expected to show lless similatities. To amalyze these suggestions two groups of strains were selected and tested. Group A consisted of 10 pairs of isolates of pig farmers and pigs from the same farm, which both had the same resistance pattern. Group B included 13 at random selected pairs of strains isolated from a pig farmer and pigs living at the same farm, but showing different resistance patterns. Either the pig or the pig farmer isolate of group $B$ had a similar resistance pattern as the strains in group A. The matching strain from the same pair of group B had a different resistance pattern.

The nalidixic acid resistant recipient strain $E$. coli $\mathrm{K} 12$ was susceptible to all antibiotics to which resistance was tested.

Biotypes of the strains used were determined using API-20E biochemical system (BioMerieux, Den Bosch, The Netherlands) according to the instructions of the manufacturer.

\section{Plasmid isolation and analysis}

Plasmid DNA was extracted by a modification of the method described by Kado and Liu (9). The molecular weights of the plasmids were determined by agarose gel electrophorese using $0.7 \%$ agarose gel and running at $75 \mathrm{~V}$ during four hours. Ethidiumbromide was used to visualize DNA with ultraviolet light after running was completed. A Salmonella typhimurium strain (kindly provided by Dr. $\mathbb{N}$. van Leeuwen, RIVM) containing five plasmids $(91,39,7.6,5.8$ and $4.4 \mathrm{~Kb})$ was used as reference.

Whole DNA content from donor/transconjugant strains, showing resistance to the most prewalent pattern oxytetracycline-streptomycin-sulphamethoxazole (OtSSmx), was digested witl restriction endonuclease EcoRl acconding to the instructions of the manufacturer and extracted by an alkaline lysis method (27). Plasmid isolation and restriction analysis was minimal performed twice. Examples are shown in Figures 1,2 and 3.

\section{Transfer of resistance}

Conjugation experiments were performed by broth mating as follows: overnight cultures $\left(37^{\circ} \mathrm{C}\right.$ ) in BHI (brain heart infusion bouillon, Oxoid CM225) of recipient and donor strains were $1: 10$ diluted in $\mathrm{BHI}$ and shaken for two hours $\left(37^{\circ} \mathrm{C}\right)$. Equal volumes $(2 \mathrm{ml})$ of donor and recipient were put together in $2 \mathrm{ml}$ BHI and incubated for another two hours 
at $37^{\circ} \mathrm{C}$ with gently shaking to allow conjugation. Dilutions $\left(10^{3}-10^{\circ}\right)$ of the conjugation mixture were inoculated on Iso-sensitest ${ }^{\mathbb{R}}$ agat plates (Oxoid CM471) containing nallidixic acid $32 \mathrm{mg} / \mathrm{l}$ and one of the antibiotics to which the donor was resistant. If no conjugation was observed after two hours the nating was repeated overnight at $37^{\circ} \mathrm{C}$ without agitation. Those strains which than still failed to transfer resistance were not further examined.

The frequencies of transfer were calculated as the ratio between the number of transconjugants and the number of colony forming units (CFU) of the donor strain. Depending on the antibiotic used for the selection the frequency of transfer may vary. For sake of simplicity in the Tables $\mathbb{1 , 2}$ and 4 the mean frequency of transfer is given.

The antibiotics and concentrations used in the selective plates were : $4 \mathrm{mg} / 1$ trimethoprim; $20 \mathrm{mg} / \mathrm{l}$ neomycin and streptomycin; $32 \mathrm{mg} / \mathrm{l}$ amoxycillin, chloramphenicol and oxytetracycline and $256 \mathrm{mg} / \mathrm{l}$ sulphamethoxazolle. After overnight incubation at $37^{\circ} \mathrm{C}$ from each selective plate three $E$, coli-like colonies were picked up randomly and tested for the indole reaction and for growth at $42^{\circ} \mathrm{C}$. If the reactions were positive the isolates were considered to be $E$. coll and stored at $-20^{\circ} \mathrm{C}$ until use. As control, the same procedure was followed using donor with $\mathrm{BHI}$ as recipient instead of $E$. coli $\mathrm{K} 12$ overnight culture and recipient with $\mathrm{BHI}$.

Co-transfer of resistance to other than the antibiotics used for selection was analyzed by susceptibility testing (as described before, 23) of the transconjugants.

For further experiments six pig farmer and six pig strains were selected as donor based on differences in frequency of transferring resistance to $E$. coli $\mathrm{K} 12$, after two hours of mating. From both pig and pig farmer isolates three strains with a frequency less than 5 $\log$ and three with a frequency of 5 log or more (Table 4) were randomly chosen. Likewise one pig and one human wild strain, susceptible to the antibiotics tested, were selected from our collection of faecal $E$. coli isolated from pigs and heallthy residents $(17,23)$ and used as recipient in those mating experiments. The recipient strains were made nalidixic acid resistant by several passages on nalidixic acid ( $32 \mathrm{mg} / \mathrm{l}$ ) containing Iso-sensitest ${ }^{R}$ agar plates.

Finally conjugation experiments were performed between the five susceptible strains of group B with their corresponding resistant strains. 


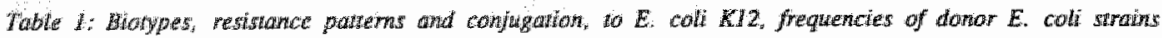

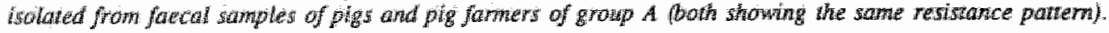

\begin{tabular}{|c|c|c|c|c|c|}
\hline Group & nr & API & R patern & TFm & ramige \\
\hline \multirow[t]{10}{*}{$p$} & 61 & 1044512 & ons & $\ldots$ & \\
\hline & 77 & 5144572 & $015 \sin x$ & $9.0 \times 10^{-9}$ & $\left(0-2.7 \times 10^{-7}\right)$ \\
\hline & 80 & 7144572 & Onssin & $4.3 \times 10^{10}$ & $\left(0.1 .3 \times 10^{-9}\right)$ \\
\hline & 86 & 7044552 & AmxCOSSInXTmp & $2.3 \times 10^{4}$ & $\left(1.6 \times 10^{-4}-3.1 \times 10^{-4}\right)$ \\
\hline & 121 & 5044572 & SmxTmp & $2.7 \times 10^{-5}$ & $\left(2.5 \times 10^{-5}-2.9 \times 10^{-5}\right)$ \\
\hline & 188 & 1004552 & $\operatorname{Ors} \mathrm{m} x$ & $\therefore$ & \\
\hline & 1.95 & 5044552 & Ams & $\ldots$ & \\
\hline & 205 & 5044552 & $\operatorname{SS\operatorname {tan}x}$ & $\ldots$ & \\
\hline & 210 & 5144542 & AmxOSSmxTmp & $6.6 \times 10^{-6}$ & $\left(0.2 .6 \times 10^{-5}\right)$ \\
\hline & 243 & 5144572 & OLS & $5.0 \times 10^{-6}$ & $\left(0.1 .0 \times 10^{-5}\right)$ \\
\hline \multirow[t]{10}{*}{$\mathrm{PE}$} & 61 & 5144572 & Ots & $\therefore$ & \\
\hline & 77 & 1144552 & OtSSmx & $\cdots$ & \\
\hline & 80 & 5144552 & $\operatorname{Orsin} x$ & $3.9 \times 10^{4}$ & $\left(0.3 .2 \times 10^{-8}\right)$ \\
\hline & 86 & 5144172 & AmxCOLSSmxTmp & $2.3 \times 10^{-6}$ & $\left(0-8.6 \times 10^{-5}\right)$ \\
\hline & 121 & 5144572 & SmxTmp & $3.7 \times 10^{-9}$ & $\left(3.2 \times 10^{-5}-4.2 \times 10^{5}\right)$ \\
\hline & 188 & 5144572 & $0 u \sin x$ & $7.7 \times 10^{-5}$ & $\left(2.7 \times 10^{-1}-1.9 \times 10^{-4}\right)$ \\
\hline & 195 & 5044572 & $A m \times S$ & $\ldots$ & \\
\hline & 205 & 5044542 & $\operatorname{SSSm} x$ & $\therefore$ & \\
\hline & 210 & 5144572 & AmxOt5SmxTmp & $8.6 \times 10^{-5}$ & $\left(0-2.1 \times 10^{-4}\right)$ \\
\hline & 243 & 5144572 & Ots & $\therefore$ & \\
\hline
\end{tabular}

$u r=$ strain number, $A P I=$ bionype according to $A P I 20$ E biochentical system, $R$ patterm $=$ resistance patrem, Mur: = mean transfer frequency to $E$. coll KI2, ramge = range of transfer frequencies of transconjugans selected" from seweral selective plates. $\ldots=$ no conjugation abserved after ovemight conjugation. $P=p i g . P F=p i g$

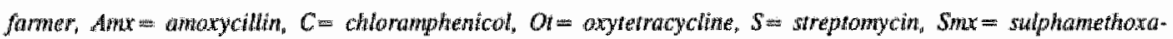
sole, Timp os trimethoprim.

\section{RESULTS}

\section{Biotypes}

Only one pair of strains of group A and one of group B showed exactly the same biotype and three pairs of each group were similar (only differing in fermentation of one sugar). The biotypes 5044552 and 5144572 were most prevalent among both groups of strains (Tables 1,2 ). 


\section{$\begin{array}{llllllllllllllllllll}2 & 3 & 4 & 5 & 6 & 7 & 8 & 9 & 10 & \| 12 & 13 & 14 & 15 & 16 & 17 & 18 & 19 & 20\end{array}$}

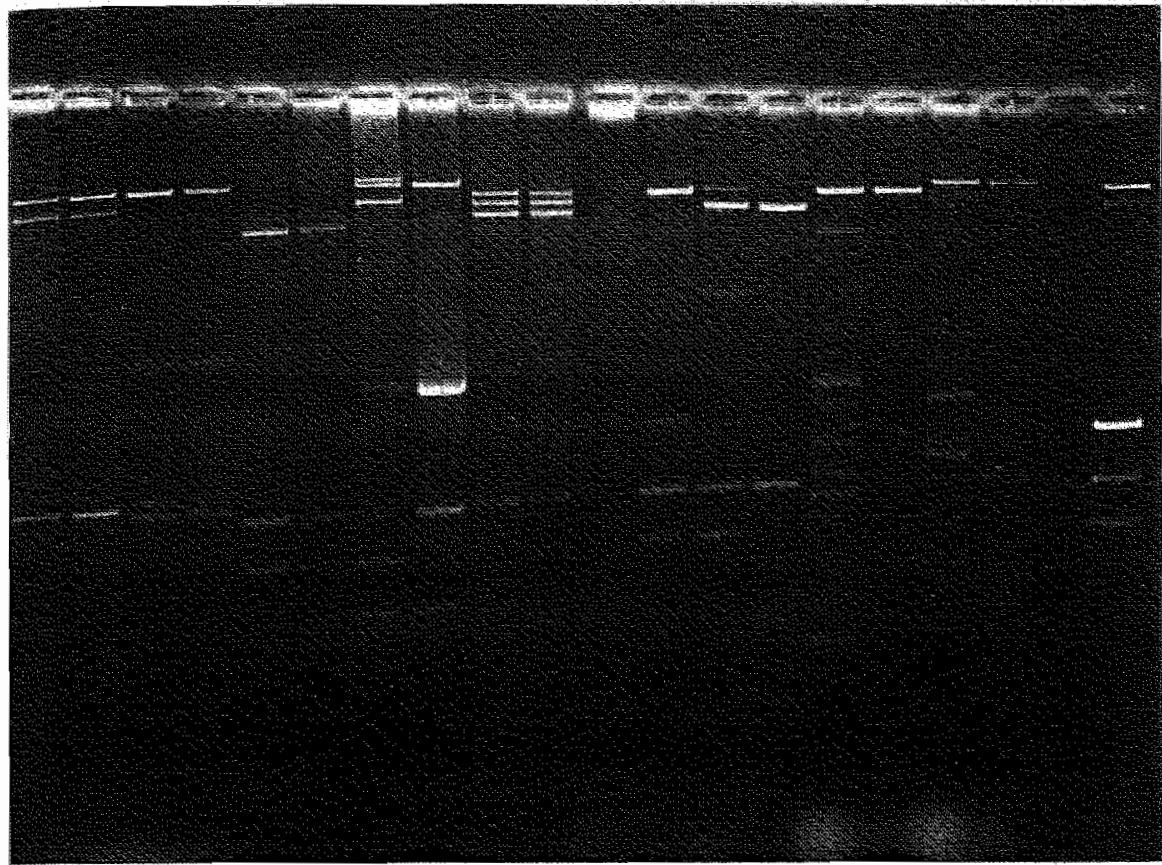

Figure 1: Agarase gel electrophoresis of plasmid DNA extracted from E coll donor and transconjugant strains of pig farmers and pigs of oroup A (lane 1-14) and B (lane 15-18) showing resistance to OrSSmx. Lame 1, 3, 5, 7, 9,11 and 13 are pig donor strains $42,123,128,155,181,260$ and 289 , respectively. Lane 15,17 and 18 are pig janner donor strains 48,65 and 133, respecrively. The even numbers are the vransconjugants of the preceding donor strains, except for lane 18. Lane 20 shows the reference Salmonella typhimarium strain with size standards in descending order $91,39,7.6,5.8$ and $4.4 \mathrm{~Kb}$.

\section{Plasmid patterns of pig (P) and pig farmer (PF) strains}

The plasmid pattern of the pig and pig farmer strains used are shown in Table 3, no plasmids were detectable in two strains (PF155 and PF260) with phenotypes sulphamethoxazole and amoxycillin-sulphamethoxazole, respectively. The number of plasmids ranged from one to 11 , plasmid sizes from $204 \mathrm{~Kb}$ to $1.4 \mathrm{~Kb}$. Both groups showed diverse whole plasmid patterns per resistance phenotype. Comparing the plasmid profiles of strains with resistance pattern OtSSnx no obvious similarities between pig and pig farmer isolates could be observed for group $B$ strains (Figure 1). Even group A isolates from pigs and pig farmers living at the same farm showed different plasmid patterns (Figure 2). Further analysis of the OtSSmx resistant isolates using EcoR1 digestion of plasmid DNA showed distinct different profiles (Figure 3). 


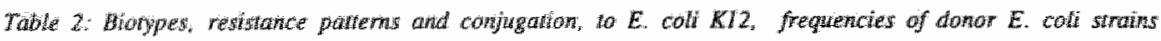

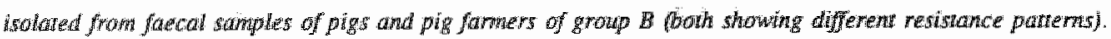

\begin{tabular}{|c|c|c|c|c|c|}
\hline Gitoup & mir & API & R pattern & Trm & range \\
\hline \multirow[t]{13}{*}{$p$} & 15 & 5144.52 & SrixxTmp & $1.4 \times 10^{-5}$ & $\left(1.2 \times 11^{-7}-2.7 \times 10^{-5}\right)$ \\
\hline & 42 & 5144572 & Oussmx & $24 \times 10^{\prime}$ & $\left(1.6 \times 10^{3}-2.9 \times 10^{-4}\right)$ \\
\hline & 48 & 504452 & Ots & $m_{\infty}$ & 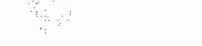 \\
\hline & 65 & 514452 & . & & \\
\hline & 85 & 5044542 & NeOrsismx & $19 \times 10^{-5}$ & $\left(0-4.8 \times 10^{-5}\right)$ \\
\hline & 123 & 5144552 & Orssmx & $1.3 \times 10^{8}$ & $\left(0-40 \times 10^{-8}\right)$ \\
\hline & 128 & $\$ 144572$ & Otssmx & $46 \times 10^{-6}$ & $\left(1.2 \times 10^{7}-4.3 \times 10^{-6}\right)$ \\
\hline & 133 & 5144572 & $* *$ & 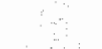 & \\
\hline & 155 & 5044552 & OtSSmx & $6.9 \times 10^{6}$ & $\left(2.8 \times 10^{-6}-1.1 \times 10^{45}\right)$ \\
\hline & 161 & 5444542 & SnxTmp & $39 \times 10^{6}$ & $\left(4.2 \times 10^{-2}-3.5 \times 10^{-6}\right)$ \\
\hline & 181 & 5044552 & Oussmx & $19 \times 10^{7}$ & $\left(0-5.4 \times 10^{-7}\right)$ \\
\hline & 260 & $\$ 444552$ & OLSSm $x$ & $2.2 \times 10^{7}$ & $\left(0.6 .5 \times 10^{-7}\right)$ \\
\hline & 289 & 5144552 & OtSSinx & $8.8 \times 10^{8}$ & $\left(0.2 .2 \times 10^{-7}\right)$ \\
\hline \multirow[t]{13}{*}{$P F^{*}$} & 15 & 5044552 & NeOSSmxTmp & $2.9 \times 10^{-5}$ & $\left(0-8.3 \times 10^{-5}\right)$ \\
\hline & 42 & 5044552 & $\operatorname{SS} \operatorname{Sin}$ & $4.7 \times 10^{-8}$ & $\left(0-9.4 \times 10^{-5}\right)$ \\
\hline & 48 & 5044552 & OtsSmx & $7.6 \times 10^{-5}$ & $\left(0 \times 1.4 \times 10^{-4}\right)$ \\
\hline & 65 & 5044172 & $\operatorname{OrsSim} x$ & $\cdots$ & \\
\hline & 85 & 7144572 & $\operatorname{SSin} x$ & $\ldots$ & \\
\hline & 123 & 51,44572 & $* *$ & & \\
\hline & 128 & 5144552 & $*$ & & \\
\hline & 133 & 5044572 & OrSSmx & $\ldots$ & \\
\hline & 155 & 5044552 & $\operatorname{Sin} x$ & $\ldots$ & \\
\hline & 161 & 5044552 & $* *$ & & \\
\hline & 181 & 5044552 & Amx CNeOIS & $\ldots$ & \\
\hline & 260 & 5144572 & AnnxSmx & $\ldots$ & \\
\hline & 289 & 5144572 & AnixOts & $1.1 \times 10^{-6}$ & $\left(0-4.5 \times 10^{-6}\right)$ \\
\hline
\end{tabular}

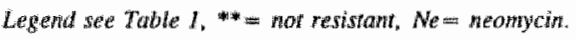

\section{Transfer of resistance}

In group A about $50 \%$ of the strains tested, six out of ten pig and five out of ten pig farmer strains, were able to transfer antibiotic resistance to $E$. coll K12 (Table 1). For the group B isolates the figures were ten out of 11 pig and four out of ten resistant pig farmer isolates (Table 2).

In group A plasmid transfer from antibiotic resistant $E$. coli strains, isolated from pig, farmer and pigs from the same farm, to $E$. coli $\mathrm{K} 12$ was observed in four out of the ten 


\section{$\begin{array}{lllllllllllll}1 & 2 & 3 & 4 & 5 & 6 & 7 & 8 & 9 & 10 & 11 & 12 & 13\end{array}$}

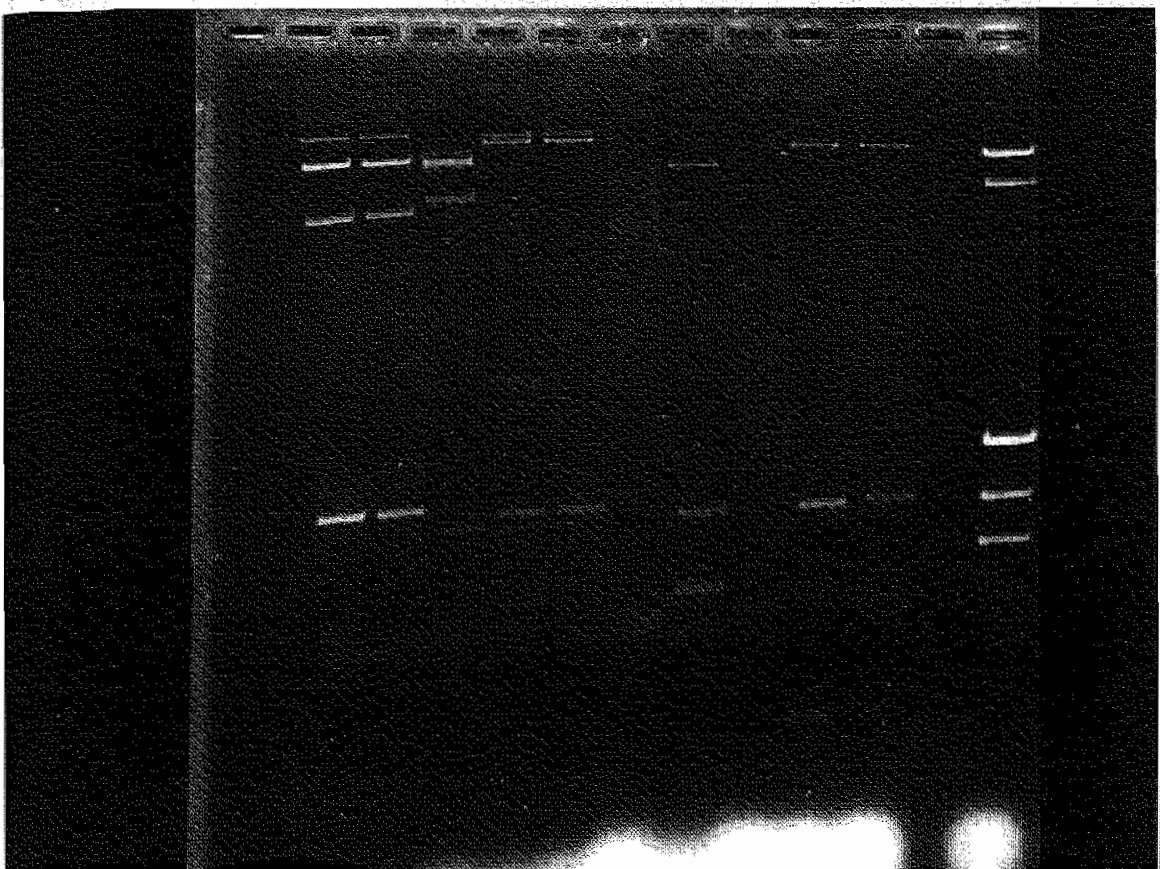

Fignire 2: Agarose gel electrophoresis of plasmid DNA extracted from E. coli donor (D) and transconjigant (T) strains of pig famers and pigs of group A showing resistance to OuSSmx. Lane $2=D$ P77, lane $3=$ TP77, larte

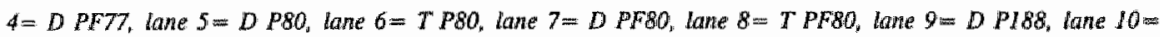
D PFI88, tane 11 = TPFI88 and lane 13 shows the rejerence strain. Footmote: unformately wo wisible plasmids could be obserwed for donor strains PF80 and P188 on this get in lane 7 and 9, respectively. Prewows plasmid isolations did show the presence of plasthids in these stranss (Table 3 .

combinations (Table 1). With three other pairs no transfer was observed. In another two pairs (nr. 77 and 243 ) only the pig strains transferred their resistance and of pair 188 only the pig farmer isolate showed transferable resistance. The mean frequency of transfer of the group A pig isolates ranged from $4.3 \times 10^{-10}$ to $2.3 \times 10^{-4}$ and for the pig farmer strains from $3.9 \times 10^{-8:}$ to $8.6 \times 10^{-5}$.

In group B two pig isolates (nr. 65 and 133) were susceptible, whereas the corresponding pig farmers isolates, both resistant to OtSSmx, did not transfer their resistance to $E$. colt K12 (Table 2). In contrast, three pig isolates (nr. 123, 128 and 161) did show transferable resistance of OtSSmx to $E$. coll $\mathrm{K} 12$, whereas the corresponding pig farmer strains were susceptible. Of three other pairs (nr. 155, 181 and 260) both pig farmer and pig isolates 


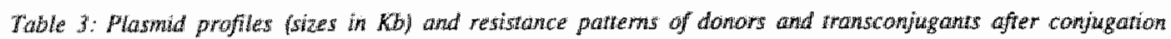
with $E^{*}$ coll $K / 2$

\begin{tabular}{|c|c|c|c|c|}
\hline nit & $\begin{array}{l}\text { Donor } \\
\text { R partern }\end{array}$ & Plasmid profile & $\begin{array}{l}\text { Transeonjugayt } \\
\text { R transferred }\end{array}$ & Plasmid(s) transferted \\
\hline \multicolumn{5}{|c|}{ Group $A$} \\
\hline \multirow[t]{4}{*}{$P=210$} & AñxOtSSmXTmp & 107911958441.8 & Amxot & 10791 \\
\hline & & & AmxOt $\operatorname{Sm} x$ & 107 \\
\hline & & & AmxOt SmxTmp & 1.0791 \\
\hline & & & SSimxTmp & 914.41 .8 \\
\hline P 210 & AnxOLSSmxTmp & 56195.8 & AmxOISSmxTmp & 56195.8 \\
\hline \multirow[t]{3}{*}{ PF 86} & Anx COtSSmxTnp & 81453.93 .2 & AmxCOSSTmxTmp & 81 \\
\hline & & & AmxCOLSSmxTmp & 81457.65 .83 .93 .2 \\
\hline & & & AmxCOsSSmxTmp & 8145 \\
\hline P 86 & AnxCOLSSmxTmp & 107812.6 & AmxCOSSmxTmp & 10781 \\
\hline$P=121$ & Smxtmp & 1125.82 .7 & SmxTrnp & 746.02 .7 \\
\hline $\mathrm{P} 121$ & SnxTmp & 746.02 .7 & SnxTmp & 746.02 .7 \\
\hline PF205 & SSmx & 5.8 & $\ldots$ & \\
\hline P 205 & SSSmx & 916.85 .83 .5 & $\ldots$ & \\
\hline PF195 & AmxS & 1073917 & $\cdots$ & \\
\hline P 195 & AnxS & 1079139 & $\cdots$ & \\
\hline PF 61 & ots & 9176.28105 .13 .5 & $\ldots$ & \\
\hline 961 & OtS & 91763.9 & $\cdots$ & \\
\hline $\mathrm{PP}_{43}$ & ots & 135913.9 & $\ldots$ & \\
\hline P 243 & Ots & 10556 & Ots & 105 \\
\hline$P F>77$ & $\operatorname{otsin} x$ & 795928.4 .61 .4 & $\cdots$ & \\
\hline P 77 & OsSsmx & 1105224115.64 .8 & OsSsmx & 1105224115.64 .8 \\
\hline PF 80 & OnSSimx & 595.13 .1 & OtSSm $x$ & 595.13 .1 \\
\hline p 80 & Orssinx & 13511011105.14 .631 & $\operatorname{OtsSm} x$ & $\begin{array}{ll}135 & 11011105.13 .1\end{array}$ \\
\hline \multirow[t]{2}{*}{ Pros } & OtsSimx & 2041005.41 .7 & OtSSmx & 20.41005 .41 .7 \\
\hline & & & $\operatorname{SS} \min$ & 100 \\
\hline P 188 & Otssmx & 107395.82 .6 & $\ldots$ & \\
\hline
\end{tabular}


Tabule 3: continued

\begin{tabular}{|c|c|c|c|c|}
\hline & \multicolumn{2}{|l|}{ Donor } & \multicolumn{2}{|l|}{ Transconjugant: } \\
\hline rir & $\mathbf{R}$ pattern & Plasmid profile & R transferred & Plasmid(s) tranterted \\
\hline \multicolumn{5}{|c|}{ Group B } \\
\hline P 42 & OtSSmx & 36224.4 & Otssmx & 36228.94 .4 \\
\hline PF 48 & \multicolumn{2}{|c|}{ OtSSmx 65229.38 .57 .869605 .24 .72 .3} & $\operatorname{SSm} x$ & 65 \\
\hline PF 65 & \multicolumn{2}{|c|}{ OtSSmx 102128.96 .96 .55 .64 .93 .63 .22 .41 .9} & $\ldots$ & \\
\hline$P^{\prime} 123$ & $\operatorname{OtSSm} x$ & 49134.84 .42 .2 & Otssimx & 49134.84 .42 .2 \\
\hline \multirow[t]{2}{*}{ P. 128} & \multirow[t]{2}{*}{ OtSSmx } & \multirow[t]{2}{*}{214.33 .2} & OnSSint & 214.33 .2 \\
\hline & & & $\operatorname{SSm} x$ & 214.33 .2 \\
\hline PF133 & OtSSmx & 1025.8 & $\cdots n$ & \\
\hline P 155 & DoSSmx & 10278359.14 .63 .52 .6 & Otsinx & 789.14 .62 .6 \\
\hline P 181 & OtSSmx & 4930234.8 & OtSSmx & $493023,4.8$ \\
\hline P 260 & OtSSmx & 567.85 .24 .1 & $\operatorname{Orsin} x$ & 567.8524 .1 \\
\hline \multirow[t]{2}{*}{ P 289} & \multirow[t]{2}{*}{ OtSSmx } & \multirow[t]{2}{*}{653.5155 .24 .1} & ot & 6535 \\
\hline & & & $5 S \mathrm{~m} m \mathrm{x}$ & 355.4 \\
\hline P 48 & Ots & 14 & $\ldots *$ & \\
\hline P 15 & SmxTmp & 74226.0 & SmxTrap & 746.0 \\
\hline \multirow[t]{2}{*}{ P 161} & \multirow[t]{2}{*}{ SmxTmp } & \multirow[t]{2}{*}{746.01 .8} & SmxTtup & 287.8 \\
\hline & & & SnxTinp & 746.0 \\
\hline $\mathrm{PF} 42$ & $\sin x$ & 16214138.17 .14 .4 & $\operatorname{sSm} x$ & 1621.48 .17 .15 .84 .4 \\
\hline PF 85 & $\operatorname{SSm} x$ & 188.97 .15 .84 .82 .92 .61 .9 & $\ldots$ & \\
\hline PF289 & AmxOLS & 91396.558 & OLS & 9139 \\
\hline PFI81 & AmxCNeOtS & 309.57 .66 .8 & $\ldots$ & \\
\hline p 85 & NeOtsSm $x$ & 1126.25 .8 & NeOASSinx & 112 \\
\hline \multirow[t]{2}{*}{$P F \| 5$} & NeOLSWuxTmp & 55286.54 .9 & NeO1S5mx minp & 155.556 .5 \\
\hline & & & NeOHSmXTmi & 556.5 \\
\hline $\mathrm{PP} 260$ & AmxSmx & $* *$ & & \\
\hline PFis5 & Strux & $*$ & & \\
\hline
\end{tabular}

Legend sec Table 1. 
Table As Resistance pathems and conjugation Grequentches of domor $E$ coli strains trolated from faecal samples of

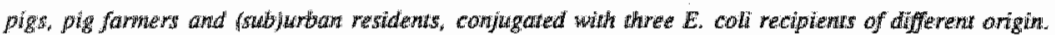

\begin{tabular}{|c|c|c|c|c|}
\hline nit & $\mathrm{R}$ prattern & recipient & TFin & range \\
\hline \multirow[t]{3}{*}{ P 15} & Sinx Trinp & $\mathrm{KI2}$ & $1.4 \times 10^{-5}$ & $\left(1.2 \times 10^{-7}-2.7 \times 10^{-5}\right)$ \\
\hline & & Pig & $5.2 \times 10^{5}$ & $\left(5.0 \times 10^{85}-5.3 \times 10^{5}\right)$ \\
\hline & & Human & $4.7 \times 10^{5}$ & $\left(9.2 \times 10^{*}-4.7 \times 10^{-5}\right)$ \\
\hline \multirow[t]{3}{*}{ P 42} & Osssmix & $K 12$ & $2.4 \times 10^{3 i}$ & $\left(1.6 \times 10^{5}-2.9 \times 10^{-5}\right)$ \\
\hline & & pig & $1.2 \times 10^{5}$ & $\left(3.5 \times 10^{-6}-2.7 \times 10^{-5}\right)$ \\
\hline & & Hownan & $4.2 \times 10^{3}$ & $\left(0-1.0 \times 10^{-4}\right)$ \\
\hline \multirow[t]{3}{*}{ p 86} & AnixConsin $\times \operatorname{Tmp}$ & p $\quad$ K12 & $2.3 \times 10^{-4}$ & $\left(1.6 \times 10^{-4}-3.1 \times 10^{-4}\right)$ \\
\hline & & Pig & $3,9 \times 10^{4}$ & $\left(2.3 \times 10^{-6}-5.0 \times 10^{-6}\right)$ \\
\hline & & Human & $5.5 \times 10^{t 1}$ & $\left(3.6 \times 10^{-9}-1.2 \times 10^{-5}\right)$ \\
\hline \multirow[t]{3}{*}{ P121 } & SmxTmp & $K_{12}$ & $2.7 \times 10^{-5}$ & $\left(2.5 \times 10^{5}-2.9 \times 10^{-5}\right)$ \\
\hline & & Pig & $4.4 \times 10^{-5}$ & $\left(4.0 \times 10^{5}-4.8 \times 10^{5}\right)$ \\
\hline & & Human & $2.9 \times 10^{-5}$ & $\left(1.3 \times 10^{-5}-1.6 \times 10^{5}\right)$ \\
\hline \multirow[t]{3}{*}{ P128 } & Otssin & $\mathrm{K} 12$ & $4.6 \times 10^{-6 i}$ & $\left(1.2 \times 10^{-7}-4.3 \times 10^{-6}\right)$ \\
\hline & & Pig: & $1.2 \times 10^{-7}$ & $\left(0-3.6 \times 10^{-7}\right)$ \\
\hline & & Human & $1.4 \times 10^{-4}$ & $\left(0-4.2 \times 10^{-6}\right)$ \\
\hline \multirow[t]{3}{*}{ P155 } & $0 . \sin x$ & $\mathrm{~K} 12$ & $6.9 \times 10^{-6}$ & $\left(2.8 \times 10^{-6}-1.1 \times 10^{-3}\right)$ \\
\hline & & Pig & $1.8 \times 10^{-4}$ & $\left(1.5 \times 10^{-4}-2.4 \times 10^{-4}\right)$ \\
\hline & & Human & $2.8 \times 10^{6}$ & $\left(7.0 \times 10^{-2}-2.8 \times 10^{-6}\right)$ \\
\hline \multirow[t]{3}{*}{ PF48 } & OtsSinx & $\mathrm{K} 12$ & $7.6 \times 10^{5}$ & $\left(0-1.4 \times 10^{-5}\right)$ \\
\hline & & Pig & $3.2 \times 10^{\circ 7}$ & $\left(3.5 \times 10^{-8}-2.5 \times 10^{-7}\right)$ \\
\hline & & Human & $5.3 \times 10^{-10}$ & $\left(0-1.6 \times 10^{2}\right)$ \\
\hline \multirow[t]{3}{*}{ PF80 } & $\operatorname{OtsSm} x$ & $\mathrm{~K} 12$ & $3.9 \times 10^{-8}$ & $\left(0-3.2 \times 10^{-8}\right)$ \\
\hline & & Pig & $6.7 \times 10^{-9}$ & $\left(0-2.0 \times 10^{-8}\right)$ \\
\hline & & Human & $5.3 \times 10^{-8}$ & $\left(0-1.2 \times 10^{-18}\right)$ \\
\hline \multirow[t]{3}{*}{ PF86 } & AunxCOUSSmxTmp & p $\quad$ K12 & $2.3 \times 10^{06}$ & $\left(0-8.6 \times 10^{-5}\right)$ \\
\hline & & Pig & $3.7 \times 10^{-8}$ & $\left(0.1 .1 \times 10^{-7}\right)$ \\
\hline & & Human & $6.4 \times 10^{-8}$ & $\left(2.1 \times 10^{-4}-1.4 \times 10^{-4}\right)$ \\
\hline \multirow[t]{3}{*}{$\mathrm{PF} 121$} & SnxTmp & K12 & $3.7 \times 10^{-5}$ & $\left(3.2 \times 10^{-5}-4.2 \times 10^{-5}\right)$ \\
\hline & & Pig & $1.2 \times 10^{-4}$ & $\left(1.0 \times 10^{-4}-1.4 \times 10^{-4}\right)$ \\
\hline & & Human & $3.7 \times 10^{-4}$ & $\left(3.3 \times 10^{-4}-4.1 \times 10^{-4}\right)=$ \\
\hline \multirow[t]{3}{*}{ PF1.88 } & Otssinx & K12 & $7.7 \times 10^{-5}$ & $\left(2.7 \times 10^{-8}-1.9 \times 10^{-4}\right)$ \\
\hline & & Pig & $3.4 \times 10^{-16}$ & $\left(0-6.0 \times 10^{4} \mathrm{y}\right)$ \\
\hline & & Human & $2.4 \times 10^{-9}$ & $\left(1.8 \times 10^{-9}-3.6 \times 10^{-9}\right)$ \\
\hline \multirow[t]{3}{*}{ PM210 } & AmxOtSSnxTmp & $\mathrm{K} 12$ & $8.6 \times 10^{-5}$ & $\left(0-2.1 \times 10^{-4}\right)$ \\
\hline & & Pig & $4.2 \times 10^{-5}$ & $\left(0-1.5 \times 10^{-5}\right)$ \\
\hline & & Human & $3.8 \times 10^{-6}$ & $\left(0-1.9 \times 10^{-5}\right)$ \\
\hline
\end{tabular}

$K 12=$ recipient strain $E$. coli $K 12$, Pig $=$ porcine $E$. coli recipient strain, Human $=$ Human $E$. coli recipient stroin, see also legend Table 1 . 
were resistant to different antibiotics, only the pig isolates showed transferable resistance. The group $B$ isolates transferred their resistance with mean frequencies ranging from $1.3 \times 10^{-8}$ to $2.4 \times 10^{-5}$ for the pig strains and from $4.7 \times 10^{\text {th }}$ to $7.6 \times 10^{5}$ for the pig farmers isolates (Table 2).

Moreover, no transconjuganits could be isolated after mating resistant pig strains $(n=2)$ of group B with corresponding susceptible pig farmer strains. Similarly, from the same group resistant pig farmer $(n=3)$ isolates did not transfer their resistance to corresponding susceptible pig isolates.

\section{Resistance patterns of transconjugants (Table 3)}

The resistance phenotypes of the transconjugants of both pig and pig farmer isolates were in general similar to those of the donor strains. Although selection on streptomycin or oxytetracycline containing agar plates yielded not always transconjugants, selection on other antibiotics (e.g. sulphamethoxazole or amoxycillin) did result in general in transconjugants with the same resistance pattern as those of the domor isolates. Exceptions were found for P289, PF48 and PF210 which transferred only part of their resistance to E. coli $\mathrm{K} 12$, whereas transconjugants from P128 and PF188 showed either a similar resistance pattern as that of the donor or were resistant to streptomycin-sulphamethoxazole only.

\section{Transfer of resistance to different recipients}

The frequencies of transfer from the antibiotic resistant pig isolates either to $E$. coli $\mathrm{K} 12$, or to susceptible pig or human recipient strains, were quite similar (Table 4). Only the human strain was a less efficient recipient for the donor isolates PF 48 and PF188 than $E$. coli K12. In contrast transfer from PF86 to the human recipient tended to occur with a higher frequency than to the pig recipient. Although not all plasmids observed in the donor strains could be detected in their transconjugants the plasmid patterns obtained with the different recipients were in general similar to those of the donor strain.

\section{DISCUSSION}

Several studies strongly suggest the presence of a common pool of resistance in microm organisms endogenous to the intestinal flora of humans and animals, from which transfer of resistance to bacteria belonging to the flora of other animals and humans may take 


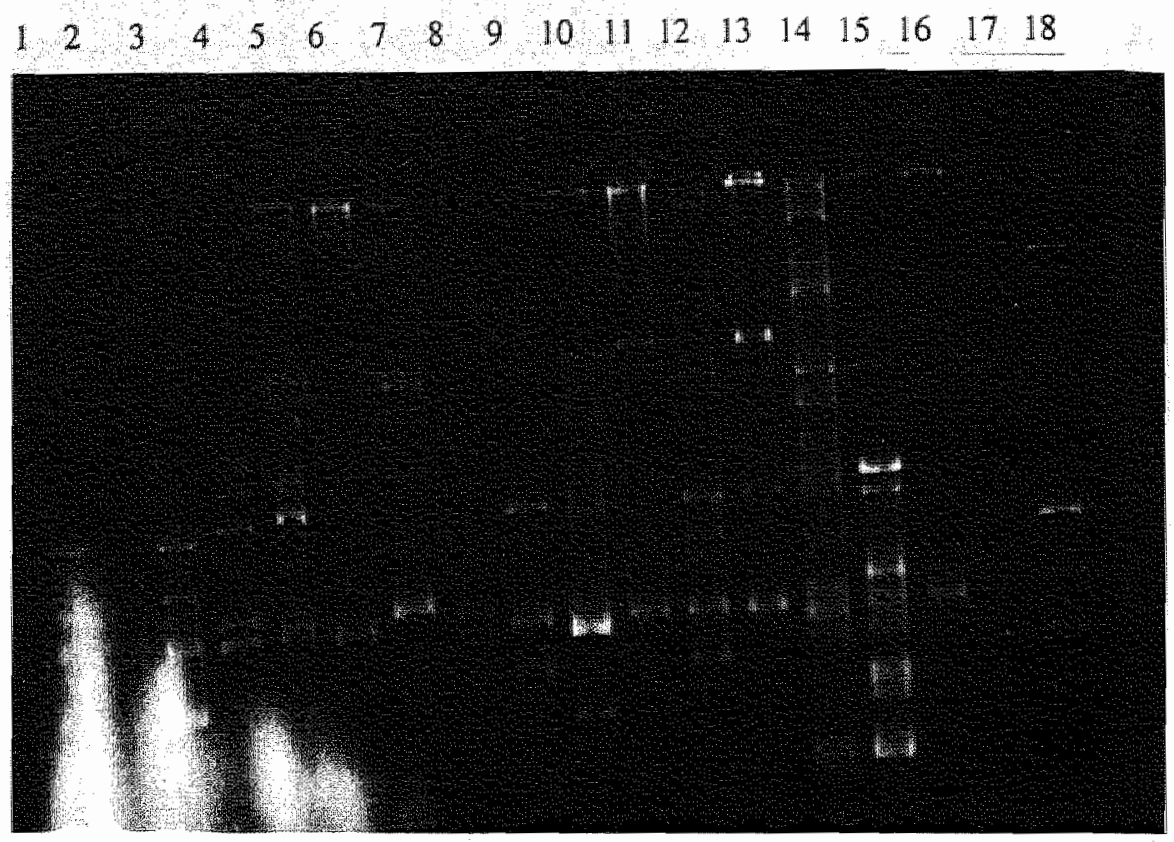

Figure 3: Agurose gel electrophoresis of phasmi DNA fragments from EcoRI digests from ONSSmx resistant iransconingant $(T)$ and donor $(D) E$. coll isolates of group A and B. Lane $1=T$ PT7, Lane $2=T P 80$, lane $3=T$ PF80, lane $=T$ PFI8: lane $5=D$ PF77, lane $6=D$ Pl88, lane $7=T$ P42, lane $8=7$ PI23, lane $9=T$

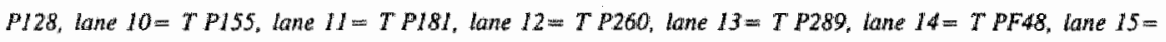
D PFOS. lane $16=D$ DF $\$ 3$ and lane 18 shows the reference straim.

place $(12,14,15)$. However, this hypothesis is not confirmed by others (24). In an attempt to provide some evidence for this hypothesis we analyzed biotypes, plasmids, plasmidprofiles and transfer frequencies of plasmids of strains isolated from faecal samples of pig farmers and their pigs. In this study two groups of strains isolated from the faecal flora of pig farmers and pigs living at the same farm were analyzed. Group $A$ included pairs of pig famer and pig isolates with the same resistant patterns and group $\mathbb{B}$ included pairs of strains with different resistance patterns, but one of the isolates of each pair was the same as the resistance patterns observed in group $A$. If a common pool of bacteria or plasmids should exist, which easily could be transferred, it is to be expected that plasmid patterns of pig-pig farmer combinations of group $\mathrm{A}$ isolates should show more similarities than the patterns of group $B$ isolates. In addition it might be expected that strains from group $A$ could transfer their resistance more easily than the group $B$ isolates.

In the literature the ability of multi resistant $E$. coli strains to transfer resistance to $E$. coli 
K12 ranged from $26 \%$ to $61 \%$ for human isolates and from $50 \%$ to $76 \%$ for pig derived strains $(1,2,3,4,5,6,16,19,21,24)$. The variation in transferability between the different studies can be explained by differences in antibiotic concentration used in the selective plates and/or by differences in methods used. However, overall there is a tendency for a higher transferability for pig isolates compared to human strains. Similar observations were done in the present study (Tables 1,2 ). Although differences in ability to transfer resistance were observed, the transfer frequencies of pig and pig famer strains were in the same size of order and ranged between $10^{-40}$ and $10^{-4}$ and between $10^{-3}$ and $10^{-5}$. respectively. The transferability to $E$. coli $K 12$ of the pig and pig farmer strains of group A was similar, but of group B more pig isolates (ten out of 11) showed transfer of resistance than the pig farmer strains (four out of ten).

Combinations of $\operatorname{OtSSmx}$ were frequently observed resistance patterns in the original group of pigs examined (23). Also in other countries this transferable resistance pattern has been observed frequently in pig populations $(1,28)$. Smith $(28)$ suggested that these pigs constitute a reservoir of transferable resistance genes and therefore pigs might be a possible source of resistance for human intestinal bacteria. In the present study six strains (three pairs) of group $A$ and ten strains of group $B$ (three PF and seven P strains) showed resistance to OtSSmx. In group A OtSSmx resistance was transferable in two PF and two P isolates, however, transfer of OtSSmx by both pig and pig farmer strains was observed in pair 80 only. The plasmid patterns of these donor strains showed only two plasmids in common ( 5.1 and $3.1 \mathrm{~Kb}$ ). Pig farmer and pig donor strains of pair 77 and pair 188 of group A shared no plasmids. In group $B$ in one PF and all P isolates OtSSmx resistance were transferable. The highest freguencies of transfer were observed for two pig farmer strains (nr. 48 and 188). More information about the homogeneity of the OtSSmx resistant isolates was obtained by restriction endonuclease analysis. After EcoRI digestion of the plasmid DNA of those strains more than half of the bands obtained were different. These findings suggest the absence of a relationship between these isolates (24). In general the present study showed only minimal similarity between whole plasmid patterns in pig and pig farmer strains with the same resistance phenotype.

Most pairs of strains of Group $A$ and $B$ showed different biotypes, not corresponding with the antibiotic resistance patterns. As biotypes are in general encoded by chromosomally based genes and antibiotic resistance is mainly extrachromosomally on plasmids (21) lack of relationships between both, as observed in the present study, could have been expected. As the observed biotypes of corresponding strains differed it was suggested that the dominant intestinal $E$. coll flora of pig farmer and pig living at the same farmi were 
not the same. In the present study mainly differences, as to biotypes and antibiotic resistance phenotypes, between pig and pig fammer strains were observed. Although the transferability of plasmids of pig strains was higher than of pig farmer strains, matings with recipient strains of different origins (the laboratory strain $E$. coll $\mathrm{K} 12$ and the wild pig and human strains) showed similar transfer frequencies, suggesting the possibility of transfer of resistance plasmidis in both directions is similar. However, the reciprocal conjugation experiments of resistant pig farmer strains of group B with the susceptible wild strain isolated from pigs of the corresponding pig famer, and vice versa, showed no transfer of plasmids. Athough only five strains were investigated, the in vitro results do not support a readily in wiwo transfer of resistance plasmids between pig and püg farmer strains. Whether the in vitro results are applicable for in vivo transfer of plasmids from animals to man is not yet known. Some studies mentioned in vivo transfer of resistance plasmids from chicken to man, whereas others did not $(12,15,24)$. Spread of a resistance plasmid between chickens of the same cage and transfer of this plasmid from chicken to man have been described by Levy et al. (12). In two out of fourteen persons the presence of strains containing that particular plasmid was demonstrated in their faecal samples. During the two month study period the samples were only once positive. An explanation for this short period of colonization is difficult to give, but may be the selective pressure by tetracycline in the chicken feed and the absence of this selective pressure in humans. Linton et al. (15) described in one out of five volunteers in vivo transfer of strains from chicken to man after handling and preparing chicken carcasses without eating them. Restriction enzyme analysis showed similarity of the isolates. Also in this study the colonization of the human gut with the chicken strain was only for a short period of time i.e. ten days, but this does not exclude the possibility of transfer of resistance plasmids. Especially in persons taking antibiotics this might occur at a much lower inoculum level. In a recent study of $O^{\prime}$ Brien et al. (24) at a poultry processing plant no similarity was demonstrated between poultry $E$. coli and $E$. coli isolated from women working at the poultry processing line, none of the plasmids from the human isolates was similar to those from chicken strains. Our findings were in line with these data, only minimal similarities were observed between pairs of isolates of group $A$ concerning biotypes and plasmid palterns.

As the transferability of the pig strains of group A was lower than of group B isolates and the transfer frequencies were of the same size of order the presence of a common pool of bacterial strains or plasmids between the farmers and pigs seemed unlikely. This is supported by the results of the EcoR1 digestion of DtSSmx resistant strains.

We conclude, that the data of the present study did not provide conclusive evidence for 
the existence of a common pool of resistance plasmids anong pig famers and their pigs.

\section{ACKNOWLEDGEMENT}

We thank C. Driessen, M. Norder and J. Philips for skilled technical assistance. This work was supported by a grant, project number 28.0275, of the Prewention Fund of The Netherlands.

\section{REFERENCES}

1. Aalbaek B, Rasmussen J, Nielsen B, Einerdahl O. Prevalence of antibiotic-resisaunt Escherichia coll in Danish pigs and canle. APMIS 1991; 99:1103-1110.

2. Bourque $\mathbf{R}$, Lallier $\mathbf{R}$, Lariviere $S$. Influence of oral antibiotics on resistance and enterotoxigenicity of Escherichia coli. Can J Comp Med 1980; 44:101-108.

3. Datta N. Drug resistance and $\mathrm{R}$ factors in the bowel bacteria of Londion patients before and after admission to bospital. Brit Med $J$ 1969; 2:407-411.

4. Davies M, Stewart PR. Transferable drug resistance in man and animals: genetic relationship between Rplasmids in enteric bacteria from man and domestic pets. Austr Wet J 1978; 54:507-512.

5. Guinếe P, Ugueto N, Leeswen v N. Escherichia coli with resistance factors in vegetariaas, babiess and nonvegetarians. Appl Microbiol 1970; 20:531-535.

6. Gyles C, Palchaudhuri S, Maas WK. Naturally occurring plasmid carrying genes for enterotoxin production and drug resistance. Science 1977; 198:198-199.

7. Hirsh DC, Ling GV, Ruby Al. Incidence of R-plasmids in fecal flora of healthy household dogs. Antimicrobs Agents Chemother 1980;17:313-315.

8. Jansson C, Franklin A, Sköld $O$. Spread of a newly found trimethoprim resissance gene, dhfriX, among porcine isolates and human pathogens. Antimicrob Agents Chemonher 1992; 36:2704-2708.

9. Kado Cl, Liu ST. Rapid procedure for detection and isolation of large and small plasmids. I fiacteriol 1981: $145: 1365 \cdot 1373$.

10. Kayser FH. Evolution of resistance in microorganisms of human origin. Vet Microbiol 1993:35:257-267.

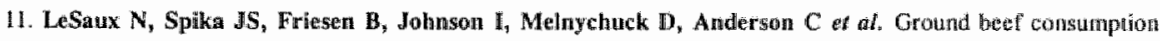
in nonconmercial setuings is a risk factor for sporadic Escherichio coll O157:H7 infection in Canada. I Infect Dis $1993 ; 167: 500-502$.

12. Levy SB, Fitzgerald GB, Macone AB. Spread of antibiotic resistant plasmids from chicken to chicken and from chicken to man. Nature $1976 ; 260: 40 \cdot 42$.

13. Levy SB. Antibiotics, animals, and the resistance gene pool. In: The antibionic paradox how miracle druggs are destroying the miracte (Levy SB, Ed), fpp 137-156, Plenum Press, New York, 1992.

14. Linton AH, Handley B, Osborne AD, Shaw BG, Roberts TA, Hudson WR. Contamination of pig cartasses at two abatoirs by Escherichia coll with special reference to O-serotypes and antibiotic resistance. I Appl Bacteriol 1976; 41:89-110. 


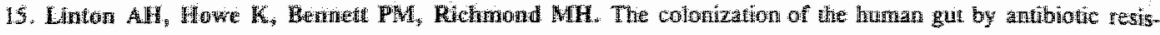

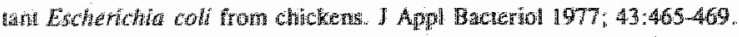

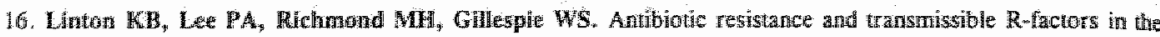

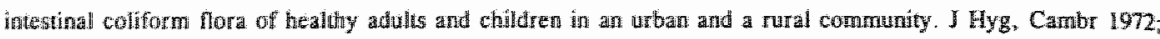
$70: 909104$

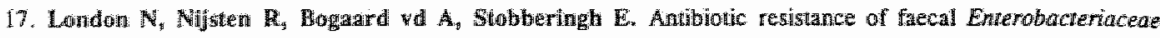

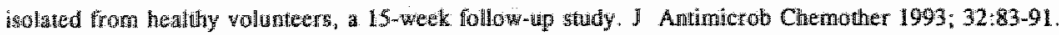

18. Maguire HCF, Cowd AA, Mackay VE, Rowe B, Mitchell E. A lage outbreak of human salmonielosis trated to theal pig farm. Epidenion lntect 1993; 110:239.246.

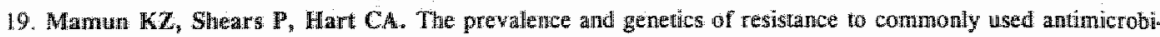
all agerts in faecal Euterobacteracede from children in Bangladesh. Epidemiol Intect 1993; 110:447-458.

20. Marshall B, Petrowsh $\mathrm{D}$, Lewy $\mathrm{S}$, Inter- and intrapecies spread of Escheriohia coll in a farm environ-

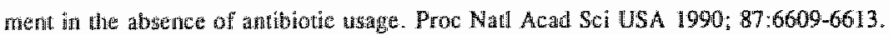

21. Mce B., Nikoleti SM. Plasmids encoding trimethoprim resüstenee in bacterial isolates from man and pigs. J Appl Bacteriol 1983; $54,225-235$.

22. Mituhash 5. Druge reststance in bacteria history, genetics and biochemistry. I Internat Med Res 1993; $21: 1-1.4$.

23. Nijsten $\mathbb{R}_{n}$ London $\mathbb{N}_{\text {, Bogaard wd }}$, Stobberingh $\mathbb{E}$. Antibiotic resistance among Escherichia colv isolated from laedal samples of pig farmers and pigg. Accepted for publication.

24. O'lrien TF, DiGitorgio J, Parsonnet KC, Kass EH, Hopkins JD. Plasnid diversity in Escherichia cali isolated from processed pesultry processors. Vet Microbjol 1993" 35:243 255.

25. Ojeniyi AA. Diren aramsmission of Escherichia coll from poultry ho humans. Epidemiol Infect 1989; 103:513.522

26. Saida K, Ike $X^{\prime}$, Mitsuhashil $S_{4}$ Drug resistance and resistance plasmids of Escherichio-coli strains isolated from pigss, slaughteres, and breeders of pigs in Japan. Antimicrol Agents Chemother 1981; 19:1032-1036.

27. Sambrook J, Fritseh EF, Manistis T. Molecular cloning: a laboratory manual, 2ndi edítion. Cold Spring Harbor Laboratory, Cold Spring Harbor, New York, 1989.

28. Smith HW. Amtibiotic-resistant Escherichia coli in market pigs in 1956-1979; the emergence of organisms with plasmid-borthe trimethoprin resistance. J Hyg , Cambr 1980;84:467-477.

29. Towner Kil, Wise $\mathbf{P J}$, Lewis MJ. Molecular relationships between trimethoprim $\mathrm{R}$ plasmids obtained from huthan and animal sources. I Appl Bacteriol 1986; 61:535-540.

30. Wise PJ, "Towne Ro, Webster CA, Slack RCB, Jones TO. Trimetoprin resistance plasmids in Escherichin call isolithd from cases of diatrhoea in cantle, pigs and sheep. I Appl Bacteriol 1985; 58:555-561. 
IN WVO TRANSFER OF RESISTANCE PLASMIDS IN RAT-, HUMAN- OR PIGDERIVED INTESTINAL FLORA USING A RAT MODEL

Nijsten R., London N., Bogaard v.d. A., Stobberingh E.

The Journal of Antimicrobial Chemotherapy, accepted for publication 


\section{SUMMARY}

Germ-free rats associated with either rat- (RIF), human-(HIF) or pig (PIF)-derived Enterobacteriaceae-free intestinal flora were used for in vivo experiments to detect transfer of antibiotic resistance.

Transfer of resistance was observed most frequently from the porcine donor strain to acceptor strain Escherichia coli K12, showing the highest number of transconjugants in the faeces of HIF-rats. The rats associated with the human donor strain and E. coll Kl2 as acceptor showed transconjugants less frequently. Only the HIF-rats yielded transconjugants on each sampling day and none at all could be isolated from the PIF-rats. Almost no transconjugants were found in the faeces of rats assaciated with the pig donor strain and $a$ wild human $E$. coli strain as acceptor.

Factors such as the nature of the donor and recipient strains as well as the origin of the intestinal flora seemed to have an influence on plasmid transfer. Transferability was highest in the HIF-rats and could be increased by administration of lincomycin.

This study showed that in vivo transfer of resistance plasmids is possible in rats associated with intestinal floras of different origins. The human intestinal flora seemed to permit better transfer of resistance than that derived from the pig or the rat. 


\section{INTRODUCTION}

Transfer of resistance has been described among species of Enterobacteriaceae between animals and even between animals and humans $(14,18,20)$. Contamination with resistant bacteria is not considered to be the major cause of spread of antibiotic resistance between populations, but the carry over of resistance factors (plasmids) has been blamed (12).

As the normal intestinal flora represents a lafge reserwoir of resistance plasmids (11) heal thy animals might be expected to constitute a reservoir of resistance genes. Microorganisms might survive in the gut flora and transfer their plasmids to other nonpathogenic or pathogenic intestinal inhabitants or even transfer their resistance to the bacterial flora of other individuals (1). Several studies showed that intensively reared animals such as pigs and chickens have a high incidence of resistant faecal $E$. coll $(10,18,21)$. As infection risks increase when large numbers of animals are concentrated, the quantity of antibiotics used therapeutically and for prevention of bacterial infection is large. Therefore, the faecal $E$. coli pig flora constitutes a possible reservoir of resistance plasmids which might be transferred to humans. This may be a greater public health threat than carriage of pathogenic Enterobacteriaceae by animals or the sporadic occurrence of antibiotic residues in meat.

As observed by Corpet (2), in vitro transfer results cannot be simply extrapolated to the in wivo situation. Therefore, next to in vitro conjugation studies, in wivo studies are necessary in order to investigate the possibility and extent of plasmid transfer in the presence of the intestinal flora. Germ-free (GF) animals do not harbour a microbial flora and can be colonized with intestinal flora from other species $(3,13,19)$. By keeping these animals in isolators, contamination with environmental bacterial strains or resistance plasmids is avoided and transfer experiments can be executed.

In the present study, GF rats were used for in wivo investigation of antibiotic resistance transfer. The aim of this study was to investigate whether in wivo transfer of antibiotic resistance to $E$. coli $\mathrm{K} 12$ was influenced by the origin of the intestinal flora used. A porcine- and a human-derived donor $E$. coli strain harbouring resistance plasmids, both showing good in vitro conjugation activity with $E$. coli $K 12$ (16), were administered to GF rats associated with different Enterobacteriaceae free intestinal floras (human, pig or rat). In addition to these experiments, transfer from the porcine donor strain to a wild human recipient was also examined. 


\section{Animials}

Eightern male germ-free (GF) rats (WU/Cpb/Bo) of $250-350 \mathrm{~g}$ were divided at random into rine groups of two rats and used for three experiments. Three isolators, each housing two rats in a macrolon cage; were used each experiment. The animals were kept and handled in isolators, before and during the experiment, under conditions as required for GF anmols (8). The autoclaved drinking water was acidified with $\mathrm{HCl}$ to a $\mathrm{pH}<3$ except when $E$. coll or antibiotics were added.

\section{Intestinal floras}

Standard humart (5) and standard rat (6) intestinal flora were used. As pig flora free of Enterobacteriaceae was not available this was produced following the recommendations of Koopman et al. (9). In short: faeces collected from healthy pigs were diluted $1: 10$ and plated on to anaerobic agar plates (FAA-agar ${ }^{k}$ : fastidious anaerobic agar, LabM no 90 , Zoetermeer, The Netherlands) containing $5 \%$ sheep blood, haemin ( $5 \mathrm{mg} / \mathrm{l})$ and menadio ne $(10 \mathrm{mg} / \mathrm{l})$. Colistin $(16 \mathrm{mg} / \mathrm{l})$ was added to the plates to inhibit growth of Enterobacteriaceate. After incubation for five days at $37^{\circ} \mathrm{C}$ in an anaerobic glove box in an atmosphere consisting of $80 \% \mathrm{~N}_{2}, 10 \% \mathrm{CO}_{2}$ and $10 \% \mathrm{H}_{2}$, the growth of each plate was harvested, resuspended in approximately $1 \mathrm{ml}$ diluent and used to seed a new agar plate without colistin. In order to check for residual Enterobacteriaceae $0.1 \mathrm{ml}$ was spread over a Levine-agar plate (Oxoid CM69). After five days of incubation the Enterobacteriaceaefree growth on each plate was harvested, resuspended in 1 ml $10 \%$ skim milk (Oxoid L31) and frozen at $-70^{\circ} \mathrm{C}$ untill use. All manipulations were performed inside the anaerobic glovebox.

\section{Bacterial strains}

Two donor and two recipient strains were tested (Table 1). Experiments I and III were performed with $E$. coll donor strain P86. This isolate from a healthy pig was resistant to amoxycillin, chloramphenicol, oxytetracycline, streptonycin, sulphamethoxazole and trimethoprim. $E$. coll donor strain $\mathrm{H} 1803$, isolated from a healthy person and showing resistance to amoxycillin, oxytetracycline, streptomycin and sulphamethoxazole, was used in experiment II. Two nalidixic acid resistant $\left(\mathrm{nal}^{\mathrm{R}}\right)$ E. coli strains were used as recipients: $E$. coli $\mathrm{K} 12$ was used in experiments $\mathbb{I}$ and II and $E$. coli H2361, a wild strain isolated from a healthy person, in experiment III. All strains used, except $E$. coli $\mathrm{K} 12$, were isolated during another study (17). 


\section{Procedure}

Rats were first colonized with the nalidixic acid resistant recipient $E$. coll $(\mathrm{K} 12$ or $\mathrm{H2361}$ ) by adding $2 \mathrm{ml}$ of an overnight culture (approximately $9 x^{1010 \mathrm{~g}} \mathrm{CF}$ ) to $250 \mathrm{mil}$ of nonacidified drinking water which was provided as the only source of water for the rats during 24 hrs. Three days later faeces, were collected and examined for the presence of the recipient strain. On day four the intestinal floras were given by gastric gavage ( $1 \mathrm{ml}$ ). Each group of two rats was housed in a separate isolator. The rats housed in one isolator were given the pig intestinal flora (PIF), two other rats the rat intestinal flora (RIF) and the other two rats received the human intestinal flora (HIF). On day eight faeces were collected for inventarisation of the intestinal flora, including susceptibility testing of the nal ${ }^{\text {R }}$ recipient $E_{\text {. }}$ coli. Sampling was followed by administration of the donor strain (approximately $9 x^{10} \log \mathrm{CFU}$ ) in $250 \mathrm{ml}$ of non-acidified drinking water on day 14 . Further on, faeces were collected: and checked for the presence of transconjugants on days 21,28 and 32 . After faeces collection on day 32 lincomycin $(100 \mathrm{mg} / \mathrm{l})$ was added to the drinking water for six days. On day 38 faeces were again collected and lincomycin administration stopped. Finally, faeces were collected on day 47. Faecal samples were collected directly from the anus of each individual rat.

\section{Bacteriological analysis of the faecal samples}

Nine $\mathrm{ml}$ of diluent was added to each gram of faeces in an anaerobic glovebox within 30 minutes of collection of the faeces. Each homogenate was serially diluted tenfold (10'$10^{8}$ ) and the (an)aerobic flora calculated. For enumeration of the anaerobic flora the dilutions were inoculated on anaerobic agar plates with and without antibiotics (ciprofloxacin $0.5 \mathrm{mg} / 1$ and trimethoprim $5 \mathrm{mg} / \mathrm{l}$ ) and incubated at $37^{\circ} \mathrm{C}$ for five days in an anaerobic glovebox in an atmosphere containing $10 \% \mathrm{H}_{2}, 10 \% \mathrm{CO}_{2}$ and $80 \% \mathrm{~N}_{2}$. The bacterial counts on the antibiotic-containing plates were compared with the corresponding plates without antibiotics , in order to check for the growth of facultative anaerobic bacteria.

The total aerobic flora was enumerated on $5 \%$ sheep blood agar (Oxoid CM 55). The number of CFU of the donor strain was dettermined on Iso-sensitest ${ }^{k}$ agar plates (Oxoid CM471) contaiming a selective antibiotic. The agents tested and the concentrations used were as follows: amoxycillin ( $32 \mathrm{mg} / \mathrm{l})$, chloramphenicol ( $32 \mathrm{mg} / \mathrm{l}$ ), oxytetracycline (32 $\mathrm{mg} / 1)$, streptomycin $(20 \mathrm{mg} / \mathrm{l})$, sulphamethoxazole $(256 \mathrm{mg} / \mathrm{l})$ and trimethoptim $(4 \mathrm{mg} / \mathrm{l})$. The recipient and transconjugant strains were selected on plates containing nalidixic acid. $(32 \mathrm{mg} / 1)$ either alone or in combination with one of previously mentioned antibiotics. To prevent overgrowth by Gram-positive bacteria vancomycin $(7.5 \mathrm{mg} / \mathrm{l})$ was added to all 


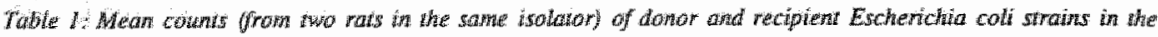

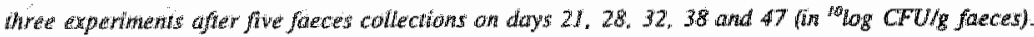

\begin{tabular}{|c|c|c|c|}
\hline & & $\begin{array}{l}\text { DONOR } \\
\text { mean SD }\end{array}$ & $\begin{array}{l}\text { RECIPIENT } \\
\text { men } S D\end{array}$ \\
\hline \multirow[t]{4}{*}{ Experiment I } & & 286 & $\mathrm{~K} 1.2$ \\
\hline & PIF & $8.6 \pm 0.3$ & $7.0 \pm 0.3$ \\
\hline & RIF & $8.2 \pm 0.3$ & $6.8 \pm 0.2$ \\
\hline & $M$ & $8.6 \pm 0.5$ & $5.8+0.4$ \\
\hline \multirow[t]{4}{*}{ Expetiment II } & & $\mathrm{H} 1803$ & K.12 \\
\hline & PIF & $8.5 \pm 0.3$ & $5.2 \pm 0.5$ \\
\hline & RIF & $8.8 \pm 0.5$ & $4.2 \pm 0.4$ \\
\hline & HIF & $9.0 \pm 0.2$ & $5.3 \pm 0.5$ \\
\hline \multirow[t]{4}{*}{ Experiment III } & & P86 & K2 2361 \\
\hline & PIF & $7.9 \pm 1.1$ & $7.3 \pm 0.5$ \\
\hline & RIF & $8.1 \pm 0.6$ & $7.9 \pm 0.4$ \\
\hline & HIF & $7.6 \pm 0.7$ & $7.7 \pm 0.6$ \\
\hline
\end{tabular}

$S D=$ sfandard deviaton, PIF/RIF/WIF = pig/rathuman intestinal flora associared rats. $P 86=$ wild porcine doutor strain, H1803 = wild human donor strain, $K 12=$ E. coli $K 12$ recipient strain, $H 2361=$ wild human recipient strain.

agar plates. The plates were incubated for $24-48 \mathrm{hrs}$ at $37^{\circ} \mathrm{C}$ in air. In addition, each of the $10^{-1}$ diluted faecal samples $(1 \mathrm{ml})$ was cultured overnight under antibiotic pressure (256 mg/1 sulphamethoxazolle and $32 \mathrm{mg} / \mathrm{l}$ nalidixic acid) in $5 \mathrm{ml}$ BHI (brain heart infusion broth1), and when no transconjugants were found the next day these overnight cultures were inoculated on to antibiotic-containing plates for transconjugant detection. If transconjugants were isolated from these agar plates, this is represented as + in Tables 2 and 3. E. coll identification and susceptibillity testing was performed as previously described (15). The ddentification of the first $50 \mathrm{E}$. coli isolates was confirmed with Api-20E biochemical system (BioMerieux, Den Bosch, The Netherlands). The transfer frequency was calculated as the ratio of the number of transconjugants to the number of recipients. The number of transconjugants per rat were counted as the mean number of transconjugants present on all selective plates tested (Figure 1). Aerobic and anaerobic counts of the faecal flora of SPF (specified pathogen free) WU-rats were determined as controls. 


\section{Plasmid isolation}

Plasmid DNA was extracted by a modification of the method described by Kado \& Liu (7). The molecular weights of the plasmids were determined by agarose gel electrophoresis using $0.7 \%$ agarose gel and runing at $75 \mathrm{~V}$ for four hours. Ethidiumbromide was used

to visualize DNA with ultraviolet light after the run was completed. A Salmonella typhimurium strain (kindly provided by Dr. N. van Leeuwen, RTVM) containing five plasmids $(91,39,7.6,5.8$ and $4.4 \mathrm{~Kb})$ was used as reference.

\section{RESULTS}

\section{In vitro}

The mean frequency of transfer between porcine donor strain P86 and recipient $E$. coli $\mathrm{K} 12$ in vitro was $2.3 \times 10^{-4}$. A lower frequency of transfer was observed with recipient H2361 $\left(5.5 \times 10^{-6}\right)$. The human donor strain $\mathrm{H} 1803$ showed a frequency of transter to $E$. coli $\mathrm{K} 12$ similar to that of P86 $\left(2.3 \times 10^{-4}\right)$ except for oxytetracycline for which no transfet at all was found.

\section{In wiyo}

All bacteriall counts are given in ${ }^{10} \mathrm{log}$ CFU/g faeces. The minimum transconjugant detection level was $2.0^{10} \log \mathrm{CFU} / \mathrm{g}$ faeces. The total aerobic counts of the two control rats were 7.7 and 7.8 and the total anaerobic counts 9.0 and 9.1 .

In GF rats colonized only with a recipient $E$. coli strain the number of $E$. coli per gram faeces was constant $(8.9 \pm 0.2)$ independent of the recipient used. After establishment of the intestinal floras the numbers of $E$. coli K12 per gram faeces decreased to approximately $6.8 \pm 1.0$, whereas for the wild-recipient strain $H 2361$ no such decline could be observed $(8.6 \pm 0.5)$ either in PIF-, RIF- or HIF-rats. All rats showed rather constant total anaerobic $(9.4 \pm 0.6)$ and aerobic counts $(8.5 \pm 0.7)$. Both donor strains showed good colonization in the different intestinal floras (Table 1). As the rats kept in the same isolator showed minimal variation in CFU/g faeces of donor and recipient strains, the means of two rats per isolator are presented in Table 1.

After establishment of the donor strains, but before lincomycin administration, the number of anaerobes and aerobes remained at the same level as before in all rats. A slight increase (approximately $1 \mathrm{log}$ ) in total aerobic counts was observed in all experiments after lincomycin administration. In contrast, the total anaerobic counts decreased after 


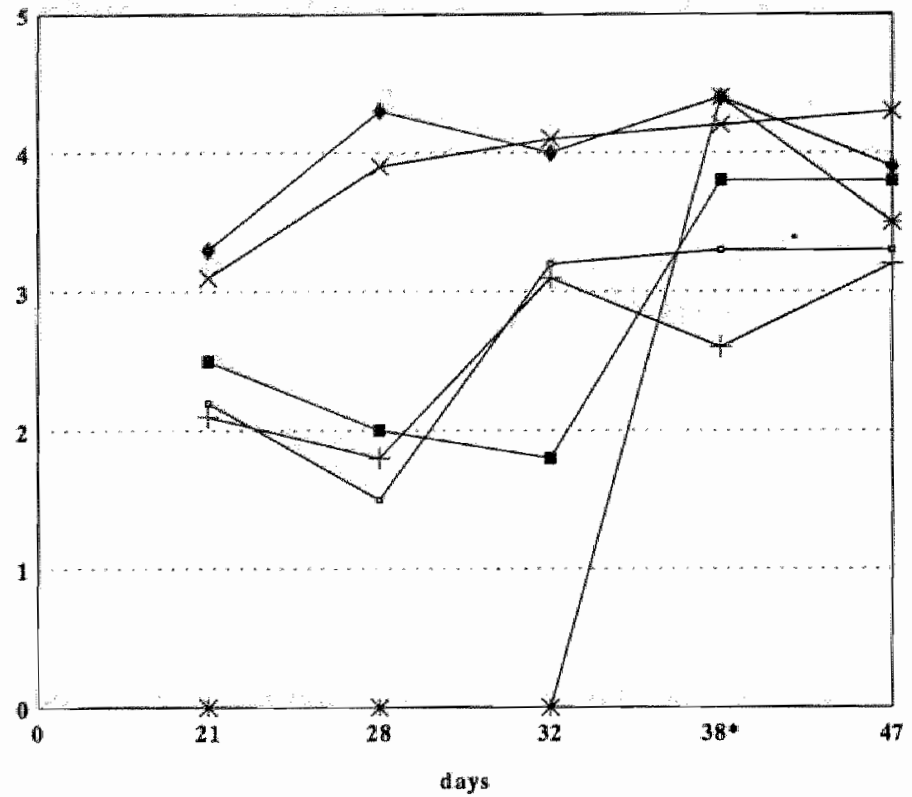

$\rightarrow$ rat II PUF

+ rat 12 PIF

* rat 13 RIF

- rat IA RIF

* ral Is MIF

- rat 16 HIIF

Figure 1: Mean number of sransconjugames isolated from GF rats associated with pig-, rat- or humtan-derived Enterobacteriaceae-free intestinal flaras (experiment 1). PIF/RIF/HF-rats:= pig/rat/fuman intestimal flara assaciated ratis, $*$ lincamycin admintistered.

lincomycin administration (approximately 4 logs), but returned to normal levels one week after the administration of this drug was stopped. The numbers of donor strains were similar for each flora in each experiment, except that a possible influence of lincomycin on the donor counts could be observed in the PIF-rats (Table 1) in experiment III. The number of recipients differed per experiment. Before lincomycin administration, recipient E. coli K12 was present in lower numbers than recipient $\mathrm{H} 2361$ (experiment III). The lowest number of CFU/g faeces was found in experiment II for recipient $E$. coli $\mathrm{K} 12$, especially in the RIF-rats.

On days 21,28 and 32 (thus before lincomycin administration), the number of recipient E. coli $\mathrm{K} 12$ strains in experiment I ranged from 6.9 to 7.0 for the PIF-rats and from 6.6 to 7.0 for the RrF-rats, but decreased approximately one log for the HIF-rats (5.9-6.2). The numbers of recipient $E$. coli $\mathrm{K} 12$ strains in experiment II before lincomycin administration ranged between 4.6 and 5.4 in the PIF-rats, 4.1 and 4.5 in the RIF-rats and between 5.1 and 5.8 in the HIF-rats. In experiment III the numbers of recipients per intestinal flora were of the same order as the numbers of donor strain P86 (Table 1). Lincomycin administration seemed to be of no influence on the numbers of recipient strains. 


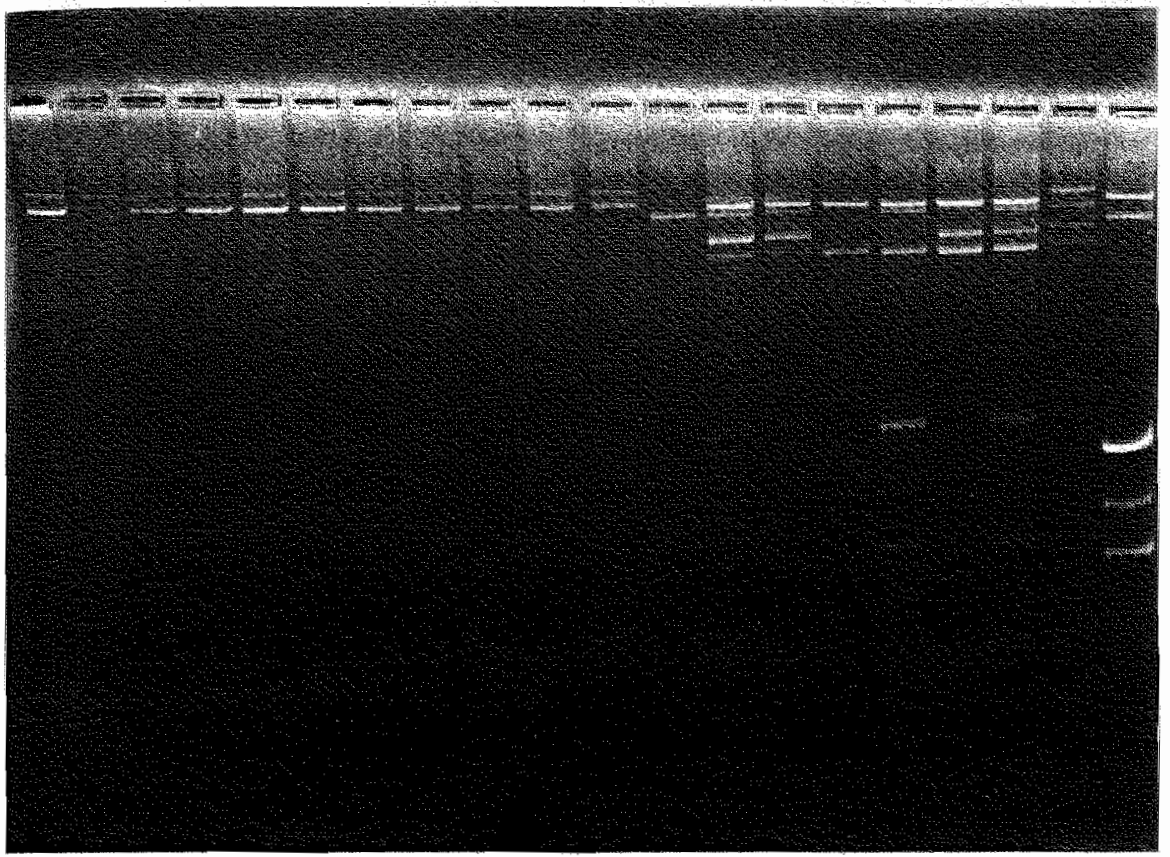

Figure 2: Agarose gel electrophoresis of plasmid DNA extracted from parcine and human $E$. coll donor strains (D) and some transconjugants $(T)$. Lane 1-8. $T$ of experiment $I_{0}$ resistance pattem amoxycillin-chloramphenicolaxytetracycline-strepromycin-sulphamethoxazole-trimethoprim (Anx COSSSmaThp); lane 9-10 T of experiment III (Amx COtSSmxTmp); lane 11 D P86 (AnxCOtSSmxTmp); lane $12 T$ of experiment II (SSinx): lane 13-14 TT of experiment II (AmxOtSSmx), lane 15-18 T of experiment II (Amx:SMx); lame 19 D H1803 (AmxOrSSmx). In lane 20 the reference strain Salmonello tophimurium with size siondards in descending order $91,39,7.6,5.8$ and 4.4 $K b$ is extracted. Footnote: unfortunately the second plasmid of the transconjugant in lane 2 is not wisible on this figure, however it was slightly wisible on the gel.

\section{Transconjugants}

Experiment I: donor E. coll P86, recipient E. coli K12.

On day 21, transconjugants could be observed for all rats, except for rat 13 (Figure 1). Both HIF-rats showed the highest number of transconjugants and these could be selected on each selective plate. Remarkably, before lincomycin administration, one RIF-rat (I4) showed transconjugants at each sampling whereas the other one (13) showed none at all. After lincomycin administration, transconjugants were observed in all rats, showing the highest rates for the HIF-rats and the lowest rates for the RIF-rats. All transconjugants 


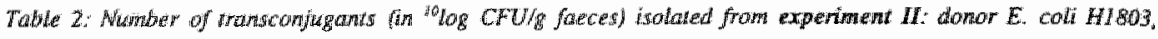
reciplent E. coll KI2.

\begin{tabular}{|c|c|c|c|}
\hline$d a y$ & 21 & 28 & 32 \\
\hline
\end{tabular}

\begin{tabular}{|c|c|c|c|c|c|c|c|c|c|}
\hline PIT tratit ne. & $M i$ & $\mathbb{1 2} 2$ & III & 12 & 111 & II2 & III & 112 & $\mathrm{~m}$ \\
\hline Ams & . & - & * & - & " & - & - & 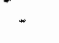 & $=$ \\
\hline or & - & - & $\therefore$ & - & - & - & - & - & - \\
\hline$s$ & . & - & ": & - & 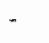 & - & - & - & . \\
\hline $\operatorname{Srrix}$ & $\therefore$ & - & - & " & - & - & - & $=$ & - \\
\hline RIF rat nir. & 113 & 114 & II 3 & II4 & 113 & 114 & III & 114 & $\mathbb{1 1 3}$ \\
\hline Am: & - & 2.0 & . & + & - & - & . & + & - \\
\hline Ot & - & + & - & + & - & 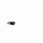 & - & + & - \\
\hline S & - & - & - & - & 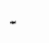 & - & - & + & - \\
\hline $\operatorname{Srnx}$ & - & + & - & $*$ & - & + &. & + & - \\
\hline
\end{tabular}

\begin{tabular}{|c|c|c|c|c|c|c|c|c|c|}
\hline Huf rat ne. & IIS & 116 & IISS & 116 & 115 & 116 & IIIS & 116 & IIS \\
\hline $\operatorname{Amx}$ & 3.9 & 3.8 & 3.1 & 3.0 & 3.1 & 29 & 3.8 & 3.5 & 4.0 \\
\hline $\mathrm{Ot}$ & + & $*$ & + & + & $\sharp$ & f & + & + & + \\
\hline$s$ & 3,0 & 3.0 & 2.9 & + & 2.3 & 2.3 & 3.9 & 2.5 & 3.7 \\
\hline $\operatorname{Smx}$ & 3.6 & 3.5 & 3.5 & 3.2 & 3.0 & 2.5 & 3.6 & 3.2 & 4.1 \\
\hline
\end{tabular}

day $=$ sampling day; * = linconycin admintistrated; PIF/RIF/HIF-rats = pig/rat/human intestinal flora associated

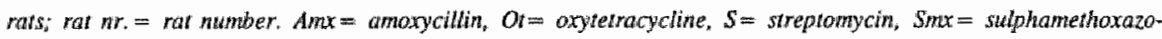
te. $-=$ absence of rransconjugants afrer overnight selection under antibiotic pressure, t= presence of transconjugants after overnight selection sunder antibiotic pressure, but not after ovemight incubation without antibiotic selective pressure. Detection limit transconjugants: $2.0^{\circ} \mathrm{log}$ CFU/g faces.

showed the same resistance pattern as the donor strain. The two large plasmids observed in the donor strain were present in all transconjugants (Figure 2). A third small plasmid was only present in some transconjugants.

In experiment $I I$, using donor $E$. coli $\mathrm{H} 1803$, recipient $E$. coll $\mathrm{K} 12$ transconjugants were observed in all HIF-rats (Table 2). In contrast, only one of the two RIF-rats showed minimal transfer of resistance and no transfer at all was found in the PIF-rats. Almost all transconjugants showed resistance to amoxycillino oxytetracycline-streptomycin-sulphamet hoxazole and amoxycillin-streptomycin-sulphamethoxazole, some strains were resistant to streptonycin-sulphamethoxazole. The plasmid profile of the transconjugants resistant to amoxycillin-oxytetracyctine-streptomycin-sulphamethoxazole was the same as for the donor strain. Strains with amoxycillin-streptomycin-sulphamethoxazole or streptomycinsulphamethoxazole showed only part of the donor plasmid profile (Figure 2). 


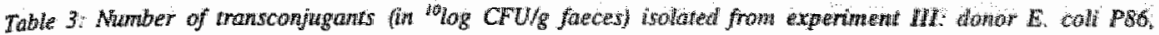
recipien E. coll HR2361.

\begin{tabular}{|c|c|c|c|c|c|c|c|c|c|c|}
\hline \multirow{2}{*}{ PIf rat ar. } & \multicolumn{2}{|c|}{21} & \multicolumn{2}{|c|}{28} & \multicolumn{2}{|c|}{32} & \multicolumn{2}{|c|}{$38 *$} & \multicolumn{2}{|c|}{47} \\
\hline & IIII & $\mathrm{III} 2$ & IIII & 1112 & IIII & 1112 & IIII & $1 \mathrm{TL2}$ & MIII & 112 \\
\hline$A \min x$ & + & + & $\div$ & - & - & - & 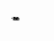 & - & - & - \\
\hline c & + & + & 4.1 & + & - & - & - & 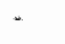 & $\approx$ & - \\
\hline Ot & - & + & " & - & - & . & - & - & 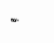 & " \\
\hline$s$ & - & - & . & - & - & - & - & " & - & - \\
\hline $\operatorname{Smx}$ & - & + & + & . & - & - & " & - & - & - \\
\hline Tmp & + & + & - & - & - & " & . & - & 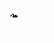 & - \\
\hline RIF rat nor. & 11113 & $\mathrm{III} 4$ & 1113 & 1114 & IIn3 & 1114 & 1113 & III4 & III3 & HII \\
\hline Amx & - & - & - & - & - & - & . & + & . & + \\
\hline $\mathrm{C}$ & - & - & - & - & $\infty$ & - & - & + & - & + \\
\hline Ot & * & - & . & - & a & + & - & + & 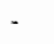 & $\#$ \\
\hline$s$ & - & - & - & - & . & + & - & + & - & + \\
\hline $\operatorname{Smx}$ & - & .' & - & - & + & to & $\infty$ & 4 & - & + \\
\hline Tmp: & 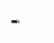 & - & . & - & - & + & - & + & - & + \\
\hline HIE rat $\pi \mathrm{r}$. & IIIS & Ill6 & 1115 & III6 & III5 & II16 & IIIS & 11116 & IIIIS & 1116 \\
\hline Amx & - & - & - & - & - & " & - & ."' & - & " \\
\hline C & - & - & . & - & - & - & - & ." & - & - \\
\hline Or & - & - & . & - & - & - & - & - & . & " \\
\hline $\mathbf{s}$ & - & - & - & - & $=$ & - & - & - & - & " \\
\hline $\operatorname{Snn}$ & - & n & - & + & - & . & . & - & - & - \\
\hline Tmp & - & - & - & . & $=$ & - & - & . & - & - \\
\hline
\end{tabular}

C: chloranphenicot, Tmp = trimethoprims; see also legend Table 2 .

In Experiment III, using donor $E$. coli P86 and recipient $E$. coli R2361, almost no transfer of resistance was obserwed (Table 3). Only once were PIF-rat transconjugants observed in a sample without owernight incubation under antibiotic pressure. After overnight selection under antibiotic pressure, transconjugants were isolated most frequently from PIF rats, but only once from a HIF-rat. No differences were observed before and after lincomycin administration. Also in this experiment only one RIF-rat showed transfer of resistance. All transconjugants showed the same resistance pattern as the donor strain. The two large plasmids obserwed in the donor strain were present in all transconjugants (Figure 2). A third small plasmid was only present in some transconju- 
gants.

\section{DISCUSSION}

In the present study in vivo plasinid transfer from will porcine and human $E$. coll strains to E. coll K12 was observed. Moreover the data strongly suggest that in vivo transfer of antibiotic resistance is influenced by the donor and recipient used as well as the colonization resistance (22) of the intestinal flora. The time-schedule chosen, i.e. day of administration of the intestinal floras and donor strains and of collecting faecal samples, was based on data obtained in a pilot study which showedl clearly that after these time intervals the bacterial counts of recipient, anaerobic and aerobic bacteria remained constant.

After associating the rats with an intestinal flora the concentration of recipient $E$. coli $\mathrm{K} 12$ decreased in the faeces, which might be due to factors such as competition for substrates and for adhesion-sites in the intestine or the production of growth inhibitors (4). However competition or inhibition seemed to be of minor influence for both wild donor strains.

Although rats associated with a homologous rat flora (RIF) were expected to have an optimal colonization resistance, both wild porcine and human donor strains (P86, H1803) could colonize these floras in high numbers in all three experiments. In contrast, however, the transfer activity in these rats (RIF) was less than in the HIF-rats (exp. I and II).

One might expect that rats housed in the same cage would become colonized with the same flora. However, one RIF-rat in experiment I showed no transfer before lincomycin administration although the other one did (Figure 1). The intestinal flora of this rat seemed to prevent transfer of resistance and colonization by transferred strains. Indeed, after disturbing this flora with lincomycin the transfer rate was comparable to that of the human flora. No obvious increase in CFU of transconjugants/g faeces was observed in the $\mathbb{H}$ Fi-rats of experiment $\mathbb{I}$ after lincomycin administration. This finding might be explained by the already high number of transconjugants in relation to the number of recipient $E$. coli K12.

The observations in the present study strongly suggest that the intestinal flora influences the frequency of transfer. The rat intestinal flora inthibited transfer more efficiently than the human intestinal flora. This is probably due to a better colonization resistance provided by a species-specific flora.

The differences in transferability observed in experiments I and II might be due to the use of different donor strains. Although with both donor strains in witro transfer was observed 
as well as in vivo colonization of the rats in high numbers, differences in uransfer activity were recorded. A higher frequency of transfer was observed for the porcine donor strain P86 compared to the human strain H1803. Thus P86 seemed to be a better donor of plasmids than the human strain H1803. A second difference was the lower numbers of recipient strain $E$, coli $\mathrm{K} 12$ that were able to colonize the rats in experment $\mathrm{II}$. In addition, resistance transfer in both experiments was most frequeitly observed in the presence of the human flora, thus suggesting that this flora can pick up pig-derived resistance plasmids. Comparing experiments I and III (the same donor strain), clear differences in transferability were observed which might be related to the use of different recipients.

As expected, lincomycin administration caused a reduction in the growth of anaerobic bacteria, however no increase in the numbers of donor or recipient $E$. colt strains was observed. After lincomycin administration, no transconjugants were observed for the PIFrats in experiments II and III in neither of which could transconjugants be isolated on day 32. No influence on the frequency of transfer in the RIF rats in experiments II and III was observed after lincomycin administration and lincomycin seemed only to be of minor influence in these experiments. Into account the data obtained, one has to realize that no detection of transconjugants in the faeces does not prove absence of plasmid transfer and it is possible that the numbers of transconjugants present were below the detection level.

In conclusion, in vivo transfer of antibiotic resistance is possible using GF rats associated: with different sorts of intestinal flora. In general, the highest frequency of transfer was observed when the rats were colonized with human flora. This might be due to the fact that human flora permits better transfer of resistance. However, more and extended experiments are necessary.

\section{ACKNOWLEDGEMENT}

We thank E. wan Dam, M. Hazen, I. Nillesen C. Driesen, J. Philips and M. Norder for skilled technical assistance. This work was supported by a grant. project number 28.0275, of the Prevention Fund of The Netherlands.

\section{REFERENCES}

1. Anderson ES. The ecology of transferable drug resistance in the Enterobacteriacede. Ann Rew Microbiol $1968 ; 22: 131-180$.

2. Corpet DE. Roplasmid transfer and antimictrobial residues in gnotoxenic animal models. I Tox Clin 
Experiment 1984: 8:21.34.

3. Corpet DE. Microbial ecology of the intethre. In witro, ist wivo and mathenatical models. Rev Sci Techn of In: Epiz 1989; 8:391-403.

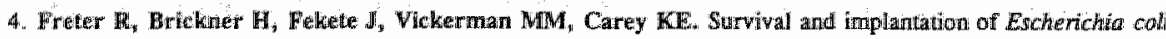
th the intestinal aract. Inftect Inim 1983: 39:686-703.

5. Heidt PJ, Waaty w D, Vossen JM, Hendriks WDH. The use of a human donor flora for recontamination following antibiotic decontamination. Prag Fo Nutr Sci 1983; 7:53-63.

6. Heidt PJ, Kovpman JP, Kennis HM, Logt wd JTM, Hectors MPC, Nagengast FM et al. The use of a ratderiwed thicroflora for providing colonization resistance in SPF rats. Lab Anumals 1990; 24:375-379.

7. Kado CI, $\mathrm{CH} \mathrm{ST}_{\mathrm{ST}}$. Rapid procedure for detection and isolation of large and small plasmids. J Bacteriol 1981: 145:1365 1373.

8. Koopman JP, Welling GW, Huybregis AWM, Mullink JWMA, Prins RA. Association of germ-free mice with intestinal microfloras. $Z$ Yersuchstierk $1981 ; 23: 145-154$.

9. Koopman JP, Logt wd JTM, Heessen FWA, Brink wd ME, Scholten PM, Hectors MPC, Nagengast FM. Elimination of murine yiral pathogens from the cecal contents of mice by anaerobic preparation. Lab Animals $1989 ; 23: 76-80$.

10. Langlois BE, Dawson KA, Leak I, Aaron DK. Effect of age and housing location on antibiotic resistance of fecal colitorms from pigs in a non-antibiotic-exposed herd. Appl Environm Microbiol 1988; 54:1341-1344.

11. Lester SC, Pillar Pla del M, Wang F, Perez-Sehael I, Jiang $\mathbb{H}_{3} \mathbf{O}^{\prime}$ Briten TF. The carriage of Escherichia coll resisunt to antimicrobial agents by healthy children in Boston, in Caracas, Venezuela, and in Qin Pu, China. N Engl J Med 1990; 323:285-289.

12. Levy SB. Microbial resistance to antibiotics. An evolving and persistent problem. Lancet 1982; 83-88.

13. Mallet AK, Bearne CA, Rowland IR, Farthing MJG, Cole CB, Fuller $R$. The use of rats associated with a human faecal florat as a model for studying the effects of diet on the human gut microflora. $J$ Appl Bacteriol 1987; 63:39-45.

14. Marshall B, Petrowski D, Levy SB. Inter- and intraspecies spread of Escherichic coli in a farm environment in the absence of antibiotic usage. Proc Natl Acad Sci USA 1990; 87:6609-6613.

15. Nijstem R, London N, Bogaard wd A, Stobberingh. E. Antibiotic resistance of Enterabacteriaceae isolated from the faecal flora of fattening pigs. Vet Quart 1993; 15:152-156.

16. Nijsten $\mathbf{R}$, London $\mathbf{N}$, Bogaard vd A, Stobberingh $\mathbf{E}$. In wirro transfer of antibiotic resistance between fuecal Escherichic coll strains isolated from pig farmers and pigs. Accepted for publication.

17. Nljsten R, London N, Boggard vd A, Stobberinght E. Antibiotic resistance among Escherichia coli isolated from faecal silmples of piyg farmers and pigs. Accepted for publication.

18. Ojenigi AA. Direct transmission of Escherichia colf from poultry to humans. Epidemiot Infect 1989; 103:51:3-522.

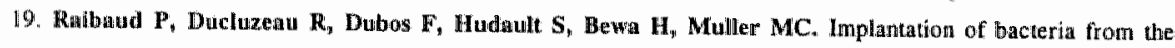
digestive tract of man and various animals into gnotobiotic mice. Am J Clin Nutr 1980; 33:2440-2447.

20. Smith HW. The trinsfer af antibiotic resistance between strains of Enterobacteria in chicken, calwes and pigs. I Med Micrabiol 1970; 3:165-180.

21. Snith HW. Antibiotic-resistant Escherichia coli in market pigs in 1956-1979; the emergence of organisms with plasmidoborne Irimethoprim resistanee. I Hyg. Cambr 1980; 84:467-477.

22. Waaij vd D, Berghuis-Vries de JM, Lekkerkerk-Wees vd JEC. Colonization resistance of the digestive tract in conventional and antibiotic-treated mice. I Hyg. Cambr 1971; 69:405-411. 
SURVEILLANCE OF ANTIBIOTIC RESISTANCE AMONG PIGS USING FAECAL FLOOR DROPPINGS FROM TRUCKS TRANSPORTING FATTENING PIGS

Nijsten R., London N., Bogaard v.d. A., Stobberingh E. 


\section{SUMMARY}

Faecal samples from farm pigs $(n=291)$ and faecal floor droppings from trucks, transporting fattening pigs to the slaughterhouse in the same region $(n=292)$, were analyzed for prevalence and degree of antibiotic resistance in Escherichia coli. In addition, the antibiotic susceptibility of $E$. coli isolated from both groups was determined.

The aim of this study was to examine whether, instead of the cumbersome and time consuming collection of individual rectal faeces samples from pigs, floor droppings collected from trucks transporting fattening pigs could be used for resistance surveillance. Both the prevalence and high degree of resistance observed were of the same size of order. This was also observed for susceptibility testing and the $M I C_{5090}$ distribution. Most frequently isolated resistance patterns for both groups were oxytetracycline-strepromycin and oxytetracycline-streptomycin-sulphamethoxazole.

From this study it appears that faecal floor droppings collected from trucks transporting fattening pigs are useful for antibiotic surveillance and therefore can be used for detection of changes in antibiotic resistance in the faecal flora of a pig population. Consequently, contimuous surveillance of resistance seems feasible. 


\section{INTRODUCTION}

There is a growing concern about the increase of antibiotic resistance in pathogenic bacteria mainly as a consequence of extensive use of antibiotics both in human and veterinary medicine $(8,13,19)$. As resistance develops in rough relation to antibiotic use the best way to minimise emergence of resistance, without hampering optimal care, is to minimise the use of antibiotics by using them only if they are really indicated. This can be reached by developing an antibiotic policy and an antibiotic formulary aimed to improve rational treatment of bacterial infections and minimizing emergence and spread of resistant bacteria $(2,14)$. Different formularies can be written for different populations e.g. for medical antibiotic use by patients and for veterinary use by different groups of animals in a certain province or country. Implementation of an antibiotic policy should be followed by monitoring the use of antibiotics and by survellance of antibiotic resistance in the target population, not only of isolated pathogenic bacteria but of the non-pathogenic faecal flora as well $(2,22)$.

As intestinal bacteria carrying resistance factors are wide-spread in the environment $(16,19,23)$ the faecal flora in humans and animals is considered to be a good indicator for the regular monitoring of antibiotic resistance in a population $(1,11,12,24)$. However, regular sampling of large numbers of individual pig faecal samples collected at farms is laborious, time-consuming and very expensive. Hence, this method is not suitable for a contimuous resistance surweillance.

This study was undertaken to answer the question whether faecal droppings collected from trucks are indicative for the faecal bacterial resistance in pigs living in the same region at different farms. If in faecal samples collected from the floor of trucks transporting fattening pigs the antibiotic resistance of Escherichia coll is of the same size of ordar as in the regional pig population this material could be used for resistance survellance on a regular or ever continuous base. The prevalence and high degree of resistance of the isolates of both groups as well as the susceptibility were determined and compared. As the prevalence of resistance strongly depends on the method used the high degree of resistance is considered to be a more reliable and relevant parameter for resistance surveillance than the prevalence of resistance $(3,4,17)$. The probability of spread of antibiotic resistant bacteria or resistance genes to susceptible strains is higher in animals of which a majority of the faecal Enterobacteriaceae flora is resistant (i.e. high degree of resistance) than in animals with low numbers of antibiotic resistant strains (i.e. low degree of resistance). 


\section{Collection of the faecal samples}

Fresh faecal samples from two different groups of pigs living in the same region were collected. One group, described in a previous study (21), consisted of mixed faecal samples $(n=291)$ from mature gilts and/or heavy porkers collected per rectum at pig farms. Only one sample per farm was analyzed. The second group consisted of floor dropping samples $(\mathrm{n}=292$ ) from trucks transporting fattening pigs from different farms. Immediately after delivering the pigs at the slaughterhouse two samples were taken from each truck. After collecting, the samples were sent to the bacteriological laboratory where they were diluted $\left(10^{1}\right)$ in $0.9 \%$ saline, containing $20 \%(\mathrm{v} / \mathrm{v})$ glycerol and stored at $20^{\circ} \mathrm{C}$ until examined.

\section{Bacteriological analysis of the faecal samples}

To compare the results of both methods of faeces collection the prevalence and degree of resistance as well as the susceptibility and $\mathrm{MIC}_{50 / 50}$ were determined. However, if truck sampling is an useful alternative for sampling individual pigs the data, especially the high degree of resistance, obtained with both methods must be of the same size of order.

The methods used to determine the prevalence and degree of antibiotic resistance and the antibiotic susceptibility were as described previously (20). The breakpoint concentrations used for determining antibiotic susceptibility are shown in Table 2.

\section{RESULTS}

The data observed for the farm pigs have been presented in a previous study (21). Sixty-nine and $93 \%$ of the colonies tested isolated from farm pig and floor dropping samples, respectively, with the morphology typical for $E$. coll on Levine-agar were identified as $E$. coli. The other colonies tested were also Enterobacteriaceae: Klebsiella spp., Citrobacter spp., Enterobacter spp. and Proteus spp. All faecal farm pig samples showed growth on the agar plates without antibiotics, whereas 6 of the 292 floor droppings failed to grow. E. coli could not be isolated from four farm pig samples and 11 floor droppings because of overgrowth by Bacilless spp. In addition, from two farm pig samples and 27 floor droppings, respectively, the colonies with the morphology of $E$. coli isolated were indole negative and excluded for susceptibility testing. Finally 285 and 248 E. coli strains isolated from faecal samples collected at farms and from trucks, respective- 
1y: were tested for susceptibillity.

\section{Prewalence of antibiotic resistance}

The prevalence of resistance to neomycin, amoxycllin, trimethoprim, oxytetracycline and sulphamethoxazole ranged between $92 \%$ and $100 \%$ for the farn pigs and between $73 \%$ and $89 \%$ for the floor droppings (Table 1). The prevallence of resistance to the other antimicrobial agents tested was distinctly lower for both groups.

\section{Degree of antibiotic resistance}

For both groups of faecal samples examined a high degree of resistance was observed for the antimicrobial agents commonly used in veterinary medicine $\mathbb{1}$,e. amoxycillin, neomycin, oxytetracycline, sulphamethoxazole and trimethoprim (Table 1). The highest percentages in farm pigs and toor droppings were found for oxytetracycline and sulphamethoxazole. For the other compounds the percentages were distinctly lower.

For both groups of samples comparable high degree of resistance percentages were observed with exception of the floor droppings, which showed a considerably higher

Table 1: Prevalence and high degree of antibionic rexistant Escherichin coli in pig faeces collected at pig farms $(n=29 l)$ and from trucks transporting fattening pigs $(n=286)$.

\begin{tabular}{|c|c|c|c|c|c|}
\hline & & Prevall & & High o & \\
\hline Antib & & Farms & Trucks & Farms & Trucks \\
\hline & $\mathrm{mg} / \mathrm{l}^{\wedge}$ & $\%$ & $\%$ & $\%$ & $\%$ \\
\hline Amx & 25 & 98 & 84 & 11 & 12 \\
\hline$A p *$ & 32 & 8 & 1 & 0 & 0 \\
\hline Cip & 4 & 2 & 0 & 0 & 0 \\
\hline Flu & 4 & 2 & 1 & 0 & 0 \\
\hline $\mathrm{Ft}$ & 50 & 17 & 4 & 0 & 0 \\
\hline $\mathrm{Ne}$ & 8 & 92 & 73 & 2 & 2 \\
\hline $\mathrm{Ot}_{\mathrm{t}}$ & 25 & 100 & 89 & 25 & 45 \\
\hline $\sin x$ & 100 & 100 & 89 & 24 & 27 \\
\hline Trmp & 8 & 99 & 77 & 7 & 3 \\
\hline
\end{tabular}

mg/l": Antibiotic concentrations in the agar plates. ": Apramycin was only tested for the last 144 faecal samples of the farm pigs and for all srack samples, Amx = amaxycillin. Ap $=$ apramycin. Cip = ciprofoxacin, Flu flumequin, $N e=$ neomycin, $F t=$ mitrofurantoin, $O t=$ oxytutracycline, Smx $=$ sulphamethoxazole, Tmppece rrimethoprin. 


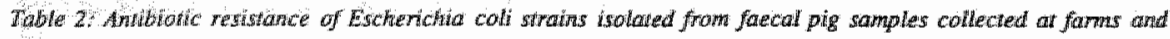

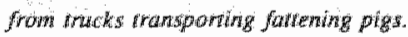

\begin{tabular}{|c|c|c|c|}
\hline \multirow{2}{*}{\multicolumn{2}{|c|}{ Antitibiotie }} & \multicolumn{2}{|c|}{ Antibiotic resigiant $E$. coll strains } \\
\hline & & \multirow{2}{*}{$\begin{array}{l}\text { Farms }(n=285) \\
\text { n }(\text { 简) }\end{array}$} & \multirow{2}{*}{$\begin{array}{l}\text { Trucksi (nim } 248) \\
\text { nil }(\%)\end{array}$} \\
\hline & $\mathrm{mg} / /^{n}$ & & \\
\hline Amu & 16 & $72(25)$ & $50(20)$ \\
\hline Ap & 16 & $0(0)$ & $0 \quad(0)$ \\
\hline Ame: & 16 & $0 \quad(0)$ & $0(0)$ \\
\hline c & 8 & $38(13)$ & $40(16)$ \\
\hline $\mathrm{Fi}$ & 32 & $23(8)$ & $10(4)$ \\
\hline On & 4 & $3(1)$ & $4(2)$ \\
\hline Na & 8 & $10)$ & $2(1)$ \\
\hline Ne & 16 & $20(7)$ & $15(6)$ \\
\hline or & $\mathbb{1 6}$ & $163(57)$ & $171(69)$ \\
\hline s & 16 & $20:(78)$ & 208:(84) \\
\hline $\sin x$ & 128 & $129(45)$ & $118(48)$ \\
\hline Tmp & 2 & $46(16)$ & $31(13)$ \\
\hline
\end{tabular}

mg/t: breakpoint concentration, according to Klingeren et al. (7) and for apramycin according to Hunter (6).

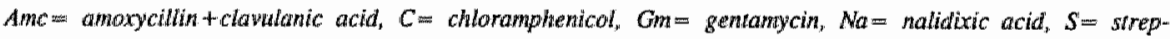
nomycin. See also legend Table 1.

Table 3." Most frequenty isolated pantems of dnug resistant Escherichia coli strains isolated from faecal pig samples collected at farms and from trucks transporting fattening pigs.

Percentage of E. coli strains

$\begin{array}{lll}\text { Resistance } & \text { Frarms }(n=285) & \text { Trucks }(n=248) \\ \text { Puttern } & n(\%) & n(\%)\end{array}$

\begin{tabular}{lll}
\hline & & \\
Or $s$ & $42(15)$ & $53(21)$ \\
Or s $\sin x$ & $27(10)$ & $35(14)$ \\
$s \sin x$ & $21(7)$ & $12(5)$ \\
Anx & $15(5)$ & $29(12)$ \\
\hline
\end{tabular}

Legend set Table 1 
percentage of oxytetracycline resistance.

\section{Anibiotic resistance}

Both groups showed the highest resistance percentages for sulphamethoxazole, oxytetracycline and streptomycin ranging between $45 \%-71 \%$ and $48 \%-84 \%$ for farm pigs and floor droppings, respectively (Table 2). Seventy different resistance patterns could be distinguished for the farm pigs and 50 for the floor droppings. Most of these patterns (46 farm pig and 31 floor dropping samples) were observed only once or twice. The three most frequently recorded resistance patterns in both groups were a combination of streptomycin and/or oxytetracycline and/or sulphamethoxazole (Table 3). These patterns did occur more or less with the same frequency in both populations. Only resistance to streptomycin alone seemed to be higher in the floor dropping isolates $\left(12 \%\right.$, versus $5 \%$ ). The $\mathrm{MIC}_{50}$ and $\mathrm{MIC}_{90}$, considered to be the best predictive values for clinical efficiency, were also similar for both groups (Table 4).

Table 4: MICSO (ng/l) and MIC9O (mg/l) of Escherichita coll strains isolated from faecal pig samples collected at forms and from tracks transporting jotrening pigs.

\begin{tabular}{lllll}
\hline & \multicolumn{2}{l}{ Farms $(\mathrm{n}=285)$} & \multicolumn{2}{l}{ Trucks $(\mathrm{n}=248)$} \\
Antibiotic & MIC50 & MIC90 & MiC50 & MIC90 \\
\hline Amx & 8 & 264 & 4 & $\geq 64$ \\
Ap & 4 & 8 & 8 & 8 \\
Annc & 4 & 16 & 4 & 8 \\
C & 8 & 16 & 8 & 64 \\
Gm & 0.5 & 1 & 1 & 2 \\
Na & 4 & 8 & 4 & 8 \\
Ne & 2 & 4 & 51 & 8 \\
Fr & 16 & 32 & 16 & 32 \\
Ot & $\geq 256$ & $\geq 256$ & $\geq 256$ & $\geq 256$ \\
S & 32 & $\geq 128$ & 64 & $\geq 128$ \\
Smx & 64 & $\geq 1024$ & 64 & $\geq 1024$ \\
Tmp & 0.5 & 512 & 0.5 & 512 \\
\hline
\end{tabular}

MC50 = Minimal Inhibitory Concentration (mg/h) at which $50 \%$ of the strains are inhibited, MC90= $90 \%$ intibited. See also legend Tables 1 and 2. 
The present study showed that the prevalence and high degree of resistance to most compounds tested were for both groups of faecal samples of the same size of order. In addition, the antibiotic resistance percentages of the $E$. coli isolated, the $\mathrm{MIC}_{50 \% \text { G }}$ distribution as well as the resistance patterns most frequently observed were of the same size of order in both groups. No explanation for the higher percentage of high degree of resistance to oxytetracycline observed in the floor droppings could be found. However, in a previous study about monitoring of amtibiotic resistance in fattening pigs on a single farm the high degree of resistance to oxytetracycline varied over time as well (20). Differences between both groups were found in percentage indole negative samples and samples with overgrowth by Bacillus spp. The floors of the trucks were probably contaminated with a high diversity of soil bacteria, resulting in more difficulties with bacterial overgrowth and indole negative strains during processing these samples.

Continuous surveillance of antibiotic resistance of pathogenic and non-pathogenic microorganisms is an essential part of an optimal antibiotic policy. The faecal flora is considered to be an important reservoir of antibiotic resistant genes and thus useful for antibiotic resistance monitoring of the healthy animal or human population $(12,15,24,25)$. Therefore, an easy method to obtain indicative faecal samples at regular intervals is required. Smith (24) investigated individual faecal samples of pigs at markets, during 1956 and 1970-1979, to reflect the occurrence of antibiotic resistance in the pig population. In

The Netherlands trading of pigs at markets is strongly discouraged, because of spread of infectious diseases prevention. In this study floor droppings from trucks transporting pigs for slaughter were collected as an alternative for individual pig faecal samples. The data of the present study strongly suggest that the alternatiwe for antibiotic resistance surveillance investigated in this study is useful and relatively easy to perform. Therefore, this method could make more regular or even continuous resistance surveillance in pigs. feasible. We are aware of the fact that this method does not take into account differences in factors such as pig age, husbandry methods, particular health problems, nutrition, preventive and therapeutic antibiotic use $(5,9,10)$ which are present at different farms. However, these differences are for surveillance of antibiotic resistance in a certain region or country less important. The data obtained are essential for resistance epidemiology, necessary for an antibiotic policy, that aims to minimise the emergence and spread of antibiotic resistance.

To prevent problems caused by contamination with soil bacteria, it might be advisable to collect faecal samples at the evisceration-line in the slaughterhouse instead of floor 


\section{ACKNOWLEDGEMENTS}

We thank M. Norder, C. Driessen and J. Philips for skilled technical assistance and P. Terporten for fhis help with statistical problems. Also we thank the Animal Health Laboratory South Netherland (Prof. Dr. It. MI.J.M. Thelen) and Dr. P.A.M. Verhoeven of the National Inspection Service for livestock and meat (RVW) and the mamagement of the slaughterhouse Coveco for their co-operation. We are Prof. Dr. A. Knotnerus, Prof. Dr. P. Kaipschild and Dr. J.E.B. Hunter very gratefull for their suggestions and crithall reading of the mamuscript. We are also thankful to Dr. Möller for his program for the andysis of drag resisiant bacteria (18), This work was supported by a grant, project number 28.0275 , of the Prevention Fund of The Netherlands.

\section{REFERENCES}

1. Ahart JG, Burton GC, Bhenden DC. The infuence of antimicrobiall agents on the percentage of tetracyclineresistant bacteria in faeces of humans and animals. I Appl Bacteriol 1973; 44:183-190.

2. Bogaard vd AEMM. A veterinary antibiotic policy: personal view on the perspectives in The Netherlands. Vet Microbiol 1993n 35:303-312.

3. Bonten M, Stobberingh E, Phillps J, Houben A. High prevallence of antibiotic resistant Excherichia coli in fecal samples of students in the south-east of The Netherlands. J Antimicrob Chemother 1990; 26:585-592.

4. Bonten M, Stobberingh E, Phillps J, Houben A. Antibiotic resistance of Escherichia coli in fecal samples of healthy people in two different areas in an industrialized country. Infect 1992; 20:258-262.

5. Bourque $\mathbf{R}$, Lallier $\mathbf{R}$, Lariviere $\mathbf{S}$. Influence of oral antibiotics on resistance and enterotoxigenicity of Excherichia coli. Can I Comparat Med 1980; 44:101-108.

6. Hunter JEB. Apramycin-resistant Escherichia coli in farm animals and man. Thesis, University of Liverpool 1992.

7. Klingeren v B, Mouton RP. Standatdisatie $v$.gewoligheidsbepalingen. Verslag van de werkgroep richulinen gewoeligheids bepalingen. Rijksinstituut woor Volksgezondheid ert Milleuhyglene, Bilthoven, The Netherlands, 1990. ISBN 90-6960-004-8.

8. Kunin CM, Joluansen $\mathrm{KS}$, Worning AM, Daschner FD. Report of a symposium on use and abuse of aritibiotics worldwide. Rew Infect Dis 1990; 12:12-19.

9. Langlots BE, Dawson KA, Lealk $I_{\text {, Aaron }}$. AK. Antimicrobial resistance of fecal cofiforms from pigs in a berd not exposed ho artimicrobial agents for 126 months Vet Microbiol 1988; 18:147-153.

10. Langlois BE, Dawson KA, Leak $\mathbf{I}$, Aaron DK. Effect of age and thousing lowation on antibiotic reastance of fectl coliforms from pigs in a mon-antibioticmexposed herd. Appl Environm Mllerobiol 1988; $54: 1341$-1344.

11. Lester SC, Del Pilar-Pla M, Wang F, Perez-Schael I, Jiang H, O'Brien TF. The carriage of Escherichio coli resistant to antimicrobial agents by healthy children in Boston, in Caracas, Venezuela, and in Qin Pu, China. N Engl J Med 1990; 323:285-289. 


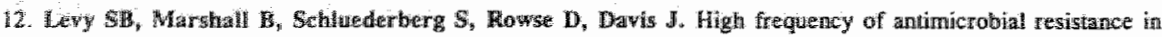
Wuman fecal Fora. Aminicrob Agents Chenother $1988 ; 32,1801$ - $180 \%$.

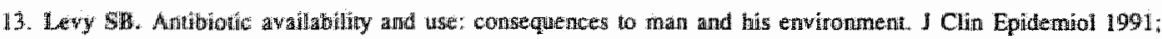

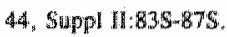

14. Lewish M. Control the spread of resistande. In: Antmicrob Chemother, 14:pp 153-159. Greenwood D (ed). Onford University Press, 1989.

15. Liston AH, Handiey B, Osborme AD, Shaw BG, Roberts TA, Hudson WR. Contamination of pigg carcasses at two battoir by Eicherichta coli with special reference to O-serctypes and antibiotic resirtance. I Appl Dacteriol 1976; 41:89, 110.

16. Linton KB, Richmonid MH, Bewan $\mathrm{R}$, Gillespie WAw Antibiotic resistance and $\mathrm{R}$ factors in coliform bacill isolated from hospital and donestic sewage. J Med Microbiol 1973; 7:91-103.

17. London N, Nijgten R, Bogaard Vd A, Stobberingh E. Antbiotic resistance of faecal Enterobacteriaceote isolated from healuhy wolunteers, a 15-tweek follow-up study. J Antimicrob Chemother 1993; 32:83-91.

18. Moller JK. A microcomputer asisited analysis of druyg resistance in bacteria. Computer Meth Progr Biomed $1986 ; 23,217-223$

19. Murray BE. Emergence of diseases caused by bacteria resistant to antimicrobial agents. In: Handbook Series in Zoonoses, Section D: antibiatics, sulfonamides and public health, 1:pp 201-216. Steele J (ed). CRC Press, lno. Boca Ratom, Florida, 1984.

20. Nijsten 14, Lordon N, Bogaard va A, Stobberingh E. Antibiotic resistance of Enterobacteriacede isolated from the fiaced flora of fattening pigs. Vet Quart 1993; 15:152-157.

21. Nijsten R, London N, Bogaard vd A, Stobberingh E. Antibiotic resistance among Eischerichia coll isolated from faecall samples of pig farmers and pigs. Accepted for publication.

22. O'Brien TF, Norton RA, Kent RL, Medeiros AA. International surveillance of prevalence of antibiotic resistance. I Antimicrob Chemother 1977; 3 Suppl C:59-66.

23. O'Brien TF, Hopkins JD, Gilleece ES, Medeiros AA, Kent RL, Blackburn BO at al. Molecular epidemiology of antibiotic resistance in Salmoneila from animals and human beings in the United Stattes. $N$ Engl Med $1982 ; 307: 1-6$.

24. Smith HW. Antibiotic-resistant Escherichia coll in market pigs in 1956-1979: the emergence of organisms with plasmid-borne trimethoprum resistance. J Hyg. Camb 1980; 84:467-477.

25. Wray C. Some aspects of the occurrence of resistant bacteria in the normal animal flora. I Antimicrob Chemother 1986; 18 Suppl C:141-147. 


\section{GENERAL DISCUSSION}

GENERAL CONCLUSIONS AND RECOMMENDATIONS 



\section{GENERAL DISCUSSION}

This thesis describes the prevalence and degree of antibiotic resistance in the faecal $E$. coll population of three groups of pigs and human volunteers living in the same area. Additionally, one $E$. coli isolate was randomly selected from each frecal ping and pig farmer sample and the susceptibility for several antibiotics was determined as minimum inhibitory concentrations. The three groups of human participants i.e. pig fammers, abattoir workers and (sub)urban residents, differed in their intensity and frequency of contact with pigs or pig products. Special attention was paid to recent usage of antibiotics by the participants themselves and other persons belonging to the same household, or for treatment of pigs at the different farms. In addition to the study of these phenotypic

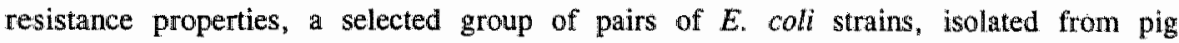
farmers and their pigs, were compared for genotypic resistance markers: transferability of antibiotic resistance in vitro and in vivo and characterization of the plasmid patterns of donor and transconjugants using DNA-fingerprinting.

In this chapter, first the results of the pig samples are compared followed by the results of the human samples and a possible relation between the presence of antibiotic resistance in both groups is discussed. Next, the importance of surweillance of antibiotic resistance in pigs is quoted and, finally, general conclusions and recommendations are made.

The faecal flora is an important reservoir of antibiotic resistant $E$. colt in a population, which might transfer resistance plasmids to pathoganic bacteria in that population. Therefore, a high prevalence of antibiotic resistance in the intestinal flora is considered to constitute a public health risk. If the human intestinal tract can be colonized by resistant bacteria or if bacteria from pigs can transfer their resistance genes to the human intestinal flora, measures to prevent this are indicated including lowering the resistance in the intestinal flora of pigs and/or hygienic measures preventing contact of humans with pig bacteria. However, referring to our results the effect of these measures could be quesrioned.

\section{Antibiotic resistance in pigs}

Faecal samples of three groups of pigs were analyzed. First, during a period of about one year at one fattening farm, faecal samples were collected at regular intervals from several pigs in the same and in different compartments in order to study the reproducibility of 
sampling and the variation in resistance, and to monitor the percentage and degree of resistance over time. The second group studied were faecal samples of pigs from the pig farmers participating in this study and the third group of faecal samples consisted of floor droppings collected from trucks that had transported fattening pigs from farms in the study area the slaughterhouse.

As shown in chapter $\mathbb{I}_{\text {, }}$ only minimal variation in prevalence of resistance in the faeces of pigs from the same and from different compartments at the same farm was found. The observed prevalence of resistance did not vary much with time, suggesting that antibiotic resistance in a pig population is relatively constant. Therefore, the mean prevalence of resistance percentage was calculated for all pigs investigated during the 11 month period (Table 1).

In all three pig groups investigated in this study the faecal samples showed the same order of magnitude for the prevalence of resistance, except for neomycin (Table 1). A certain variation in the prevalence of neomycin resistance bad also been observed in the faecal samples of groups of pigs from the same fattening farm (chapter II). No explanation could be found for this relatively high variation in resistance to neomycin observed in these

Table 1. Comparison of the prevalence (\%) and high degree (\%) of resistant Escherichia coli isolated" from different groups of pigs described in present thesis.

\begin{tabular}{|c|c|c|c|c|c|c|}
\hline \multirow[b]{2}{*}{ chapter } & \multicolumn{3}{|c|}{ Prevalence of resistance $(\%)$} & \multicolumn{3}{|c|}{ High degree of resistance ( $\%)$} \\
\hline & II & IV & VII & II & IV & VII \\
\hline \multirow[t]{2}{*}{$n=$} & 407 & 291 & 286 & 407 & 291 & 286 \\
\hline & $\begin{array}{ll}X & (S D)\end{array}$ & & & $X(S D)$ & & \\
\hline
\end{tabular}

\begin{tabular}{lllllllll} 
Amx & $81(17)$ & 98 & 84 & 10 & $(12)$ & 11 & 12 \\
Ap & 1 & $(2)$ & 8 & 1 & 0 & $(0)$ & 0 & 0 \\
Cip & 0 & $(0)$ & 2 & 0 & 0 & $(0)$ & 0 & 0 \\
Filu & $0.3(1)$ & 2 & 1 & 0 & $(0)$ & 0 & 0 \\
Ft & 8 & $(13)$ & 17 & 4 & 0 & $(0)$ & 0 & 0 \\
Ne & $51(25)$ & 92 & 73 & 1 & $(4)$ & 2 & 2 \\
Or & $94(10)$ & 100 & 89 & 32 & $(20)$ & 25 & 45 \\
Smx & $94(1)$ & 100 & 89 & $17(13)$ & 24 & 27 \\
Tmp & $88(18)$ & 99 & 77 & 3 & $(4)$ & 7 & 3 \\
\hline
\end{tabular}

Chapter II = different grouss of pigs luving at a single farm, chapter $W=$ pigs liwing at differen farms, chopser $V I I=$ floor droppings collected from thacks transporting fattening pigs. $A m x=$ amoxycillin, $A p=$ apramycin,

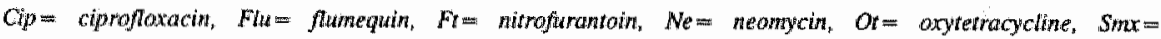
sulphamethotagote, Thip $=$ trimethoprim, $X=$ mean of the samples of pigs described in chapter $I I, S D=$ standard deviation, $n=$ number of samples tested. 
studies. The use of neomycin by the pig breeders might be a possible explanation, but no information about this use could be obtained.

A high degree of resistance was observed for antibiotics commonly used for pig treatment in veterinary medicine: amoxycillin, oxytetracycline, sulphamethoxazole, trimethoprim and neomycin. A variation in high degree of resistance for oxytetracycline could be observed.

The resistance percentages observed in the three pig groups were of the same order of magnitude (Table 2). Also, the most frequently present resistance patterns, i.e. a conbined resistance against oxytetracycline and/or sulphamethoxazole and/or streptomycin; were observed in all three groups of pigs (Table 3). The high resistance percentages to oxytetracycline and sulphamethoxazole found might be explained by the fact that these compounds are the most commonly used antibiotics for mass-medication of pigs in The Netherlands (2). Streptomycin, however, is currently only used in pigs for individual and parenteral therapy in combination with penicillin but, despite this, high resistance percentages were observed for this agent. As genes encoding resistance to streptomycin are in most cases located on plasmids and frequently in combination with other genes conferring

Table 2: Resictance percentages (\%) observed for pigs in present thesis and by other inwestigators.

\begin{tabular}{|c|c|c|c|c|c|c|c|c|}
\hline \multirow{3}{*}{$\begin{array}{l}\text { chapter } \\
n=\end{array}$} & \multicolumn{3}{|c|}{ Present thesis } & \multirow[b]{2}{*}{ reff } & \multicolumn{4}{|c|}{ Other studies } \\
\hline & II & IV & VII & & 1 & 3 & 7 & 14 \\
\hline & 387 & 285 & 248 & $\mathrm{n}=$ & 53 & 5 & 359 & 796 \\
\hline$A \mathrm{~m} x$ & 11 & 25 & 20 & Amp & 42 & 22 & 9 & 30 \\
\hline Ap & 0 & 0 & 0 & Ap & .. &.. & .. & .. \\
\hline Anc & 0 & 0 & 0 & Ame & $\therefore$ & .. & $\because$ & .. \\
\hline $\mathrm{C}$ & 13 & 13 & 16 & C & 11 & 1 & 1 & 17 \\
\hline $\mathrm{Ft}$ & 7 & 8 & 4 & $\mathrm{~F}$ & 2 & .. & $\therefore$ &.. \\
\hline $\mathrm{Na}$ & 1 & 0 & 1 & $\mathrm{~N}, \mathrm{~s}$ & 1 & .. & $\mathbb{1}$ & .. \\
\hline $\mathrm{Ne}$ & 2 & 7 & 6 & $\mathrm{Ne}$ & 24 & 13 & 1 &. \\
\hline Ot & 49 & 57 & 69 & Tet & 70 & 88 & 59 & 90 \\
\hline$S$ & 66 & 71 & 84 & S & 85 & 38 & 35 & 83 \\
\hline $\operatorname{Sin} x$ & 68 & 45 & 48 & Sul & 72 & 27 & 16 & 83 \\
\hline Tmp & 5 & 16 & 13 & Tmp & .. & .. & .. & $\therefore$ \\
\hline
\end{tabular}

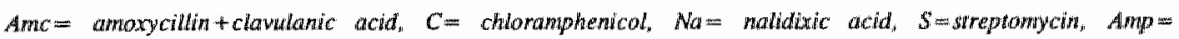

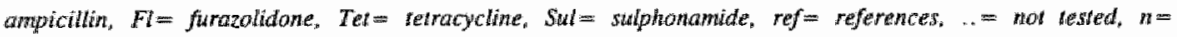
rumber of strains tested, see also legend" Table 1. 


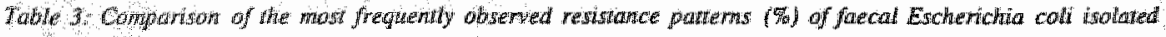
from different groups of pig described in prexent hesis.

\begin{tabular}{|c|c|c|c|c|c|c|}
\hline \multirow{2}{*}{ chaper } & \multicolumn{2}{|c|}{ II $(n=387)$} & \multicolumn{2}{|c|}{ IV $(n=285)$} & \multicolumn{2}{|c|}{ VII $(n=248)$} \\
\hline & patienen & 9 & pattera & $\%$ & paterna & $\%$ \\
\hline & $\operatorname{orssin} x$ & 20 & ons & 15 & Ots & 21 \\
\hline & $\sin$ & 12 & Dissmax & 10 & Orssm & 14 \\
\hline & SSmx & $\| 1$ & $\$ \sin x$ & 7 & $s$ & 12 \\
\hline & ous: & 8 & $\mathrm{~s}$ & 5 & $\operatorname{ssin} x$ & 5 \\
\hline & Amxoissma & 3 & AmxOts & 3 & AmxOrs & 3 \\
\hline
\end{tabular}

tegend see table 1 .

resistance to oxytetracycline and/or sulphamethoxazole, it is very likely that the usage of a terracycline or suphonamide might select for resistance to streptomycin $(6,14,16)$.

The small variation in resistance to any of the antibiotics tested holds not only true for the prevalence and degree of resistance in the faecal samples, but also the antibiotic resistance of the individual $E$. coli isolates (the $\mathrm{MIC}_{30}$ and $\mathrm{MIC}_{90}$ ) of the group of pigs living at different farms and of the floor droppings collected from trucks were of the same order of magnitude (chapter VII).

In general it was shown that $E$. coll isolated from the intestinal flora of pigs were not only resistant to antibiotics commonly used for treatment of bacterial infections in humans, but even often a high degree of resistance could be observed against those

Table 4: Comparison of we prevalence of antbionic resistance (\%) described for pigs in present thesis and by orher investigators

\begin{tabular}{|c|c|c|c|c|c|c|c|}
\hline \multirow[b]{2}{*}{ chapter } & \multicolumn{3}{|c|}{ Present thesis } & \multicolumn{4}{|c|}{ Other studies } \\
\hline & ॥ & IV & VII & reft & 1 & 12 & 15 \\
\hline \multirow[t]{2}{*}{$n=$} & 407 & 291 & 286 & $n=$ & 53 & 47 & 100 \\
\hline & \multicolumn{7}{|l|}{$X(\mathrm{SD})$} \\
\hline $\operatorname{Ann} x$ & $81(17)$ & 98 & 84 & Amp & 84 & 89 & 50 \\
\hline Fit & $8(13)$ & 17 & 4 & $\mathrm{Fl}$ & 6 & $\therefore$ & 15 \\
\hline Ne & $51(25)$ & 92 & 73 & $\mathrm{Ne}$ & 47 & .. & 1 \\
\hline o & $94(10)$ & 100 & 89 & Tet & 94 & 98 & 100 \\
\hline $\sin x$ & 94 (11) & 100 & 89 & Sul & 96 & .. & 89 \\
\hline Tmp & $88(18)$ & 99 & 77 & Trupu & .. & .. & 36 \\
\hline
\end{tabular}

See lagend Tables 1 and 2. 
antibiotics: amoxycillin ${ }_{\text {it }}$ tracyclines, sulphonamides and trimethoprin.

Studies in other countries have also shown that the intestinal fora of healthy prgs is a reservoir of resistant bacteria (Tables 2 and 4). Differences in prevalences of resistance between these studies could be observed, but they night be explained by differences in sample selection, sampling procedures, laboratory methods and breakpoints used to differentiate between susceptible and resistant, but might also have been caused by differences in regional and local factors. These differences might be due to factors such as differences in prevalence of diseases, antibiotic usage, husbandry methods, hygienic measures, and/or disease control procedures. High resistance percentages to tetracyclines, sulphonamides and streptomycin, however, was commonly found in all these studies (Table 2). Hence, the faecal flora of healthy pigs represents a large reservoir of resistant bacteria. If these resistant bacteria are able to colonize the human gastro-intestinal tract or transfer their resistance genes to the human microflora, they might constitute a possible source of resistance for the human gastro-intestinal flora and consequently for bacteria (potentially) pathogenic for humans.

\section{Antibiotic resistance in healthy humans}

The prevalences and high degrees of antibiotic resistance in the stool samples of both abattoir workers and (sub)urban residents were of the same order of magnitude. Significantly higher values were found for the pig farmers (chapter III), although these were still lower than those noticed in the faecal samples of pigs (chapter IV).

A recognised important risk factor for the development of resistance in a population is the amount of antibiotic used in that population. Pig farmers are not only exposed to antibiotics directly by using these agents for treatment of personal infections, but also indirectly during treatment of pigs or handling medicated pig feed. Moreover, people may acquire resistant bacteria in their endogenous flora from their environment i.e. via contact with animals or animal products, but also from other sources such as vegetables. Pig farmers have daily and extensive contact with pigs and pig waste. Abattoir workers come regularly in contact with faecal bacteria during pig slaughtering or handing contaminated pug carcasses and meat. The difference between pig farmers and abattoir workers lies in the exposure to veterinary antibiotics (either directly or indirectly) by farmers as well as the intensity and time of contact with pigs and pig faeces.

Several other studies have reported higher prevalences of resistant bacteria in both 
famers and animal handers than iv people without, or with less intensive, animal contacts $(8,9,12,14,18)$. These investigators suggested that contact with animals which thad been treated with antibiotics was the cause of these higher prevalences. Only a few studies analyzed the recent usage of antibiotics for treatment of personal infections by the participants one of the risk factors for antibiotic resistance $(8,12)$. Recent antibiotic use for treatment of personal infections in this study was higher both in pig farmers and abattoir workers than in the (sub)urban residents ( $5 \%$ and $8 \%$ versus $0 \%$, respectively). Abattoir workers were mostly treated locally for infections of minor skin wounds (dr. M.L.T. Qukk $v$. Millingen, personal communication). The antibiotic use mentioned by pig farmers might be for treatment of chronic non-specific respiratory affictions (CARA) which can be considered an occupational disease (13). This disease tends to cause regular acute exacerbations requiring antibiotic treatments. The regular use of antibiotics to treat these respiratory infections might have been a cause of the high prevalences of resistance in the faecal flora of the pig farmers. Attendant, contact and ingestion of medicated pig feed cannot be excluded as a risk factor for the presence of antibiotic resistance in the faecal flora of pig farmers. However, as described in chapter IV, ingestion of medicated pig feed seemed to be very unlikely to influence antibiotic resistance in pig farmers, as the theoretically daily ingestion of antibiotics was extremely low.

No significant differences were observed between abattoir workers who had intensive contact and those with less intensive contact, suggesting that minor differences in contact with pigs are not important. However, as pig farming is mainly a family business these people will usually have had contact with pigs and pig faeces for their entire lives, whereas the exposure to pig faecal flora can be expected to be much less for abattoir workers who work a regular 38 hrs week.

Consequently the higher prevalence of antibiotic resistance in pig farmers compared to the other human groups is multifactorial. Regular and intensive contact with pigs and pig faeces as well as long-term personal antibiotic use by pig farmers are possible factors of influence. As the faecal pig samples collected at different fams showed significantly higher prevalences of resistance than those of the pig farmer, the possibility of a flow of resistance genes from pigs to farmers might be suggested.

\section{Transfer of antibiotic resistance}

Further analysis, however, showed that in only $4 \%$ of the faecal pig and pig farmer samples, collected att the same farm, was the same resistance pattern present dominantly. 
The most frequently resistance patterns encountered in pig farmer isolates were different from those most commonly found in the isolates from pigs. Pig famer isolates nawnly showed resistance to amoxycillin, sulphamethoxazole and streptomycin-sulphamethoxazole and pig isolates to oxytetracycline-streptomycin and oxytetracycline-streptomycusulphamethoxazole. Moreover plasmid transferability studies and plasmid DNA-finger printing did not show regular similarities between both groups, not even between pained pig and pig farmer strains. The plasmid profiles of plasmids isolated from pig farmer strains were quite different from those isolated from pig strains.

Differences in transferability in vitro between pig and pig farmer isolates were observed. Most pig strains could readily transfer resistance, whereas less than $50 \%$ of the pig farmer strains could transfer their resistance plasmids. In vivo transfer of resistance to a suitable acceptor was detected with a human as well as a pig donor strain. The data suggested that rats associated with a human intestinal flora permitted better transfer of resistance than in rat or pig flora associated rats.

In all the above data i.e. phenotypically only $4 \%$ of the isolates from the paired samples had the same resistance pattern, so that the genotypical differences in plasmid transferability in vitro and in wivo and the lack of similarity of plasmid DNA-fingerprints between the two groups strongly suggest that the faecall flora of pig farmers and pigs form more or less two separated pools of resistance genes with only limited exchange of resistance plasmids. O'Brien et al. (11) also showed that resistance plasmids isolated from human and animal (chicken) strains were highly diverse. In contrast, other investigators $(4,17)$ found similarities among plasmids in animal and human isolates.

In a recent study in Sweden a dhfrIX-resistance gene mediating resistance to trimethoprim, widely spread among porcine isolates of $E$. coli, was detected only in one out of 434 trimethoprim resistant human $E$. coli strains. The authors concluded that transfer of resistance from pigs to humans is feasible (5).

\section{Antibiotic resistance surveillance in pigs}

It should be a goal in veterinary medicine to try to lower the carriage of antibioticresistant strains in animals. The data presented in this thesis did not show a major public health problem, but to safeguard the efficacy of antibiotics for treatment and prevention of bacterial diseases in animals now and for the future it is important to keep the carriage of antibiotic-resistant strains low $(2,10)$. Taking their responsibility to achieve this, the 
veterinary profession in The Netherlands has developed a veterinary antibiotic policy to prevent the emergence and dissemination of resilstance as much as feasible, but without hampering optimal treatment of sick animals (2). The backbone of this veterinary antibiotic policy is one mational antibiotic formulary: a limited list of preferred antibiotics, based on scientific data and practical experience. Essential, for the advice given in this formulary and in future updates, is regular information about trends in resistance devellopment. Also for evaluation of the impact of the policy, regular surveillance of resistance in animals is necessary. Careful record keeping of all pathogens isolated from animals, complete with antibiotic susceptibilities, is important. However, as in veterinary medicine culturing and stusceptibility testing is done mainly in case of treatment failure or from autopsy material, use of these data alone can lead to an exaggerated view of the prevalence of resistance in an animal population. It is therefore important to monitor regularly the prewalence and high degree of antibiotic resistance in the intestinal $E$. coli population in different groups of healthy animals to follow the effect of antibiotic usage in that population. A regular analysis of prevalence and high degree of resistance of the faecal flora and of isolated pathogenic bacteria by animal species, age group and organ system involved, should be made for different regions as well as nationally. This gives early warning of the emergence of resistance and/or cross-infection and clustering of resistant strains which may need special attention. A reliable, feasible and affordable method to obtain representative samples is therefore desirable.

In chapter VII prevalence and high degree of resistance as well as antibiotic susceptibility of $E$. coli isolated from faecal pig samples from individual farms were compared with the results obtained using floor droppings collected from trucks transporting fattening pigs from the same area as the farms to the slaughterhouse. Floor droppings yielded similar results and therefore collecting faeces samples at slaughterhouses seems to be an acceptable and much cheaper alternative than faeces collection on undividual farms.

\section{REFERENCES}

1. Aalluak B, Rasmussen J, Nielsen H, Elmerdah Otsaen J. Prewalence of antibiotic resistant Escherichia coli in Danish pigs and catle. APMIS 1991:99:1103i1110.

2. Bogaard vd AEJM, Hreewsma AJ, Julicher CHM, Mostert A, Nieuwenluuijs JHM, Vaarkanap H et al. Veterinair antbioticumbeleid: asnbevelingen wan een werkgroep. Tijdschrift voor Diergeneeskunde 1994; $119: 160+183$.

3. Bourque $\mathbf{R}$, Lallier $\mathbf{R}$, Lariwiere $\mathbf{S}$. Intluence of oral antibiotics on resistance and enterotoxigentcity of Escherichia coll. Can J Comp Med 1980; 44:101 108 . 


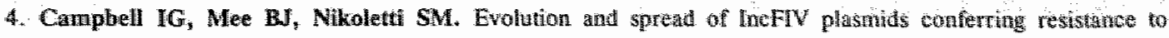
trimethoprim. Antimicrob Agents Chemother 1986; 29:807 813.

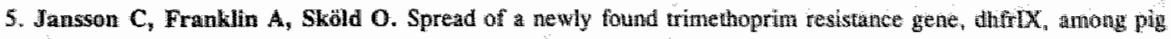
isolates and human pathogens. Antimicrob Agents Chemother 1992; 36:2704-2708.

6. Kawabe H, Tanaka: T, Mitsuhashi S. Streptomycin and spectinomycin resisance metiated by plasmids. Antimicrob Agents Chemother 1978; 13:1031-1035.

7. Langlois $\mathrm{BE}_{\text {, Dawson }} \mathrm{KA}$, Leak I; Aaron DK. Antimicrobial resistance of fecial conliforms from pigs in a herd mot exposed to antimicrobial agents for 126 months. Vet Microbiol 1988: 18:147.153.

8. Lewy SB, Fitzgerald GB, Macone AB. Changes in incestinal flora of farm personuel after introduction of a tetracyclinewsupplemented feed on a farm. N Engl I Med 1976; 295:583-588.

9. Levy SB. Emergence of antibiotic-resistant bacteria in the intestinal hora of farm inhabitanis. I Infect. Dis $1978: 137: 688-690$.

10. Mackinnon JD. The proper use and benifits of veterinary antimicrobial agents in swine practice. Vet Mictobiol $1993 ; 35: 357-367$.

11. O'Erien TF, DiGiorgio J, Parsonnet KC, Kass EH, Hopkins JD. Plasmid diversilty in Escherichia coli isolated from processed poultry processors. Vet Microbiol 1993 ; $35243-255$.

12. Ozanne G, Bedard P, Ducic S, Panisset JC. Amibiolic multiresistance among coliforms isolated from the gut of swine and abattoir workers: evidence of transfer from animal to man. Can I Public Health 1987; 78:340m 344.

13. Preller L, Vogelzang 13. Gezondheid varkenshlouder aan risico's blootgesteld. Stichting Gezondheidsdienast voor Dieren in Zuid-Nederland, Boxtel/Heythuysen, The Netherlands 1993. Rapportur 93.001.

14. Salda $K$, Ike $\mathbf{Y}$, Mitsuhashi $S$. Drug resistance and resistance plasmids of Escherichia coll strains isolated from pigs, slaughteres, $s_{\mathrm{n}}$ and breeders of pigs in Japan. Antimicrob Agents Chenother 1981; 19:1032-1036.

15. Smith HW. Antibiotic resistant Escherichia coni in markep pigs in 1956-1979: the emergence ofg organisms witliy plasmid-borne trimethoprim resistance. J Hyg, Camb 1980;84:467-477.

16. Swedberg G, Sköld $O$. Plasmid wborne sulfonamide resistance determinants studied by restrietion enzyme analysis. I Bacterijol 1983; 153:1228-1237.

17. Towner KJ, Wise PJ, Lewis Ma. Molecular relationslyaps between trimethoprim R plasmids abtained from humuan and animal sources. Appl Bacteriol 1986; 61:535-540.

18. Wells DM, James OB. Transmission of infectious atrug resistance from animals to man. II Hyg, Camb 1973 ; $71.209-215$. 


\section{GENERAL CONCLUSIONS AND RECOMMENDATIONS}

The results of this thesis suggest that the faecal flora of pigs and humans are different entities and constitute separate pools of resistance genes.

Although the intestinal $E$. coli flora of pig farmers showed higher prevalence of resistance percentages than those of (sub)urban residents and abattoir workers the data in the present thesis do not support the hypothesis that this difference is due to pig contact or involuntary intake of medicated pig feed. Another important finding is the obserwation that similar phenotypic antibiotic resistance patterns in the three populations studied were genotypically different.

Therefore, the question in the title of this thesis "Is there a relation between the antibiotic resistance in humans and pigs" can be answered. In our study this relation seemed to be negligible or even absent.

Although, in this thesis, pigs do not seem to be an important source of resistance for humans, it should be noted that the prevalence of resistance for the most commonly used antibiotics in pig medicine were extremely high, almost 100\%. Just as in human medicine, it should be a challenge for the veterinary profession to try to lower the prevalence of resistance in the intestinal flora of domestic animals for several reasons. First to safeguard the efficacy of veterinary antibiotic therapy now and for the future and second to prevent possible public health implications. The Dutch veterinary profession has taken this responsibility seriously and a veterinary antibiotic policy has recently been published. To be able to evaluate the impact of this veterinary antibiotic policy active surveillance of antibiotic resistance in animal populations, such as pigs, has to be performed regionally and nationally. This survelllance is necessary to make scientifically based recommendations for regular updates of the antibiotic guidelines in the veterinary formulary and to keep an eye on emerging public health risks. National monitoring stations have to be established for active surveillance of antibiotic resistance in different groups of healthy animals. Since in the present study results obtained from faecal pig samples collected from trucks were of the same order of magnitude as those collected at individual farms, faecal samples collected at slaughterhouses can be used for the proposed surveillance of resistance in pigs. This surveillance will give early warning of the emergence of resistance and/or cross-infection and clustering of resistant strains in a certain area, which needs special attention. In addition, resistance prevalence can be directly related to the amounts of antibiotics used in a certain group of animals, as veterinary usage of antibiotics has to be recorded by the responsible veterinary surgeon and farmer. 
Knowledge of the prevalence and degree of resistance in the bacterial flora of healiny animals will prowide veterinary surgeons with essential data for their choice of empirical therapy and could alert them to optimize their use of antibiotics. 
SUMMARY

SAMENVATTING

DANKWOORD

CURRICULUM VITAE 

The aims of this thesis were to detect if, and to what extent; antibiotic resistance can be transferred from pigs to humans and whether contact with pigs, pig products or medicated pig feed constituted a possible public health risk. Therefore, the influence of direct contact with pigs or pig products as well as recent antibiotic use in buman and pig medicine were investigated.

In the introduction, the literature is reviewed. The discovery of antibiotics had a major impact on the rate of survival from infections. However, the use of those agents resulted in antibiotic resistant bacterial populations in man and animals. Antibiotic resistance is common in bacteria, pathogenic as well as non-pathogenic, and is usually determined by plasmids. The prevalence of such plasmids and the range of antibiotics to which they confer resistance have increased greatly in the past 60 years. Resistance is common in the intestinal flora of healthy humans and animals. This flora acts as a reservoir of resistance genes which can be spread from one to the other population. The prevalence and dissemination of antibiotic resistance is a result of several factors which can be of direct or indirect influence. High risk groups are people living under poor hygienic conditions, living crowded together or using antibiatics regularly. People in close contact with food animals seem also to have a higher prevalence of resistance and therefore an attendant risk of spread of resistance from animals to man is expected. The occurrence of resistance in animals is directly related to the veterinary use of antibiotics, and this may indirectly influence resistance in humans. However, the literature is not cllear about the extent of a possible public health risk of antibiotic use in veterinary medicine.

In chaprer $U$ the prevalence and high degree of antibiotic resistance of faecal Enterobacteriaceae and the susceptibility of Escherichia coli isolates from fattening pigs at one farm was studied in time. This study showed that healthy pigs represented a reservoir of resistant Enterobacteriaceae ( $E$. coli). Antibiotic resistance was relatively constant in time for the pig population of this farm. Despite the absence of recent mass-medication during the stay at this farm, the prevalence of resistance to the most commonly used antibiotics in veterinary medicine was high. Susceptibility testing showed the highest resistance percentages for oxytetracycline, streptomycin and sulphamethoxazole, about half of the isolates showed patterns with resistance to sulphamethoxazole or a combinations of two or all of these antibiotics.

In chapter $I I$ the prevalence and high degree of antibiotic resistance of faecal $E$. coli isolated from pig farmers and abattoir workers were compared to a control group of 
(gub)urban resdents. The pig famers showed the highest percentages and the (sub)urban residents the lowest. Except for neomycin, no significant differences in high degree of resistance were observed. Remarkably, $5 \%$ of the pig farmers and $8 \%$ of the abattoir workers mentioned recent antibiotic use, whereas none of the (sub)urban residents had taken antibiotics recently. This might indicate that people in contact with pigs or pig carcasses have a greater risk of bacterial infections. As abattoir workers with a different grade of pig contact showed no significantly different prewalence of resistance, contact with pigs or earcasses seemed to be of minor influence on antibiotic resistance in these persons. We thought originally that direct contact with antibiotics in medicated pig feed, i.e. mass-medication, influenced the prevalence of antibiotic resistance in pig farmers.

In chapter IV the prewalence and high degree of resistance of faecal $E$. coli isolated from pig farmers (as discussed also in chapter III) and their pigs as well as the susceptibility(patterns) are compared. For most antibiotics, pig E. coli isolates showed significantly higher prevalence of resistance percentages than the pig farmer strains. The pig isolates were mainly resistant to oxytetracycline-streptomycin/sulphamethoxazole, whereas the resistance patterns amoxycillin, sulphamethoxazole and streptomycin-sulphamethoxazole were observed most frequently for farmer strains. Only $4 \%$ of the faecal $E$. coll isolated from pig and pig farmer living at the same farm showed the same resistance pattern. The high use of antibiotics in pig medicine in general and the intensive faecal-oral contact between pigs might explain the higher resistance percentages observed in pigs in this study. The results suggest that the resistance of the faecal flora of pig farmers and their pigs is different.

Chapter $V$ describes the results of in vitro transfer of antibiotic resistance plasmids from $E$. coll strains isolated from pigs and pig farmers living at the same farm, one group of isolates showed the same and the other group different resistance patterns. Besides similar transfer frequencies for pig farmer and pig strains, only minimal similarities could be observed with respect to biotypes, whole plasmid pattern and plasmid profile after restriction analysis. No conclusive evidence for the presence of a common pool of resistance plastnids among pig farmers and their pigs could be found.

Chapter VI describes the results of in vivo transfer of resistance plasmids present in porcine and human donor strains inoculated in gertm-free rats associated with different Enterobacteriaceae-free intestinal floras. This study showed that in vivo transfer of resistance plasmids was possible in those rats and that the pig $E$. coli donor showed better transfer activity than the human donor. The origin of the intestinal flora seemed to influence the frequency of transfer. The human intestinal flora permitted better transfer of resistance: the highest number of transconjugants could be isolated from rats associated 
with this flora. As expected, rat flora-associated rats seemed to inhibit transfer more effciently, probably because of prowiding better colomization resistance.

In chapter WT the prevalence and high degree of resistance as well as the susceptibilities of $E$. coli isolates from pigs living at different farms are compared with the results of faecal floor droppings collected from trucks transporting fattening pigs. Both groups of isolates showed similar walues, suggesting that floor droppings are useful for antibiotic surveillance in a pig population. A difference was obserwed in number of samples with owergrowth of Bacillus spp., probably due to floor-contamination with soil bacteria. To prevent this problem it might be advisable to collect faecal samples at the evisceration-line in the slaughterhouse instead of using floor droppings from trucks.

In chapter VIII the results, as presented in the chapters II to VII, are summarised and discussed and recommendations for the future are made.

This study sthowed that both pig farmers and pigs acted as reservoirs of resistance genes. They had to be seen as different entities and constituted separate pools of resistance genes, although in vivo exchange of resistance plasmids between porcine and human strains was possible. Antibiotic resistance is multifactorial of origin. This studly showed that minimal influence on resistance could be expected by contact with pigs, pig products and waste and after intake of medicated pig feed. Usage of antibiotics for personal treatment could be a cause of the high resistance observed in pigfarmers. 
136 


\section{SAMENVATTING}

De vraggstellingen van dit proefschrift waren of, en in welke mate, antibiotica-resistentie kan worden overgedragen van varkens naar mensen en of contact met varkens, varkensproducten en gemedicineerd varkenswoer een mogelijk gevaar vormen voor de algemene gezondheid. Daarom werd zowel de invloed van direct contact tussen mensen en varkens of varkensprodukten als het recente antibioticum gebruik in de humane- en diergeneeskunde onderzocht.

In de introductie wordt een overzicht van de literatuur gegeven. Het gebruik van antibiotica was hoofdzakelijk bedoeld voor het owerwinnen van infectie-ziekten. Eén van de consequenties van de toepassing van deze stoffen was echter de vorming van bacteriênpopulaties in mens en dier die resistent waren tegen deze antibiotica. Antibioticaresistentie is algemeen voorkomend in zowel pathogene als niet pathogene bacterien en wordt hoofdzakelijk bepaald door plasmiden. Gedurende de afgelopen 60 jaren was er een enorme toename in het voorkomen van resistentie-plasmiden en het aantal antibiotica waartegen resistentie bestaat. Resistentie is algemeen voorkomend in de darmflora van gezonde personen en dieren. Deze flora is een reservoir van resistentie-genen die van de ene naar de andere populatie kunnen worden overgedragen. Het voorkomen en de verspreiding van antibiotica-resistentie wordt bepald door meerdere factoren die direct of indirect van inwloed kunnen zijn.

Mensen die leven onder slechte hygiënische omstandigheden, in dichtbevolkte gebieden of die regelmatig antibiotica gebruiken vormen hoge risicogroepen. Personen die contact hebben met consumptiedieren lijken ook hogere resistentiewaarden te hebben, waardoor een bijkomend risico van resistentie verspreiding van dier naar mens wordt verondersteld. Het voorkomen van resistentie in dieren is direct gerelateerd aan het diergeneeskundig antibioticum gebruik en kan eventueel indirect wan invloed zijin op het voorkomen van resistentie bij de mens. De literatuur geeft echter geen opheldering over de aanwezigheid van een mogelijk gezondheidsrisico ten gevolge wan diergeneeskundig antibiotica gebruik. In hoofdstuk $I I$ worden de prevalentie en de hoge mate van resistentie van faecale Enterobacteriaceae en de gevoeligheid van Escherichia coli geïsoleerd van mestvarkens op eén bedrijf, beschreven in functie van de tijd. Deze studie toont aan dat gezonde varkens een reservoir wan resistente Enterobacteriaceae ( $E$. coli) vormen. De antibiotica-resistentie was voor de varkenspopulatie op dit bedrijf relatief constant gedurende de tijd. Ondanks de afwezigheid van groepsmedicatie gedurende het werblijf op dit bedrijf was de prevalentie wan resistentie woor de meest frequent gebruikte antibiotica in de diergeneeskunde 
hoog. De hoogste resistentie percentages werden waargenomen voor oxytetracycline, streptomycine en sulfamethoxazole, de resistentie patronen van ongeveer de helft van de isolaten vertoonden een combinatie van wee of drie van deze antibiotica of alleen resistentic tegen sulfamethoxazole.

In hoofdstuk III worden de prevalentie en de hoge mate van resistentie van faecale $E$. coll. geisoleerd van varkenshouders en slachthuispersoneel, vergeleken met een controlegroep bestaande uit isolaten van stedellingen. De varkenshouders vertoonden de hoogste percentages en de stedelingen de laagste. Met uitzondering van neomycine werden er geen significante verschillen in de hoge mate van resistentie waargenomen. Opvallend was dat $5 \%$ van de varkenshouders en $8 \%$ van thet slachthuispersoneel recent antibiotica hadden gebruikt, terwijl geen van de stedelingen recent antibioticum gebruik vermelden. Dit kan erop duiden dat mensen in contact met varkens of varkenskarkassen een groter risico op bacteriêle infecties hebben. Aangezien slachthuispersoneel met verschillende mate van varkenscontact geen significante verschillen in prevalenties vertoonden lijkt het dat contact met varkens of varkenskarkassen van beperkte invloed is op antibiotica-resistentie in deze groep. Aanvankelijk dachten we dat direct contact met antibiotica in gemedicineerd varkensvoer (groepsmedicatie) van invloed was op de prevalentie van antibioticaresistentie in varkenshouders.

In hoofdstuk $I V$ worden, naast de prevalentie en de hoge mate van resistentie, de gevoeligheidspatronen van faecale $E$. coli geïsoleerd van varkenshouders (zoals besproken in hoofdstuk III) en hun varkens vergeleken. Varkens $E$. coli isolaten vertoonden voor de meeste antibiotica significant hogere prevalentie percentages dan de stammen van de varkenshouders. De varkens isolaten waren hoofdzakelijk resistent voor oxytetracyclinestreptomycine/sulfamethoxazole, terwijl woor de varkenshouders stammen hoofdzakelijk de resistentie patronen amoxycilline, sulfamethoxazole en streptomycine-sulfamethoxazole werden waargenomen. Bijkomend vertoonden enkel $4 \%$ van de faecale $E$. coli isolaten van varkens en varkenshouders afkomstig van hetzelfde bedrijf dezelfde resistentie patronen. De hogere resistentie percentages waargenomen voor de varkens, zouden verklatrd kunnen worden door het veelvuldig gebruik van antibiotica in de varkensgeneeskunde en het intensief faecaal-oraal contact tussen varkens. De resultaten suggereren een verschil in resistentie van de faecale flora van varkenshouders en varkens.

Hoofdstuk $V$ beschrijft de resultaten van in witro overdracht van resistentie-plasmiden van $E$. coli stammen geïsoleerd van varkens en varkenshouders afkomstig van hetzelfde bedrijf, een groep isolaten vertoonde dezelfde en de andere groep verschillende resistentie patronen. Behalve vergelijkbare overdrachtsfrequenties voor de varkenshouders- en varkensstammen, konden enkel geringe overeenkomsten in biotypen, volledig plasmidpa- 
moon en plasmidprofiel na restrictie-analyse worden waargenomen. Deze studie levert geen duidelijk bewijs voor de aanwezigheid van é̉n gemeenschappelljke poel van resistentieplasmiden voor varkenshouders en warkens.

Hoofdstuk $V$ beschrijft de resultaten van de in wiwo overdracht van resistentie-plasmiden van een varkens en een humane donorstam geïnoculeerd in kiemvrije ratten welke geassocieerd waren met verschillende Enterobacteriaceae-vrije darmflora"s. De studie ljet zien dat in wiwo overdracht van resistentie-plasmiden mogelijk was in deze ratten. De varkens $E$. coli donor vertoonde een betere overdracht dan de humane donor. De soort darmflora leek wan invloed te zijn op de overdrachtsfreciuentie. De humane darmflora liet een betere resistentie-overdracht toe: het hoogste aantal transconjuganten kon worden geissoleerd van ratten geassocieerd met deze flora. Zoals verwacht leek het dat in ratten geassocieerd met rattenflora de overdracht effectiever geremd werd, waarschijnlijk ten gevolge van de aamwezigheid van een betere kolonisatie-resistentie.

In hoofdstuk VI werden de prevalentie en de hoge mate van resistentie evenals de gevoeligheid van $E$. coli isolaten van varkens afkornstig van verschillende bedrijven vergeleken met mestmonsters verzameld van de bodem wan vrachtwagens die de varkens naar het slachthuis transporteerden. De overeenkomstige waarden waargenomen voor beide groepen suggereren dat vrachtwagenmonsters bruikbaar zijn voor de observatie. (surveillance) van antibiotica-resistentie in een varkenspopulatie. Wel was er een verschil in aantal monsters die Bacillus spp. overgroei vertoonden, waarschijnlijk toe te schrijven aan contaminatie met bodembacteriën. Om dit probleem te voorkomen lijkt het raadzaam om, in plaats van bodemmonsters, in het slachthuis faeces te verzamelen aan de evisceratielijn.

In hoofdstuk VIII worden de resultaten, beschreven in de hoofdstukken II tot en met VII, besproken en bediscussieerd en worden a anbevelingen voor de toekomst gedaan

Deze studie toonde aan dat warkenshouders en warkens reservoirs van resistentie-genen vormen. $\mathrm{Zij}$ moeten beschouwd worden als verschillende entiteiten die afzonderlijke poelen van resistentie-genen vormen, ahoewel in vivo uitwisseling van resistentieplasmiden mogelijk is. De oorsprong van antibiotica-resistentie is multifactorieel. Factoren zoals contact met varkens, varkensprodukten, faeces en opname wam gemedici neerd varkenswoer lijken van geringe invloed te zijn op het voorkomen van antibioticaresistentie in de onderzochte personen. Het gebruik van antibiotica woor eigen therapie is een mogelijke oorzaak van de hogere resistentie waarden waargenomen voor de varkenshouders. 


\section{DANKWOORD}

Bij de afsluiting van dï proefschrift wil ik allen danken die op enigerlei wijze hebben bijgedragen aan het kumnen uitwoeren en het tot stand komen wan deze dissertatie. Enkele personen wil ik met mame noemen en bedanken.

Allereerst wil ik alle personen die faeces hebben ingestuurd bedanken, zonder hun omvangtijke bijdrage was dit onderzoek niet mogelijk geweest.

Ton van den Bogaard, mijn co-promotor, ondanks dubbele afspraken kon er toch tijd worden vrijgemaakt om de resultaten en problemen van dit onderzoek te bespreken en waardewolle adviezen te geven. Tevens heb ik veel steun gehad aan je gedegen kennis van het veterinaire wereldje.

Ellen Stobberingh, mijn tweede co-promotor, tijdens het sollicitatie gesprek vanuit de achtergrond agerend bleek jij tijdens het onderzoek duidelijk aanwezig te zijn. Bedankt voor de kritische opmerkingen en de goede begeleiding van dit onderzoek.

Prof. Dr. J.A. Knottnerus, mijn promotor, wil ik bedanken voor de prettige wijze waarop hiji vooral de laatste fase van het onderzoek heeft begeleid.

Nancy, de eerste ontmoeting met jou had belangrijke gevolgen voor mij, het begin van dit onderzoek. Ik bedank je voor de fijne samenwerking en de gezellige tijd. Ik heb veel steun gehad van je gedegen kennis van de biochemie en van het reilen en zeillen op het lab. Daarnaast was er ook altijd dat opbeurende woord of schouderklopje dat zo hard nodig was om met plezier verder te kunnen.

Christel en Marjon, bergen werk hebben jullie verzet. Bedankt voor jullie hulp bij de praktische uitwoering van de experimenten en het accurat bijhouden van de vele resultaten.

José, tweemaal per week kwam jij onze ploeg zowel lichamelijk als geestelijk versterken. Dit heb ik als zeer prettig ervaren.

Jan, ook jij hebt je steentje bijgedragen. Gedurende, maar ook na de korte periode dat jij actief betrokken was bij dit onderzoek, liet je je mening duidelijk horen.

Daisy, ook al zat je op een ander lab, op "onze" kamer was je volop aanwezig. Naast het vele werk was er voldoende tijd om eens goed te lachen of een serieus gesprek te voeren. Wandla, bedankt woor de gezellige tijd en soms heftige discussies.

Peter, dankzij jouw kennis wan de statistiek was het mogellijk verantwoorde toetsen los te laten op de vele onderzoeks-gegevens.

Medewerkers van het CPV, met name Eep van Dam, Math Hazen en Jacqueline Maes bedankt voor jullie hulp bij dit onderzoek. 
De Vakgroep Medische Microbiologie bedank ik voor de prettige manier van samenwerken.

Familie Mares, bedanki voor de gastrrijheid, de interesse en de bereidheid on op ieder gewenst tijdstip faecesmonsters te mogen verzamelen op jullie bedrijf. Altijd stond er na afloop koffie met koekjes klaar en kon ik mij ontdoen van de "geurige" overall.

Professor Dr. Ir. M.J.M. Tielen van de Gezondheidsdienst voor dieren te Boxtel, de directies en bedrijfsgeneeshundige diensten van Coveco te Weert en Encebe te Boxtel, de directie en keurmeesters wan de RVV kring Weert wil ik bedanken voor de bijdrage aan het verzamelen van de faeces monsters, waardoor dit onderzoek mogelijk werd.

Dr. B.I. Davies, bedankt woor het inhoudelijk en taalkundig advies.

Mijn ouders, dank ik voor de mogelijkheden om te kumnen studeren en om de manier waarop zij mij altijd gesteund en gestimuleerd hebben bij verdere keuzes in mijn leven.

Lieve Andreas, zonder jouw geduld en begrip, zeker gedurende de eerste periode waarin het vanwege de grote afstand moeilijk was om voldoende tijd woor jou vrij te maken en er zelfs af en toe tijdens de kostbare weekeinden dat we samen konden zijn gewerkt moest worden, had ik dit onderzoek nooit tot een goed einde kunnen brengen. Jouw steun was onontbeerlijk. 


\section{CURRICULUM VITAE}

Ruth Nijsten werd geboren op 19 februari 1963 te Bunde. In 1982 behaalde zij het Atheneum-B diploma aan scholengemeenschap Stella Maris te Meerssen.

$\mathrm{Na}$ in Nederland te zijn uitgeloot voor de studie diergeneeskunde begon zij in oktober 1982 aan deze studie aan het Rijks Universitair Centrum Antwerpen Belgiè en behalde het dierenartsexamen un 1988. Het eerste anderhalve jaar na het afstuderen nam zij waar in diverse praktijken voor gezelschapsdieren. Vervolgens heeft zij gedurende een jaar gewerkt als praktizerend dierenarts in een praktijk voor gezelschapsdieren. $\mathrm{Na}$ twee maanden werkzaam te zijn geweest als keuringsdierenarts bij de Rijksdienst voor keuring van Vee en Vlees trad zij 1 mei 1991 in dienst als toegevoegd onderzoeker bij de vakgroep Medische Microbiologie van de Rijksuniversiteit Limburg. In de afgelopen drie en een half jaar werd ondler begeleiding van dr. E. Stobberingh en drs. A. van den Bogaard door het Praeventiefonds gesubsidieerd onderzoek verricht. De bevindingen zijn beschreven in dit proefschrift. 